\title{
Contemporary Music Notation for the Flute: A Unified Guide to Notational Symbols for Composers and Performers
}

\author{
Ms. Eftihia Victoria Arkoudis \\ West Virginia University, eftihiavarkoudis@gmail.com
}

Follow this and additional works at: https://researchrepository.wvu.edu/etd

Part of the Composition Commons, Music Performance Commons, Music Practice Commons, and the Other Music Commons

\section{Recommended Citation}

Arkoudis, Ms. Eftihia Victoria, "Contemporary Music Notation for the Flute: A Unified Guide to Notational Symbols for Composers and Performers" (2019). Graduate Theses, Dissertations, and Problem Reports. 3860.

https://researchrepository.wvu.edu/etd/3860

This Dissertation is protected by copyright and/or related rights. It has been brought to you by the The Research Repository @ WVU with permission from the rights-holder(s). You are free to use this Dissertation in any way that is permitted by the copyright and related rights legislation that applies to your use. For other uses you must obtain permission from the rights-holder(s) directly, unless additional rights are indicated by a Creative Commons license in the record and/ or on the work itself. This Dissertation has been accepted for inclusion in WVU Graduate Theses, Dissertations, and Problem Reports collection by an authorized administrator of The Research Repository @ WVU.

For more information, please contact researchrepository@mail.wvu.edu. 
Contemporary Music Notation for the Flute:

A Unified Guide to Notational Symbols for Composers and Performers

Eftihia Victoria Arkoudis

Dissertation submitted to

the College of Creative Arts

at West Virginia University

in partial fulfillment of the requirements for the degree

Doctor of Musical Arts

in Music Performance

Nina Assimakopoulos, M.M., Chair

Evan A. MacCarthy, Ph.D., Research Advisor

Cynthia B. Anderson, M.M.

Hope Koehler, D.M.A.

Dylan Collins, M.F.A

School of Music

Morgantown, West Virginia

2019

Keywords: flute, extended techniques, notation, contemporary notation, symbols, composers, flutists

Copyright @2019 by Eftihia V. Arkoudis

All rights reserved 


\title{
ABSTRACT \\ Contemporary Music Notation for the Flute: A Unified Guide to Notational Symbols for Composers and Performers
}

\author{
Eftihia Victoria Arkoudis
}

David Cope stated: "There are two basic approaches to the study of New Music Notation: codification and comprehension [...] what really needs to be done is not to keep listing the diverse ways each composer symbolizes his music or create substantially new and negating systems of notation, but to concentrate on codifying one way for future composers to symbolize their music." ${ }^{1}$

In an attempt to limit the inconsistency and complexity characterizing contemporary notation idiomatic to the flute, this paper is the first to adopt Cope's statement and ultimately apply it in relation to the notation of non-standard extended flute techniques. Following thorough examination of significant pre-existing literature pertaining to new music instrumental notation as well as comprehensive guides to contemporary flute notation, and the studying of over thirty scores for solo flute and flute ensemble, this work presents the various symbols of extended techniques employed in works since before the twentieth century, and suggests one-way to symbolize key clicks, pizzicato, tongue ram, singing and playing, speaking and playing, and aeolian sound.

The final selection of symbols in this study is based upon criteria directly related to their visual effectiveness in communicating the function of the extended technique they represent. Any symbol that resembles another preceding symbol, or is too abstract, has been rejected, and symbols that are a logical extension from traditional notation and immediately communicate the action a flutist should take to successfully produce the technique, has been retained.

\footnotetext{
${ }^{1}$ David Cope, New Music Notation (Dubuque, Iowa: Kendall/Hunt Pub, 1976), xi.
} 


\section{DEDICATION}

I dedicate this paper to my mother Kassandra, my father Spiros and my brother Nicholas. Their unconditional love and support have turned me into the woman I am today and has fueled my passion to make my dreams come true.

$\Sigma \alpha \varsigma \alpha \gamma \alpha \pi \omega ́$. 


\section{ACKNOWLEDGEMENTS}

It takes a village to raise a musician, but as it is not possible to thank everyone who has stood by me through my graduate studies in the United States, I would like to show my gratitude towards the people who were integral in the completion of this paper.

To my entire committee, for spending a considerable amount of their time attending my hearings performances, and other exams, as well as for the hours invested editing this paper. Dr. Evan MacCarthy, my committee research advisor and musicology professor, for sharing his expertise and guiding me through the writing process with his positive energy. Professor Nina Assimakopoulos, my flute professor, for her guidance and encouragement to turn my frustration

with contemporary flute notation into a subject I am now passionate about. Professor Cynthia Anderson and Dr. Hope Koehler, for supporting my habit of taking many classes not required by the graduate curriculum, and Professor Dylan Collins for accepting my invitation to be part of my committee.

My dear friends Irene Pappas, Anthony Walker, Alyssa Schwartz, and Tatiana Cassetta, who checked in with me regularly, and above all, my friend Michelle Smith, whose determination to graduate inspired me to push through. My aunts Sophia and Gina, cousins Jimmy, Jerry, and Aliki, and grandmother Aliki for their love and support, and the Merandi family, Constance, Frank, and Alexander, who have been there for me in every single way possible. Words cannot describe how lucky I feel to have had two families away from home.

Finally, thank you to West Virginia University and the College of Creative Arts for all the wonderful experiences, performances, and collaborations. Five years ago, I was writing my statement of purpose hoping that WVU will accept me for my Master's. Now, I am graduating with a doctorate as well. I am beyond blessed. 


\section{TABLE OF CONTENTS}

Abstract

Dedication iii

Acknowledgements

List of Figures vii

INTRODUCTION 1

CHAPTER ONE:

REVIEWING THE HISTORY OF

CONTEMPORARY NOTATION FOR FLUTE AND EXTENDED TECHNIQUES

CHAPTER TWO:

CONTEMPORARY NOTATION FOR FLUTE: LITERATURE

AND ITS NOTATIONAL SYMBOLS 23

Contemporary Notation for the Flute and its Challenges 27

Extended Techniques for the Flute: Standardized and Non-standardized Techniques 36

TONE COLORATION \& SPECIAL EFFECTS 37

ARTICULATION TECHNIQUES 47

$\begin{array}{ll}\text { AIR SOUND TECHNIQUES } & 48\end{array}$

PERCUSSIVE EFFECTS $\quad 50$

VOCAL TECHNIQUES $\quad 54$

CHAPTER THREE:

CREATING A UNIFIED LANGUAGE

$\begin{array}{ll}\text { Key Clicks } & 60\end{array}$

$\begin{array}{ll}\text { Pizzicato } & 63\end{array}$

Tongue Ram $\quad 66$

$\begin{array}{ll}\text { Aeolian Sound } & 69\end{array}$

$\begin{array}{ll}\text { Singing and playing } & 70\end{array}$

Speaking and playing \&

$\begin{array}{ll}\text { Vocalization of phonemes/syllables } & 72\end{array}$ 
CONCLUSION

APPENDICES

BIBLIOGRAPHY 


\section{LIST OF FIGURES}

$\begin{array}{ll}\text { Figures } & \text { Pages }\end{array}$

Chapter 1

1.1. Strauss, Don Quixote, rehearsal \#57

1.2. Tchaikovksy, The Nutcracker, Scene:

The Arrival of Clara and the Prince, mm. 1-2 11

1.3. Tchaikovsky, The Nutcracker, Scene:

The Arrival of Clara and the Prince, mm. 13-14 11

1.4. Varèse, Density 21.5, mm. 24-26 16

1.5. Villa - Lobos, Assobio a jato, movement III, mm. 222-231 17

1.6. Berio, Sequenza I, top of page $5 \quad 18$

1.7. Mekeel, The Shape of Silence, mm. 1-3 19

1.8. Levy, Orbs with Flute, Acknowledgements 20

Chapter 2

2.1. Chamberlain, French Quarter, movement I: "Bourbon Street," measure 80

2.2. Hatzis, Departures, movement III: "Progressive Blues," measure 4

2.3. Hatzis, Departures, movement III: "Progressive Blues," measure 2

2.4. Mathematical harmonic series (note representation), www.flutetunes.com 38

2.5. Alternative Name and Notation for the technique of Harmonics 38

2.6. Alternative Name and Notation for the technique of Whistle Tones 39

2.7. Alternative Name and Notation for the techniques of Glissando and Pitch Bending 40

2.8. Alternative Name and Notation for the technique of Multiphonics 42

2.9. Stockhausen, Flautina, micronotal scale, rehearsal \#8 43

2.10. Alternative Name and Notation for the technique of Quartertones/Microtones 44

2.11. Alternative Name and Notation for the technique of Bisbigliando 45

2.12. Alternative Name and Notation for the technique of Buzz Tone 46

2.13. Alternative Name and Notation for the technique of Bamboo Tones 46

2.14. Alternative Name and Notation for the technique of Flutter Tonguing 48

2.15. Alternative Name and Notation for the technique of Air Sounds 49

2.16. Alternative Name and Notation for the technique of Circular Breathing 50

2.17. Alternative Name and Notation for the technique of Key Clicks 51 
2.18. Alternative Name and Notation for the technique of Tongue Ram

2.19. Alternative Name and Notation for the technique of Pizzicato

2.20. Alternative Name and Notation for the technique of Jet Whistle

2.21. Alternative Name and Notation for the technique of Singing and Playing

2.22. Alternative Name and Notation for the technique of Speaking and Playing

\section{Chapter 3}

3.1. Notation possibilities for the technique of Key Clicks

3.2. Howell, The Avant-Garde Flute, pg. 22

3.3. Notation possibilities for the technique of Pizzicato

3.4. Notation possibilities for the technique of Tongue Ram

3.5. Notation possibilities for the technique of Aeolian Sounds

3.6. Dick, Tone Development Through Extended Techniques, pg. 8

3.7. Larson, Be Still My Soul, mm. 1-6

3.8. Saariaho, NoaNoa, mm.26-27

3.9. Patillo, Three Beats, m.6

3.10. Clarke, Zoom Tube, mm.35-36

3.11. Charke, Raga Sept, mm.1-5 


\section{INTRODUCTION}

With the turn of the century, the social-cultural aftermath of two world wars and other political and economic events that took place around the globe, generated an unmatched need for cultural innovation. Artists were on the hunt for a new artistic voice reflective of those modern times and in combination with the rapid advancement of technology, a wave of constant change came with it.

The daily exposure of the modern society to the radio, television, mobile phones, internet, and the blooming of transportation technologies, as well as the European immigration wave to America due to World War II, all contributed to new ways of perceiving and making art. In particular with music, technology undoubtedly made the world seem smaller, and especially after the 1930s, was a key reason for an unprecedented sudden musical style boom. In few other musical eras before was such a dynamic cross-cultural development and fusion of styles witnessed. Composers explored the musical and idiomatic elements characteristic to national musical styles of other countries, and experimentation became the key component to music-making. As rhythm, texture, and expanded approaches to tonality (or its abandonment entirely) became primary sources of musical inspiration, diverse musical styles arose.

The classical and avant-garde aesthetics blended with emerging Jazz idioms, the songwriting business of Tin Pan Alley, and the music of Broadway and movies, bringing forth a bustling commercial industry. Not surprisingly, the concurrence and merging of so many different musical styles gave rise to new genres of music across art and popular musical traditions, later often in combination with the construction of electronic and computer music instruments, which inspired composers of the mid- and late-twentieth century to reimagine their compositional methods and make music that is both relatable and thought-provoking. 
As a new reality was being established, what was once a timid exploration of new instrumental sounds was now transforming into a feverous one. Composers were infatuated with constantly discovering new sonorous possibilities by using traditional instruments in unconventional ways and the flute was growing into a multi-sound instrument capable of producing an expansive variety of timbral sounds and pitches. Even though this exploration was not exclusive to the contemporary era, it was certainly then that it defied the general belief that sonorous capabilities are limited to "satisfying the musical requirements of each successive (musical) epoch."2

It was a musical revelation for composers and instrumentalists to discover that with certain new playing techniques the flute and all its auxiliary instruments can produce a variety of new effects. These extended playing techniques not only enriched the musical vocabulary of solo flute playing, but also dared the notion that the flute is an exclusively monophonic in nature instrument. Bruno Bartolozzi in his New Sounds for Woodwind book wrote that "such a discovery reveals that the real capabilities of these instruments are twofold- both monophonic and multiphonic - and naturally technical developments will now turn towards a more complete exploitation of these resources. In short, a completely new field has been opened up for investigation and research."3

With reason, this unending quest to discover the next cutting-edge sound to incorporate in new works comes with its notational challenges. The precise, yet demanding, nature of effectively producing these sounds ought to come with the appropriate representative symbols; although some of them are considered standardized today, there are others that create ambiguity and confusion.

\footnotetext{
${ }^{2}$ Bruno Bartolozzi, New Sounds for Woodwind (Oxford: Oxford University Press, 1967), 3.

${ }^{3}$ Ibid., 2
} 
The task of deciphering the notation and properly executing the technique frequently becomes a daunting and time-consuming task for the performer.

As musicians continue to delve into the world of contemporary music either in collaboration with composers or by identifying as composers themselves, this task only gets more complicated. The experimental relationship between composers and performers has not only furthered the artistic freedom vital to creating and sharing new music, but also made it essential to redefine or re-invent the musical notation for the extended flute so that other performers might create and replicate these new techniques and sounds.

Nevertheless, this drive to redefine or re-invent notational symbols for older and newer sounds presents its own complications. Although composers regularly provide flutists with performance notes for their compositions, these performance instructions in contemporary music are sometimes unclear, imprecise, or too complicated to achieve accurately without the direct intervention of the composer. Often composers designate a new symbol for an extended technique that has already received a symbol in the past or even juxtapose the symbols between them. Therefore, flutists often encounter in the flute literature various names and symbols for the same extended technique.

As flutists become more well-versed in contemporary music practice, developing an eye for faster recognition of extended techniques and their notational symbols, there is an increasing desire to decode the disparate taxonomy of contemporary notation symbols for flute extended techniques. American author and composer David Cope once stated: "There are two basic approaches to the study of New Music Notation: codification and comprehension [...] The point is, what really needs to be done is not to keep listing the diverse ways each composer symbolizes his music or create substantially new and negating systems of notation, but to concentrate on 
codifying one way for future composers to symbolize their music." ${ }^{4}$ The vision of this work is to adopt Cope's statement and ultimately apply it to contemporary music notation idiomatic to the flute.

This work will aim to present the various symbols of extended techniques employed in countless works dedicated to the flute throughout the years, and following thorough examination, discussion, and comparison, suggest one-way to symbolize them.

Therefore, the main goals of this project are:

(1) to study the history of contemporary music notation by examining pre-existing scholarship and focusing exclusively on extended instrumental playing techniques employed by composers in avant-garde music

(2) to follow its evolution and transformation from the late nineteenth century to the present, as it relates to the flute, with the aid of literature dedicated to extended flute notation, and original manuscripts of selected works

(3) to establish a comparative index charting the flute extended techniques by their various names and symbols thus far

(4) to discuss and compare standardized vs. non-standardized flute extended techniques notation and

(5) attempt to collate the many symbols of representing selected extended techniques and establish a unique standardized symbol for five of those techniques:

(1) key clicks

(2) pizzicato (tongue or lip pizzicato)

(3) tongue ram or stop

\footnotetext{
${ }^{4}$ David Cope, New Music Notation (Dubuque, Iowa: Kendall/Hunt Pub, 1976), xi.
} 
(4) singing and playing and speaking and playing, and

(5) aeolian sound, also known as residual tone.

The hope is that these suggestions will not be viewed as dictating composers and performers how to notate their music. Rather, it is meant to provide them with a concise guide on how to notate a selection of extended flute techniques in a way that is instantaneously comprehensive by the performer; by connecting one symbol or action to an extended technique. A long-term goal is to eventually contribute towards an updated handbook pertaining to contemporary flute notation, which will be available as a source for both composers and performers interested in representing modern flute repertoire to use in moments of ambiguity. 


\section{CHAPTER 1}

\section{REVIEWING THE HISTORY OF CONTEMPORARY NOTATION FOR FLUTE AND EXTENDED TECHNIQUES}

Contemporary musicians, now more than ever, are composing and performing in an experimental musical era characterized by limitless creativity and continuous thirst to discover new instrumental sonorities that efficiently convey modern artistic intentions and socio-cultural movements. And although the first unconventional instrumental sounds were encountered in works dating before the 1900s, over a hundred years later, pioneering musicians are still coming up with newer instrumental techniques, adding on to this ever-evolving list.

To fully comprehend the evolution of new instrumental sounds and playing techniques, studying and observing the progress of the nineteenth century is of pertinence. ${ }^{5}$ Experimentations with new sounds and tone colors, extreme chromaticism, expansion of harmony, emancipation of dissonance, and acceptance of noise and silence as sound are developments in music closely related and influenced by the changes and discoveries made in the fields of technology, science, and other artistic and literary movements at the time. The second half of the nineteenth century was undoubtedly a precursor to the next century when it comes to artistic innovations and musical advancements. It was during this era that the first musical barriers and "rules" were broken. An increased industrialization and heightened sense of nationalism was witnessed and the need to express deep emotions led to the genesis of alternative means to do so, like discovering new sounds, changing the structure of forms, and the invention of new instruments. ${ }^{6}$ Poetry, heroes,

\footnotetext{
${ }^{5}$ Elliott Schwartz, Barney Childs, and James Fox. Contemporary Composers on Contemporary Music. 1st Da Capo Ed., Expanded ed. (New York: Da Capo Press, 1998), xv: "Any understanding of developments in twentieth-century music must inescapably begin with an awareness of the immediate nineteenth-century background."

${ }^{6}$ Marie K. Stolba, The Development of Western Music: A History. 3rd ed. (Boston, Mass.: McGraw Hill, 1998), 494; Hans Heinz Stuckenschmidt, Twentieth Century Music. World University Library (New York: McGraw-Hill Book, 1969), 7.
} 
imaginary plots, and mythological creatures continued to be the core subjects for which music was written about and composers continued to express an interest in expanding the size of the orchestra and the incorporation of distinct musical elements originating in the folk traditions of other countries.

Carl Maria von Weber had already made the first steps towards his operatic concept of Gesamtkunstwerk, and Berlioz, Schumann, and Liszt further expanded on Beethoven's and Schuberts' emotional expression and formal expansion. ${ }^{7}$ Berlioz's Treatise on Instrumentation (1844) indicates signs towards becoming more familiar with the true potential of orchestral instruments and Wagner's initiative to construct the Wagnerian Tuba demonstrated an innovator who preferred the construction of a new instrument able to produce the sound he envisioned rather than conforming to what was available to him. In his treatise's final chapter, Berlioz describes an extremely large imaginary orchestra totaling up to almost 830 musicians while he expresses that “...it would be curious to try once, in a composition written for the occasion, the simultaneous use of all the musical forces that can be gathered together in Paris. Let us suppose that the conductor had them at his command, in a vast hall designed for the purpose by an architect familiar with acoustics and music." Although this statement may sound extreme, it shows that Berlioz was already imagining new ways artists could approach the art of making music and alternative ways audiences could perceive and interpret it.

Furthermore, Wagner's rebellious attitude towards music-making opened a new world of possibilities for other composers to draw inspiration from, such as Bruckner, Mahler, Strauss, Scriabin, and early Debussy. Wagner, aside from stretching the limits of both instrumental and

\footnotetext{
${ }^{7}$ Ibid., 8.

${ }^{8}$ Pierre Boulez, and Jean Jacques Nattiez. Orientations (Cambridge, Mass.: Harvard University Press, 1986), 213 214.
} 
vocal capabilities and perfecting the concept of Gesamtkunstwerk and Leitmotiv, he also abandoned the idea of a tonal center by employing chromaticism, remote modulations, and dissonances. ${ }^{9}$ Furthermore, he masterfully exploited the colors and timbres of orchestral instruments to serve the operatic drama and its characters. His exceptional use of color was, in fact, a technique that survived as a concept all throughout the twentieth century and offered composers a wider palette to express a larger variety of emotions. Wagner established "a code of instrumental color" by either combining "small, strongly characterized groups of instruments" or by the "absence of certain timbres at given points in the action," for the purpose of successfully connecting a motive to a character or its emotional state of mind. ${ }^{10}$ Nevertheless, composers who were not influenced by Wagner's compositional writing, such as Tchaikovsky, Smetana, Dvorak, Leoš Janáček and Maurice Ravel, also left their individual mark by being deeply immersed in the musical traditional of their Russian and Czech heritage, and in Ravel's case, by the exotic and oriental elements found in Spanish, Greek, Italian, and Hebrew folk music. ${ }^{11}$

The common thread connecting all these composers, which consecutively influenced the Impressionists, Expressionists, Neo-Classical and Neo-Romantics of the twentieth century, was that they deliberately sought out for different means to fulfill their artistic vision. Rather than remaining confined in the "older" ways, they chose to experiment and broaden the realm of instrumental possibilities to convey extra-musical ideas or set a specific atmosphere and mood. In addition to reviving and individually mastering the art of instrumentation as an effective and

\footnotetext{
${ }^{9}$ Gesamtkunstwerk is the complete work of art where text, music, stage, plot and costumes are one unified concept. Leitmotiv or leading theme is a specific musical theme appointed to each character of an opera. Every time that this character appears on stage, the theme occurs.

${ }^{10}$ Pierre Boulez, and Jean Jacques Nattiez. Orientations (Cambridge, Mass.: Harvard University Press, 1986), 283.

${ }^{11}$ Hans Heinz Stuckenschmidt, Twentieth Century Music. World University Library (New York: McGraw-Hill Book, 1969), 28.
} 
impressive expressive tool, they began to incorporate new sonorous effects and instruments in their works.

The production of such sonorous effects came in various forms: the construction of entirely new instruments or technical modifications on the ones in use at the time, unusual combination of various instrumental groups, or by adapting new playing techniques. The latter one, which is of interest for this document, is also known today as extended playing techniques. These techniques are "special effects that arise from producing a sound by using a non-traditional playing way of playing an instrument," and they are so named because they have emerged as "extensions" of wellestablished techniques. One of the first extended techniques to make its appearance on the flute was the flutter-tonguing effect. This technique requests from the flutist to abandon the traditional articulation that uses the consonants $[\mathrm{t}]$ and $[\mathrm{d}]$, and instead roll the tip of the tongue on the alveolar ridge by using the consonant $[\mathrm{r}]$. The resultant sound is "a very rapid repetition of the same note, creating a tremolo effect"12 and it may also be accomplished using the uvula in the back of the mouth, which is a "glottal" flutter tonguing.

According to standard reference sources, Richard Strauss (1864-1949) was the first to introduce the flutter-tonguing technique in his tone poem Don Quixote, op.35, for cello, viola, and orchestra (1897). The technique is heard by both the principal and second flutist in rehearsal no. 57 of Variation VII, and it is notated with the German word 'Flatter-zunge' (Figure 1.1). However, this is false, as Pyotr Ilyich Tchaikovsky (1840-1893) incorporated it in his ballet The Nutcracker in 1892. Tchaikovsky inserted this technique in the second act of the ballet, in scene no.11: The Arrival of Clara and The Prince, when Clara and the Nutcracker are welcomed in the kingdom of

\footnotetext{
${ }^{12}$ Michel Debost and Jeanne Debost-Roth, The Simple Flute: From a to Z (New York: Oxford University Press, 2010), 253.
} 
Confiturembourg. He notated it with the Italian word 'frullato' after consulting Russian flutist and teacher Alexander Khimichenko, and had it repeat throughout the entire movement using the words 'sempre frullato' (Figure 1.2 and 1.3).

Figure 1.1.: Strauss, Don Quixote, rehearsal \#57

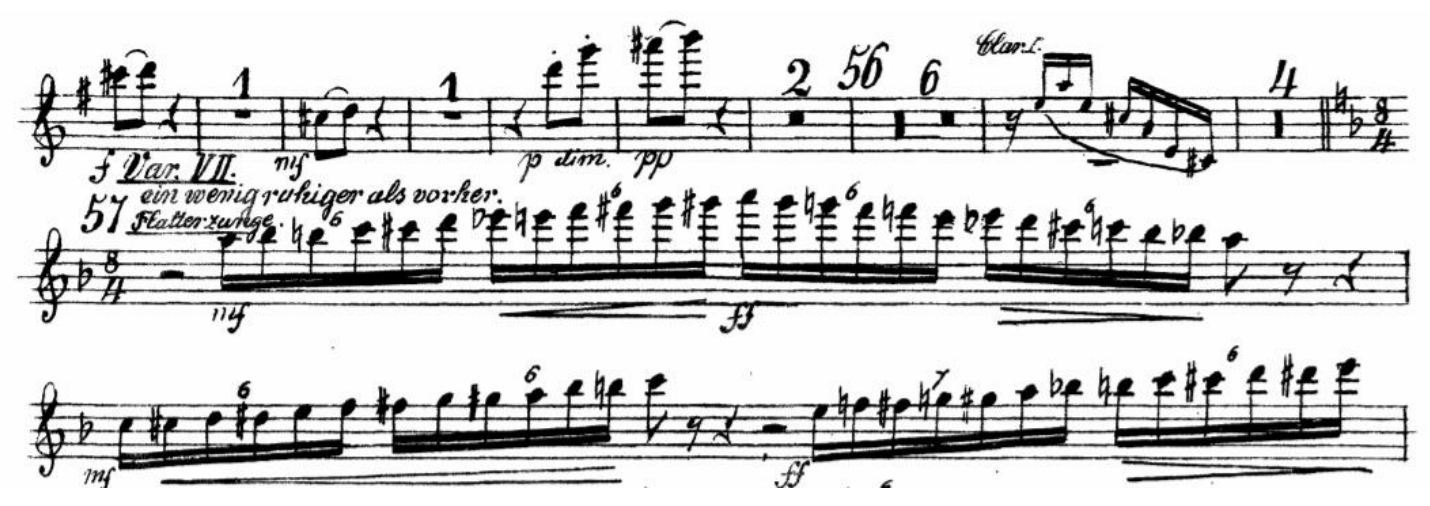

Figure 1.2.: Tchaikovsky, The Nutcracker, Scene: The Arrival of Clara and the Prince, mm.1-2

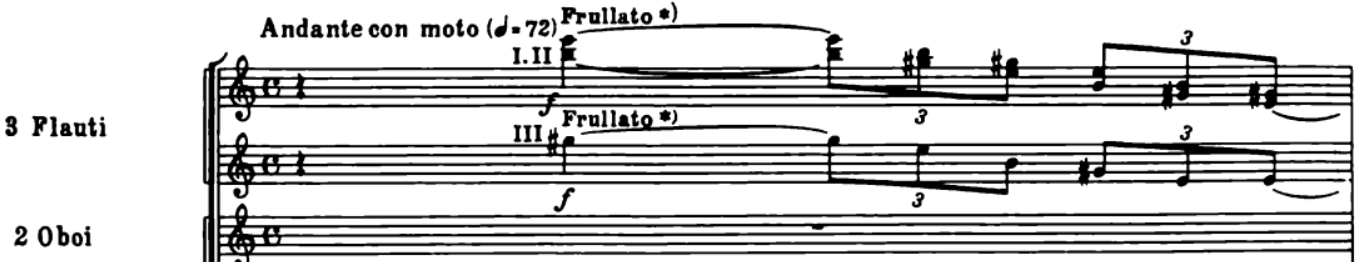

Figure 1.3.: Tchaikovsky, The Nutcracker, Scene: The Arrival of Clara and the Prince, mm.13-14

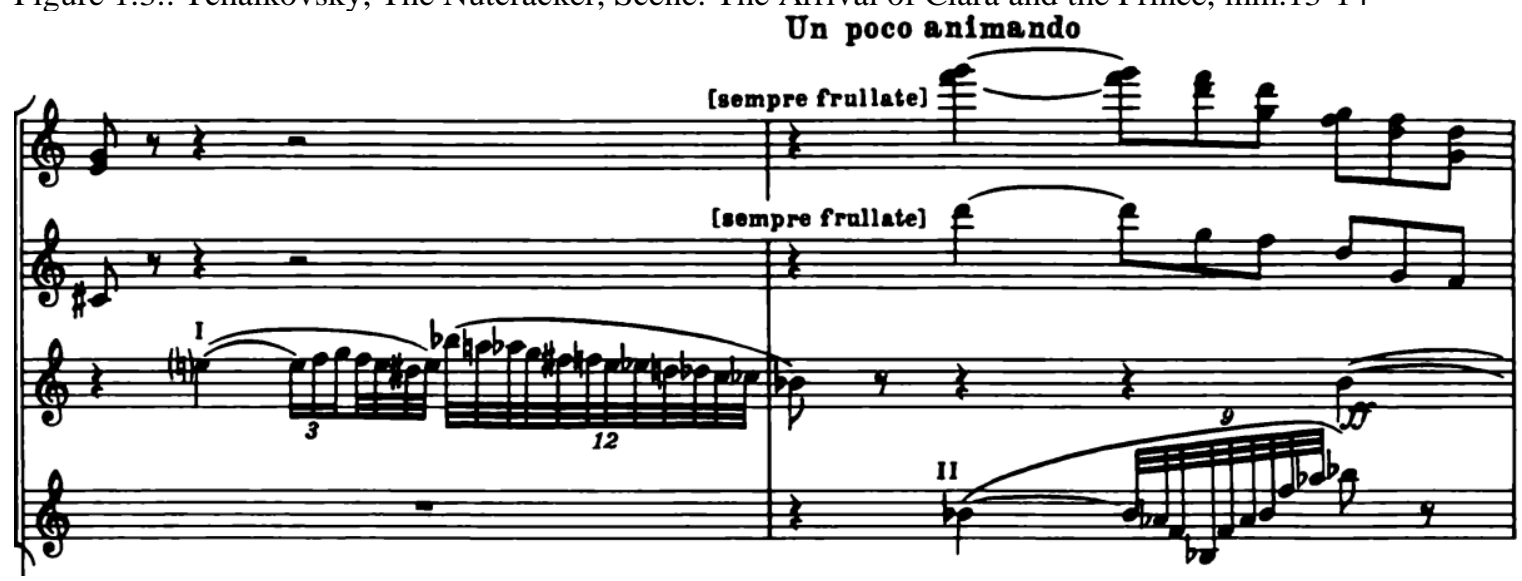


Alexander Khimichenko's memoirs of Tchaikovsky, as well as the surviving correspondence letters between them, provide further insight into how Tchaikovsky became acquainted with the flutter-tonguing technique and his eagerness to incorporate it in the ballet.

The most memorable visit by Pyotr Ilyich was that of 1891, when he conducted three [sic] concerts in Kiev [...] During one of the rehearsals Pyotr Ilyich was resting in the director's office. I went up to him and we started talking about the Conservatory. Pyotr Ilyich recalled how in Saint Petersburg he, too, had once learnt to play the flute, but said that after so many years he had forgotten everything. He lamented this and asked me to demonstrate 'some real corker' from the interesting tricks which one can achieve with the flute. I played him the variations from Ciardi's Carnaval russe and made use of the effect which is known as frullato. Pyotr Ilyich was fascinated by it and asked me to repeat once more this trick which consists of playing a chromatic scale of trilled notes across the flute's entire register, and which produces the effect of a cascade (the sound resembles that of our Ukrainian sopilka). Soon after Pyotr Ilyich's departure from Kiev I received from him a signed photograph with a letter ${ }^{13}$ in which he asked me to describe in detail the device I had demonstrated to him and to send him some music examples, since he wanted to use frullato in his new ballet The Nutcracker. ${ }^{14}$

This memoir stands as proof that the technique was already in practice, at least among Russian flutists, before Tchaikovsky heard it for the first time and decided to include it in his ballet. Furthermore, it demonstrates how folk musical elements can find their way in the world of classical music, since it was most likely inspired by the sound of the Ukrainian traditional fife, the sopilka. In a similar manner, classical contemporary flutists would share new flute techniques and musical ideas with musicians of the Jazz scene during the post-modern era uniting the best of both worlds and further expanding the flute's potential. ${ }^{15}$ Moving forward, numerous composers including Schoenberg, Stravinsky, and Shostakovich, used the flutter-tonguing technique in their works to emulate feelings such as madness, agitation, and fright or imitate the sounds of birds and animals.

\footnotetext{
13 “Tchaikovksy Research: Letter 4633,” http://en.tchaikovsky-research.net/pages/Letter 4633 (accessed March 22, 2019).

14 “Tchaikovsky Research: Aleksandr Khimichenko," http://en.tchaikovskyresearch.net/pages/Aleksandr_Khimichenko_(accessed March 22, 2019).

${ }^{15}$ Ardal Powell, The Flute. The Yale Musical Instrument Series (New Haven: Yale University Press, 2002), 274.
} 
Today, the technique is so commonly used over the past century and it is considered a standardized "classical new music technique."16

Just before the turn of the twentieth century, and shortly after Tchaikovsky's death, Claude Debussy (1862-1918) became a central figure in establishing the flute as a solo instrument capable of shifting moods with its "immense coloristic opportunities." ${ }^{17}$ Even though he may have not added or introduced any flute extended techniques in his works, his connection of the instrument to mythology in Prelude a l'apres midi d'un faune (1895) and Syrinx (1913), among others, placed it under the spotlight. His ethereal, almost floating-like melodies, dynamic variety, use of bitonality, pentatonic and whole-tone scales, transformed the flute's character in the eyes of future composers and sparked new musical ideas. ${ }^{18}$

Such a transformation continued to take place as the leader of the Second Viennese School, Arnold Schoenberg (1874-1951), and his innovative twelve-tone system brought with it the concept of pantonality. Schoenberg's dodecaphony accepted all twelve pitches of the chromatic scale as significant and treated them equally, thus opening a pathway for microtonality. Even though the concept of microtonality has its roots in ancient Greece, it became an integral part of contemporary music and a controversial matter during the twentieth century. By adding intervals smaller than a semitone on the harmonic palette, the number of pitches composers could use increased and with that came the need for a new notational system able to depict these quartertones and microtones. Composers and music theorists such as Julian Carillo, Ferruccio Busoni, Alois Hába and Harry Partch are only a few of whom dedicated their careers in promoting and

\footnotetext{
${ }^{16}$ Carin Levine and Christina Mitropoulos-Bott, The Techniques of Flute Playing: Die Spieltechnik der Flöte (Kassel: Bärenreiter, 2002), 12.

${ }^{17}$ Hans Heinz Stuckenschmidt, Twentieth Century Music. World University Library (New York: McGraw-Hill Book, 1969), 24.

${ }^{18}$ Ardal Powell, The Flute. The Yale Musical Instrument Series (New Haven: Yale University Press, 2002), 274.
} 
studying the subject of microtonality and who devoted a large body of their oeuvre to it. Nevertheless, despite the numerous attempts made towards a suitable and standardized notation for all quarter-tones and microtones possible, it remains yet, decades later, a non-standardized technique for which each composer has been choosing their own personalized language. ${ }^{19}$

Schoenberg's further exploitation of the flute's capabilities gave it a double-edged sword quality, showcasing it as both a traditional and progressive instrument. In addition to successfully pairing it with the theatrical vocal Sprechstimme technique in Pierrot Lunaire (1912), he also directed the attention towards the instrument's vast registral and dynamic contrast, and articulation range, making it possible for post-war composers to fearlessly explore the instrument's vocal character and natural fluidity. ${ }^{20}$ At the same time, Italian futurist Luigi Russolo, began to experiment with ways to translate the noises of modern industry into music. In his book The Art of Noises (1913) he presents six families of noises:

1. Roars, thunderings, explosions, hissing, roars, bangs, booms

2. Whistling, hissing, puffing

3. Whispers, murmurs, mumbling, muttering, gurgling

4. Screeching, creaking, rustling, humming, crackling, rubbing

5. Noises obtained by beating on metals, woods, skins, stones, pottery, etc.

6. Voices of animals and people, shouts, screams, shrieks, wails, hoots, howls, death rattles, sobs. ${ }^{21}$

In fact, the majority of these sounds found a place in new music written for the flute. Initially, they started out as tone differentiation techniques, such as harmonics, hollow or weak tones, whistle tones, vibrato variations, and flutter tonguing. However, they manifested into a wider variety of special effects, including glissandi, smorzato, microtones, quarter-tones, quartertone trills, quarter-tone scales, microtones, bisbigliandi, percussive effects such as key clicks and

\footnotetext{
${ }^{19}$ Gardner Read, 20th-Century Microtonal Notation, Contributions to the Study of Music and Dance, No. 18 (New York: Greenwood Press, 1990), 3.

${ }^{20}$ Ardal Powell, The Flute. The Yale Musical Instrument Series (New Haven: Yale University Press, 2002), 274.

${ }^{21}$ Luigi Russolo, The Art of Noises. Monographs in Musicology, No. 6 (New York: Pendragon Press, 1986), 28.
} 
tongue rams, explosive sounds such as jet whistle, air sounds, and singing and speaking while playing. ${ }^{22}$

Composer Edgard Varèse, who in 1915 left France and moved to the United States to pursue a fresh career writing contemporary and computer-based music, envisioned his works sounding "unlike anything that had ever been heard." ${ }^{23}$ For years, he advocated for the necessity of building new instrument's able to produce unheard sounds and his composition Density 21.5 (1936) for unaccompanied flute was his chance to demonstrate his authenticity as an artist in regards to the flute. Density 21.5 for unaccompanied flute was written as a commissioning project for French flutist Georges Barrère. The principal flutist of the New York Symphony Orchestra, who also premiered Debussy's Prelude a l'apres midi d'un faune (1895), wished for Varèse to compose a work that showed off the power of his platinum flute (21.5 is the density of platinum) - a first of its kind at the time. ${ }^{24}$ In his work, Varèse gave the flute an industrial and metallic quality. He took advantage of the instruments full range $\left(\mathrm{B}^{4}, \mathrm{D}^{4}\right)$ and dynamic capacity $(p p-f f f)$, accompanied by complex rhythmical motives, and incorporated the first percussive effect a flutist ever had to demonstrate - key clicks (added in 1946). ${ }^{25}$ Varèse's addition of key clicks, which require the flutist strongly clicks the keys of the instrument to produce a pitch resonance, signaled the beginning of a new era for the modern flute, which would take off in the 1950's (Figure 1.4).

\footnotetext{
${ }^{22}$ Nancy Toff, The Flute Book: A Complete Guide for Students and Performers. Third ed, The Oxford Musical Instrument Series (New York, NY: Oxford University Press, 2012), 273.

${ }^{23}$ Kyle J. Dzapo, Notes for Flutists: A Guide to the Repertoire. Notes for Performers (New York: Oxford University Press, 2016), 140-141.

${ }^{24}$ David Cope, New Directions in Music (Dubuque, Iowa: W.C. Brown, 1989), 24.

${ }^{25}$ Kyle J. Dzapo, Notes for Flutists: A Guide to the Repertoire. Notes for Performers (New York: Oxford University Press, 2016), 142.
} 
Figure 1.4: Varèse, Density 21.5, mm. 24-26

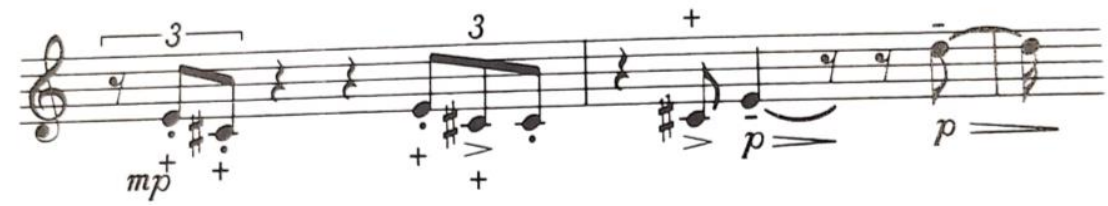

After Varèse's landmark composition Density 21.5, the number of composers and performers who wished to specialize and integrate new performance techniques in their compositions for the flute escalated significantly. Andre Jolivet's (1905-1974) Cinq Incantations (1936) is the earliest work for solo flute to use flutter-tonguing extensively as well as Olivier Messiaen's (1908-1992) La Merle Noir (1951), who aims to imitate the singing of birds as he was infatuated by them. ${ }^{26}$ Brazilian composer Heitor Villa-Lobos (1887-1959) composed the duo for flute and cello Assobio a jato (1950), or also known as Jet Whistle, wherein the third movement the flutist is asked to produce an explosive high-pitched air sound - reminiscent of a jet plane. In Villa-Lobos' scores the following instructions were included: "The only way to achieve the effect which the composer wishes, as indicated by the words imitando fischi in toni ascendenti, is to blow into the embouchure hole fff as if one were warming up the instrument on a cold day. The first blast should be fingered D, the second E, and so on through A" (Figure 1.5).

\footnotetext{
${ }^{26}$ Nancy Toff, The Flute Book: A Complete Guide for Students and Performers. Third ed, The Oxford Musical Instrument Series (New York, NY: Oxford University Press, 2012), 275.
} 
Figure 1.5: Villa-Lobos, Assobio a jato, movement III, mm. 222-231
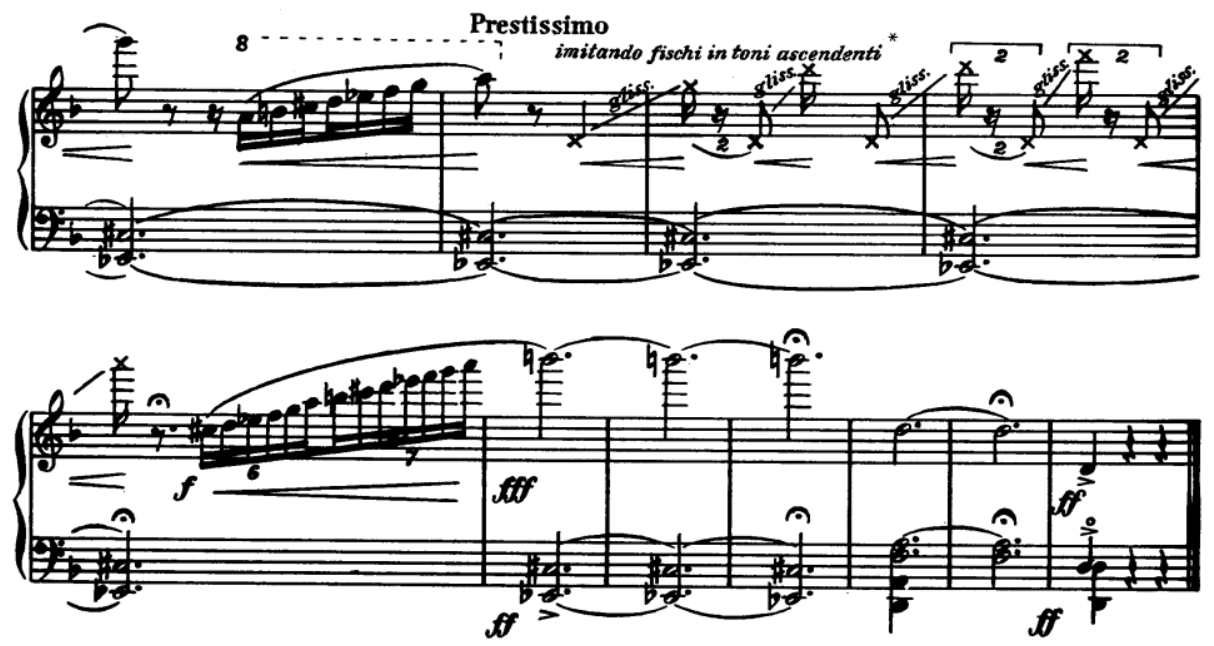

*The only way to achieve the effect which the composer wishes,

157-11 as indicated by the words imitando fischi in toni ascendenti, is
to blow into the embouchure fff as if one were warming up the

to blow into the embouchure fff as if one were warming up the

low $\mathrm{D}$, the second $\mathrm{E}$, and so on through $\mathrm{A}$.

Another new technique that was heard as early as the late 1950's was the technique of simultaneously singing and playing. There is a general misconception that this technique aroused for the first time when legendary rock flutist Ian Anderson, the lead member of the progressive rock band Jethro Tull, introduced it in the band's songs in the 1970's. Even though that may be when it became popular, it can be heard earlier by jazz flutist Sam Most on the LP The Herbie Mann - Sam Most Quintet (Bethlehem, No. BCP-40) on the song I'll Remember April (1956). ${ }^{27}$ Shortly after, composer Luciano Berio (1925-2003) added the earliest notated multiphonic for the flute, a perfect fourth G-C interval, in his Sequenza I per flauto solo (1958). In Sequenza I, Berio also incorporates flutter tonguing, extreme register leaps, and stark articulation (Figure 1.6).

\footnotetext{
${ }^{27}$ John Heiss, "The Flute: New Sounds." Perspectives of New Music 10, no. 2 (1972): 153-58.
} 
Figure 1.6: Berio, Sequenza I, top of page 5

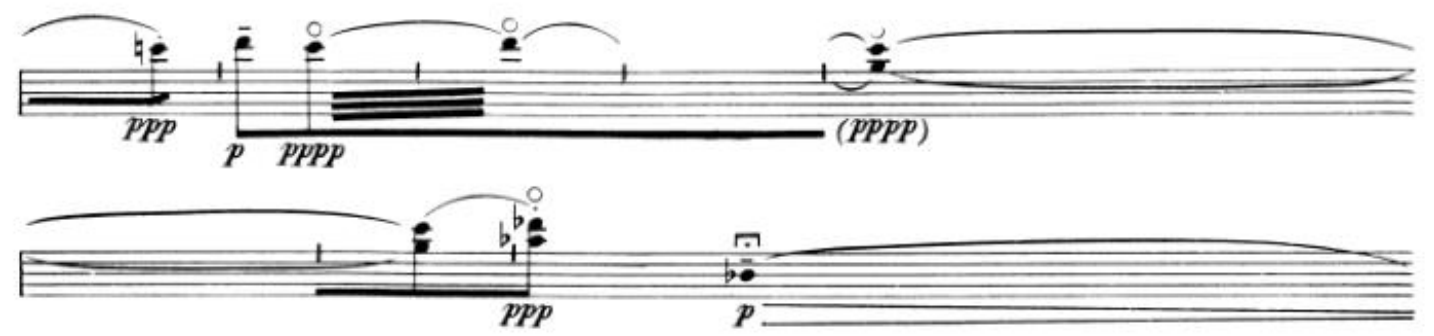

Kazuo Fukushima (1930-) is among the earliest composers to draw their inspiration from traditional Japanese music and the sound characteristics of the Japanese bamboo flute, the shakuhachi. His work Mei for solo flute (1962) was commissioned by flutist Severino Gazzeloni when German musicologist and music critic Karl Steinecke of Darmstadt passed away in a tragic accident. The work was meant to be performed by Steinecke's graveside, as an ancient Japanese faith believed that the sound of the flute can be heard by those who have passed on. In this composition, Fukushima applied techniques such as bending pitches, glissandi, overblowing, free rhythm that serves the purpose of meditation, and strong contrast of dynamics.

According to composer and flutist John Heiss (b.1938), composer Joyce Mekeel's (19311997) work The Shape of Silence (1969), may have been one of the earliest works to incorporate the technique of speaking and playing in an unaccompanied flute work. The technique calls for the flutist to recite spoken words, sharply enunciated across the embouchure hole while sustaining low register notes. This technique will be used extensively after the 1970's (Figure 1.7). ${ }^{28}$

\footnotetext{
${ }^{28}$ John Heiss, "The Flute: New Sounds." Perspectives of New Music 10, no. 2 (1972): 153-58.
} 
Figure 1.7: Mekeel, The Shape of Silence, mm. 1-3

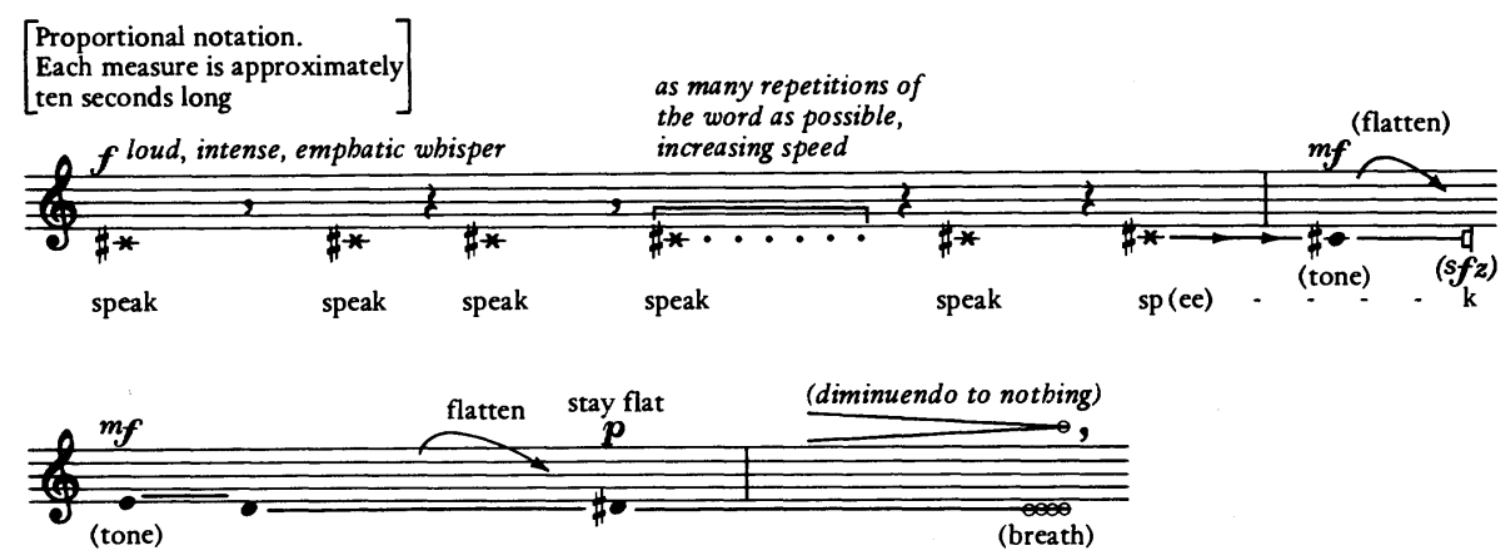

Worth mentioning is also Burt Levy's (1936-2010) Orbs with Flute (1967), which was a conglomeration of percussive effects, timbral tremolos, harmonics, glissandi, and multiphonics, and also served as an important moment in flute history. As seen in the acknowledgements of the score, this composition was the result of Levy collaborating closely with modern flutist Patrick Purswell, the author of The Avant-Garde Flute Thomas Howell, and composer-flutist David Gilbert (Figure 1.8). ${ }^{29}$ This collaboration exhibited one of the earliest shifts in the composer performer relationship. The performer's opinion, skill-set, and interpretation begin to matter and help shape the final product. Now, the performer can participate in the composition process behind and on-stage, which is a conversation expanded upon in the following chapters. ${ }^{30}$

\footnotetext{
${ }^{29}$ Burt Levy, Orbs with Flute (Cincinatti, Ohio: APOGEE PRESS, Inc., 1967).

${ }^{30}$ Elliott Schwartz, Barney Childs, and James Fox. Contemporary Composers on Contemporary Music. 1st Da Capo Ed., Expanded ed. (New York: Da Capo Press, 1998), xix.
} 
Figure 1.8: Levy, Orbs with Flute, Acknowledgments

\section{ACKNOWLEDGMENTS}

I wish to express my gratitude for the help of Patrick Purswell, Thomas Howell and David Gilbert. It was Mr. Purswell who first introduced me to the new flute techniques employed in ORBS. $\mathrm{Mr}$, Howell made the results of his experimentation available for my use and, together with $\mathrm{Mr}$. Gilbert, provided considerable assistance with the editing of the work and thepreparation of what follows.

Going back to the word "theatricality," George Crumb’s (1929-) works Night of the Four Moons (1969) and Vox Balaenae for Three Masked Players (1971), and Toru Takemitsu's Voice for solo flute (1971), are all examples of how adopting a persuasive theatrical attitude was slowly becoming as crucial as an accurate technical performance. Toru Takemitsu (1930-1996), like Fukushima, was influenced by his Japanese heritage. His work Voice for solo flute, which was written for French flutist Aurèle Nicolet, merges the flute sound with the human voice and embraces silence as a sound, to convey Japanese philosophical and spiritual ideas. Takemitsu not only utilizes techniques such as recitation, microtones, singing while playing, key clicks, lip and tongue pizzicato, residual tones, flutter tonguing, multiphonics, multiphonic tremolos, timbral trills, and growling, but also pushes the flutist to undertake the role of the multiple characters involved in Noh theater.

The strong theatrical element that was beginning to pour out from modern flute works, not only fueled a synergetic composer-performer relationship in need to create works that have a story to tell, but also provided a solid foundation for further experimentation with sound effects. Such an example was also composer Karlheinz Stockhausen (1928-2007). While Stockhausen occupied himself with other gigantic musical projects, he was also busy composing several theatrical works for his muse, Dutch flutist Kathinka Pasveer. Taking into consideration that he worked closely 
with Kathinka during the compositional process of the works, not only did he have a deeper understanding of the instrument's nature but was also fearless in going the extra mile with exploiting its sonorous capabilities. Fascinated with the instrument's timbral variety and inclination towards drama, in his work Flautina for Solo Flute with Piccolo and Alto flute (1989) he asks the interpreter to bridge the changes of instruments with sung and hummed notes, kissingnoises above the mouth-hole with beating of the keys, tongue clicks and sighing, flutter-tonguenoise alternating with irregularly staccato spitting-noises, voiceless whistling, a microtonal scale, varied vibrato, timbral trills and quarter-tones. In addition, most of the works he wrote for the flute call for the performer to assume a role, wear appropriate attire to match that role, and require theatrical movement for which Stockhausen does not fail to provide clear directions. This is commendable as Stockhausen's notation for the avant-garde flute remains until today among the cleanest and most precise notational systems used by a composer to write for the instrument.

In general, during the experimental period of 1960-1980, composers such as Luigi Nono, Heinz Holliger, Roger Reynolds, Brian Ferneyhough, Toru Takemitsu, John Heiss, Donald Erb, to name only a few, used their works as platforms to highlight all the impressive effects performers could reproduce with the flute by showing off the instrument's versatility. This new approach to flute-playing, of course, came with its music notation advancements and adjustments. As composers around the world were becoming more familiar with the new musical aesthetics, they had to devise signs to notate new playing techniques, which throughout the years, and especially during this time, inevitably led to "notational duplication, contradictions, and general confusion. ${ }^{31}$

By the 1980's, the plethora of symbols flooding contemporary notation idiomatic to the flute, the disparate individual notational systems, and the efforts performers had to put into

\footnotetext{
${ }^{31}$ Kurt Stone, Music Notation in the Twentieth Century: A Practical Guidebook. 1st ed. (New York: W.W. Norton, 1980), xvi.
} 
demystifying modern scores, made it necessary to take a step back and regulate a more efficient contemporary notation system for future generations of performers and composers. This is where musicologists, music theorists, and composer-flutists found an opportunity to write books and compendiums in which they collect all signs in use, categorize them, and attempt to standardize a symbol per technique. 


\section{CHAPTER 2}

\section{CONTEMPORARY NOTATION FOR FLUTE:}

\section{LITERATURE AND ITS NOTATIONAL SYMBOLS}

Some of the real challenges pertaining to new music notation distinct to the flute have their starting point in the post-World War I era. These times signaled a period in which composers took a great interest in the tonal possibilities of instruments as a single unit rather than part of an ensemble. ${ }^{32}$ Composers were experimenting with the variety of timbres, articulations, dynamic contrast, and extreme ranges possible on traditional instruments, and the flute gradually claimed its own unique spot in the avant-garde unaccompanied repertoire scene. The instrument's proximity to the human voice and its multifaceted quality undoubtedly gave it the power to sound like an entirely new instrument with the employment of unusual playing techniques, transforming it into an intriguing instrument for composers.

The speed in which composers and performers worldwide were exploring the capabilities of their instruments and the rapid growth of possible special effects resulted in the need to reinvent the wheel of contemporary musical notation. Regarding this matter, in a lecture he gave at Mary Austin House in Santa Fe back in 1936, Edgarde Varèse - hinting towards the possibilities arising from computerized music - stated that in this 'new primitive stage in music today,' we are 'faced with the problem of finding graphic symbols for the transposition of the composer's thought into sound. ${ }^{33}$ Not so many years later, and with Varèse belonging in the group of composers who led this new direction in music, his prediction became a new state of reality.

\footnotetext{
${ }^{32}$ Nancy Toff, The Flute Book: A Complete Guide for Students and Performers. Third ed, The Oxford Musical Instrument Series (New York, NY: Oxford University Press, 2012), 273.

${ }^{33}$ Edgard Varèse, "The Liberation of Sound," In Collected Work: Contemporary Composers on Contemporary music, Rev.Ed.(New York, NY, U.S.A.: Da Capo, 1998), 198.
} 
For the sake of preservation and posterity, composers had to design appropriate symbols and systems to represent new sounds and rhythms, therefore "the multiplicity of new and experimental instrumental techniques has been equaled, if not surpassed, by a corresponding proliferation of new instrumental symbology." ${ }^{34}$ In other words, the musical vocabulary developed to notate contemporary works kept on growing, and still does, to the extent that a cascade of notational and interpretational issues arises. It was because of the sudden and overwhelming chaotic taxonomy characterizing contemporary notation and the various symbols notating new instrumental techniques, that musicologists, music theorists, composers, and composer-flutists took the initiative to re-systemize and revamp the notational procedures in place.

It is worth observing that efforts such as these were made in Erhard Karkoschka's Notation in new Music (1966), Howard Risatti’s New Music Vocabulary (1974), Gardner Read's Music Notation: A Manual of Modern Practice (1969) and Contemporary Instrumental Techniques (1976), David Cope's New Music Notation (1976), and Kurt Stone's Music Notation in the Twentieth Century (1980). ${ }^{35}$ In addition, Risatti's and Cope's visually pleasing charts listing extended techniques across the entire instrumental realm makes it easy to navigate and compare older and newer symbols before the second millennium. The passionate work of all these men was not only a valuable attempt towards a more concise and comprehensive guide to all these modern music signs, but also inspired composer-flutists to conduct similar work regarding notation special to the modern flute.

Fortunately, the groundbreaking work of Bruno Bartolozzi in his handbook New Sounds for Woodwind (1967) and Thomas Cowell's The Avant-garde Flute: A Handbookfor Composers

\footnotetext{
${ }^{34}$ Read Gardner, Contemporary Instrumental Techniques (New York: Schirmer Books, 1976), 5.

35 Ibid., xvi.
} 
and Flutists (1974), were only the beginning of documenting the list of new playing techniques possible on the flute as well as their first notation. Bartolozzi's book provides the musician with fingerings for chromatic and microtonal scales, multiphonics, and timbric transformation of sound. ${ }^{36}$ However, being that it was the first published work to contain such information, many of the fingerings depicted are unreliable and not always yielding the results desired. Works written for the solo flute that used Bartolozzi's book as a reference point may also contain errors because of that and flutists today should be cautious when using it. Regardless, Bartolozzi's work is a significant literary source and influenced much of the repertoire written since its publication. ${ }^{37}$ Thomas Howell, on the other hand, went further to examine the different fingerings between different instruments, and provided the musician with a chart of 1826 multiphonic fingerings and instructions how to produce them. ${ }^{38}$

One year later, revolutionary composer-flutist Robert Dick published his book The Other Flute: A Performance Manual of Contemporary Techniques (1975), which is even today a musthave book in every professional flutist's library. It is a comprehensive guide to the modern flute's sonic possibilities and it includes fingerings for multiphonics, alternate fingerings, quartertones and smaller microtones, natural harmonics, glissandi, whisper tones, percussive effects, jet whistles, a discussion of techniques for piccolo, alto and bass flutes and an introduction to circular breathing. ${ }^{39}$ Other important books include James Pellerite's A modern Guide to Fingerings for the Flute (1964), Martin Gümbel's Neue Spieltechniken in der Querflotenmusik nach 19k (1974)

\footnotetext{
${ }^{36}$ Ardal Powell, The Flute. The Yale Musical Instrument Series (New Haven: Yale University Press, 2002), 273.

${ }^{37}$ Kathryn Emma Moorhead, "A Performer's Perspective on the Evolution and Realisation of Extended Flute Techniques: A Portfolio of Recorded Performances and Exegesis," (Ph.D. diss., University of Adelaide, Elder Conservatorium of Music, 2012): 5.

${ }^{38}$ Thomas Howell, The Avant-Garde Flute: A Handbook for Composers and Flutists (Berkeley: University of California Press, 1974).

39 "Robert Dick, Books: The Other Flute," https://robertdick.net/product/the-other-flute/ (accessed March 25, 2019).
} 
and Hiroshi Koizumi's Technique for Contemporary Flute Music for Players and Composers (1996).

In addition, Dick published three more books that served the pedagogical purpose of improving fundamental aspects of flute playing with the integration of extended techniques in one's practice: Flying Lessons: Six Contemporary Concert Etudes (1983), Tone Development through Extended Techniques (1986), and Circular Breathing for the Flutist (1987). On a similar path followed composer Harvey Sollberger with Quodlibetudes (1991) and composer-flutist Wil Offermans with his award-winning For the Contemporary Flutist: Twelve Studies for the Flute with Explanations in the Supplement (1992). Both books are a collection of etudes dedicated to the mastery of contemporary techniques. Other books that are indispensable to the flute literature alongside Dick's and Offerman's works are Present Day Flutes: Treatise on Contemporary Techniques of Transverse Flutes for the Use of Composers and Performers (1980) by Pierre-Yves Artaud and Techniques of Flute Playing: Die Spieltechnik der Flöte (2002) by Carin Levine and Christina Mitropoulos-Bott.

One could easily assume that because of the preeminent literature and articles published regarding contemporary flute notation, composers and performers around the world are sufficiently equipped with the guidance integral to write and perform modern works for the flute. Nevertheless, that is far from truth, as there are limited sources that primarily focus on the practice of extended techniques when it comes to recognizing their notation and successfully executing them to serve the end-goal of the interpretation. In reality, all sources mentioned above provide 
little or close to no insight concerning notational challenges and interpretational issues that arise from the disability to confidently decipher the symbols used in contemporary notation. ${ }^{40}$

In addition, and with some noteworthy exceptions, there are composers out there whose lack of thorough examination of literary sources and the oeuvre of celebrated composers, or even a close working relationship with excerpt performers in the field, leads to unclear, imprecise, and unnecessarily complicated notation, which keeps on intensifying the problem. Surprisingly, the number of composers that are oblivious to the fact that their knowledge pertaining to contemporary flute notation is deficient is much higher than the number of composers who are aware of the obscurities and ensure appropriate education and preparation prior to delivering the final product.

\section{Contemporary Notation for the Flute and its Challenges}

Problems with contemporary notation for the flute begin with the fallacious notion that an accompanying symbol description list of the extended techniques included in the work is enough for an accurate performance. Even with that list, musicians who are called to give a persuasive performance of a new work are still faced with modern musical notation obstacles, making it a challenge most of the times to interpret an avant-garde work with absolute confidence. Unlike contemporary music champions, who have invested time in researching and understanding modern musical notation, non-specialist or inexperienced performers can feel underqualified when exploring works of this style and quickly lose interest in performing them. This feeling of inadequacy stems from a number of factors; however, the manner in which composers communicate their ideas on paper plays a monumental role in this issue.

\footnotetext{
${ }^{40}$ Kathryn Emma Moorhead, "A Performer's Perspective on the Evolution and Realisation of Extended Flute Techniques: A Portfolio of Recorded Performances and Exegesis," (Ph.D. diss., University of Adelaide, Elder Conservatorium of Music, 2012): 10.
} 
Author Gardner Read, known for his prolific literary contribution on the topic of musical notation, stated: "If notation - the written vehicle of musical expression - is to become so detached from all known frames of reference that it offers no key to the composer's ideas, what useful purpose can it serve? What musical communication can arise from such an enigma as this excerpt from a score that gives no clue to the meaning of its format or to most of its new symbols? ${ }^{41}$ This statement comes to further support Christian Dimpker's suggestion that methods of notation are supposed to be as exact and simple as possible and instead of contradictory, closely related to traditional notation. ${ }^{42}$ Furthermore, Carl Dalhaus's claim that contemporary notation should be compatible with, and distinct from, all other signs of the system, comes to reinforce all ideas mentioned this far. ${ }^{43}$ Erhard Karkoschka also wrote that "new symbols must fit in sensibly with the old ones and must possess sufficient novelty to avoid confusion [...] they must be adaptable to circumstance in size and form." 44

It is with no doubt that when musical notation fails to clearly communicate the true intentions of the composer then one shall expect a series of musical misunderstandings to take place. Similar, when musical notation leaves no or little room for ambiguity, composers shall find themselves in the fortunate position of their works gaining popularity within the musical community. Reasonably, not every idea or concept will have its own unique written representation. Nevertheless, a composer who devotes time in refining his written musical language and meticulously transferring his musical thoughts onto paper initiates a circle of respect; firstly, between composer and performer, and eventually between the performer and listener. Like Harry

\footnotetext{
${ }^{41}$ Gardner Read, Music Notation: A Manual of Modern Practice (Boston: Allyn and Bacon, 1969), 451.

${ }^{42}$ Christian Dimpker, Extended Notation: The Depiction of the Unconventional (Vienna: Lit, 2013), 2.

${ }^{43}$ Carl Dahlhaus, "Notenschrift heute" in Darmstädter Beiträge zur Neuen Musik IX, ed. Ernst Thomas (Mainz 1965), 12.

${ }^{44}$ Erhard Karkoschka, Notation in New Music: A Critical Guide to Interpretation and Realisation (New York: Praeger, 1972), 5.
} 
Partch said in his article Experiments in Notation: "The composer who is moved to contribute to this stimulation bends every effort to get his music heard; and to get it heard [...] he must write his music in such a way that it will not require years, or even months, to connect fingers or lips or larynx to its execution [...]." ${ }^{.45}$

Remarkably, in no other historic musical era before has the performer's role been so pivotal in shaping the future of new music compositions. Donald Erb summed it up well, saying, "Music is made by a performer. It comes from him rather than from his instrument, the instrument being merely a vehicle. Therefore, it seems logical that any sound a performer can make be used in a musical composition. ${ }^{" 46}$ As this has been witnessed in the past with flutists Severino Gazelloni, Patrick Purswell, Aurele Nicolet, Robert Aitken, Kathinka Pasveer, Camilla Hoitenga - to name a few - performers who know their craft well and participate in the compositional process of a work can have an immense impact on its final form, notation, delivery, and success.

The truth is that the performer is the connective link between composer and audience, the only live representation of a composer's work. Therefore, the technical ability and emotional expression he or she brings to the stage are all crucial components to present a persuasive interpretation of an unknown work. There is no wrong or right interpretation: there is a successful or unsuccessful one. The performer's responsibility is to decide his or her methods to do justice by the composer's artistic vision and deliver a memorable experience to the audience. This requires that the soloist is very well acquainted with the score, confident with his or her playing techniques, and bears a theatrical concept in mind to recreate the energy necessary to engage the listener. ${ }^{47}$

\footnotetext{
${ }^{45}$ Harry Partch, "Experiments in Notation." In Collected Work: Contemporary Composers on Contemporary Music. Rev. Ed. (New York, NY, U.S.A.: Da Capo, 1998), 211.

${ }^{46}$ Bertram Turetzky, "Vocal and Speech Sounds- A Technique of Contemporary writing for the Contrabass," Composer 1, no.3 (December 1969): 169.

${ }^{47}$ Lisa Maria Cella, "A Resource Manual for the Solo Flute Repertoire of the Twentieth Century," (doctoral thesis, University of California, San Diego, 2001), 3-10.
} 
Often, memorizing the work and removing oneself from the music stand provides the performer with the freedom vital to present a convincing and dramatic performance.

On that account, before any musician reaches the level of readiness to perform a new work, an inside-out grasp of the score must be possessed. Every breath, rest, marking, phrasing, action or symbolic notation matter, and it is his or her duty to study the composer's notation with attentiveness and focus on detail. However, what many may not realize is that during this primary stage of familiarizing oneself with the score, the composer's methods of notation and structure has the power of determining the outcome of future performances. The more well-rounded command of contemporary musical notation the composer has, the more likely it is that the various future interpretations will closely resemble what was primarily envisioned.

Whether the composer desires to create a personalized musical notational system or utilize what is already in place, he or she should strive for clarity and precision in the written instructions. As this applies to every type of conversation, no musical conversation can effectively take place unless the language being used is understood among all participants: composer, performer, and listener. The composer should not underestimate the value of a clear and polished final version of the score, which should ideally consider musicians of all levels and backgrounds. The overall appearance and size of a score, a detailed description of all symbols depicted, as well as inclusive program notes, are all pertinent information to the successful performance of a new work. In Read's words: "The performer does not live who would not prefer to read the precisely notated, clear, and accurate version." 48

When musical notation becomes too complicated, it is an extremely hard and timeconsuming process for the performer to decode prior to the performance. This creates a language

\footnotetext{
${ }^{48}$ Gardner Read, Music Notation: A Manual of Modern Practice (Boston: Allyn and Bacon, 1969), v.
} 
barrier between composer and performer, and this barrier is an obstacle that only a determined musician decides to overcome. This not an issue when the composer is still alive, able to collaborate in person, or responsive to communication. Even when none of the above options are feasible, performers can still reach out to the world-premiere performer, who is the closest someone can get to the composers' musical intentions and suggestions. But, when the first two routes are inaccessible, performers are left with answering their questions either by listening to the recordings of others, opening a conversation with other performers, read literary sources, if there are any written, or surf the Internet for further assistance. And although the third route is a very common one to take, it holds the highest risk of straying away from the composers' original ideas pertaining to his work.

Thus, the composer who desires his art to appeal to a larger group of artists should generally aim for a notation system characterized by flexibility, structure, and universality. Flexibility to convey even the most complex of concepts, structure to impart artistic ideas immediately and efficiently, and universality for musicians and listeners of various backgrounds and cultures to understand how to interpret the composition. This, of course, is not a task to be taken lightly, as one's notational methods are subjective to personal taste, artistic influences, and the times.

Many composers view their notational processes as an additional avenue to express their musical thoughts and allow their artistic persona to come through. Thus, in addition to the multinational experimental attitude dominating the arts, the individualistic approach of composers in notating new playing techniques, and new music ideas, generated an abundance of notation systems, such as the approximate, qualitative, graphic, descriptive, action, symbolic, diagrammatic, electronic music and schematic notation, to name a few. ${ }^{49}$

\footnotetext{
${ }^{49}$ Christian Dimpker, Extended Notation: The Depiction of the Unconventional (Vienna: Lit, 2013$), 6$.
} 
For the purposes of this work, the focus shall remain on only two methods of notation - as they are directly related to new music written for the flute and its auxiliary instruments - the action and symbolic notation..$^{50}$ According to Karkoschka, action notation is the type of notation that instead of indicating the resultant sound (in contrast to conventional notation of pitch and duration), it describes the action leading to it. ${ }^{51}$ Now, action notation has been encountered since before the twentieth century, especially for string instruments, but can be found far more often in postwar works or works written for the flute after the 1980's. For example, composers will often write out the word "jet whistle" over a regularly notated note instead of using a symbol for it. American composer Nicole Chamberlain applies this method in her flute quartet work French Quarter (Figure 2.1). Others will use both a symbol and an accompanying text, as can be seen in Departures Concerto for Solo Flute and String Orchestra by Greek-Canadian composer Christos Hatzis (Figure 2.2).

In general, composers will use action notation either when there is no symbol in place to accurately describe the desired effect, or there are numerous different symbols and the text helps clarify any ambiguity. In the moment that the flutist reads the words 'jet whistle,' he or she knows immediately which action to take in order to produce the loud attack of air reminiscent to a jet plane.$^{52}$ Action notation, however, can also be very useful to composers who have a very specific sound or effect in mind. In this case, words function as the ideal means to recreate an idea, sound, or concept. An example of this is also by Christos Hatzis, who despite the existence of appropriate symbols to notate the technique of simultaneously singing and playing, he uses the words: "Jethro

\footnotetext{
${ }^{50}$ Ibid.,6.

${ }^{51}$ Erhard Karkoschka, Notation in New Music: A Critical Guide to Interpretation and Realisation (New York: Praeger, 1972), 3.

52 "Flute Colors: Extended Techniques for Flute" https://www.flutecolors.com/techniques/jetwhistle/ (accessed March 26, 2019).
} 
Tull" to explain what effect he is seeking for (Figure 2.3.). This kind of action notation indicates clearly that the flute player must imitate the playing of rock flutist Ian Anderson. There is, in fact, no ideal notation that communicates this very specific special effect better than words.

Figure 2.1: Chamberlain, French Quarter, movement I: "Bourbon Street," m.80

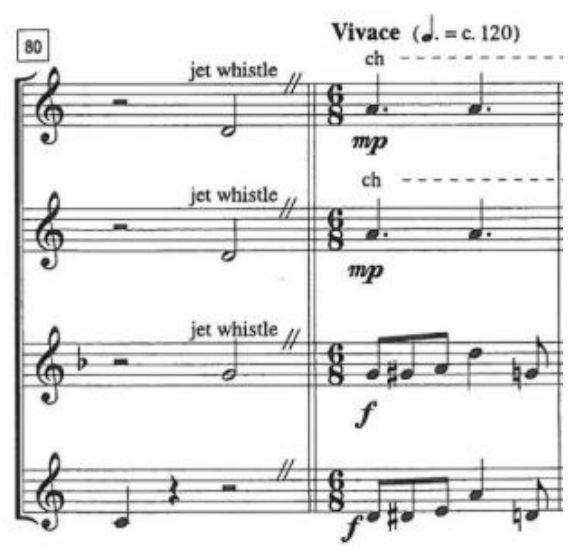

Figure 2.2: Hatzis, Departures movement III: "Progressive Blues,” measure 4

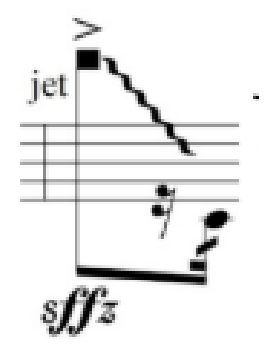

Figure 2.3: Hatzis, Departures movement III: “Progressive Blues,” measure 2

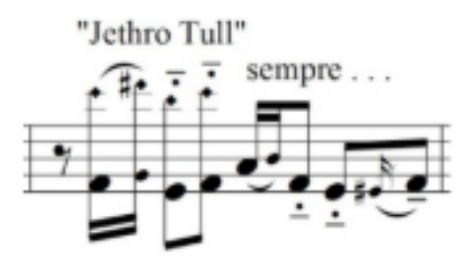


At this point it is worth mentioning that even though action notation can be immediate and helpful, composers should aim to use it only when necessary, keeping such notations as short as possible. Not only does too much text make for an overwhelming score to read, but it also disregards the useful function of symbolic notation. Similar to action notation, symbols should also be kept to a reasonable amount. ${ }^{53}$ For example, text like "blow harshly into the flute like the wind," can be considered long enough by some. Instead, the composer can employ a symbol that is directly connected to the technique of aeolian sound (or residual tone) and add the action notation "harsh, like the wind," in order to describe the exact effect more precisely. Another excellent and effective method is to assign a number to each technique that requires a detailed performance explanation and place the description on the bottom of the score, similar to a footnote, as can been seen in the works of Jennifer Higdon and Elainie Lillios. This way, the score looks clean and the notation is the right amount of elaborate. Either way, composers shall have a spherical knowledge of the symbolic notation idiomatic to each instrument, and recognize which symbols are immediately connected to which extended technique.

A rather frequent phenomenon for composers is that they designate a new symbol for a technique that already has one or even juxtapose the symbols of various techniques with one another. Accordingly, flutists often encounter contradictory directions in staple flute literature, since they come across various names and symbols for the same technique. Eventually, composers and performers will have to mutually agree on the symbology of techniques unique to the flute, otherwise this oversaturation and confusion will continue to prevent their standardization. ${ }^{54}$

It is possible for composers to still maintain their individuality within a coherent and unified notational system that masterfully combines action and symbolic notation. Possessing such

\footnotetext{
${ }^{53}$ Christian Dimpker, Extended Notation: The Depiction of the Unconventional (Vienna: Lit, 2013$), 5$.
}

${ }^{54}$ Cope, David, New Music Notation (Dubuque, Iowa: Kendall/Hunt Pub, 1976), 3. 
a skill avoids the following two extremes: an oversimplified score that generates myriad questions or an intoxicatingly busy one that turns the task of deciphering and reading a score into a daunting one. Moreover, it ensures that composers do not resort to the use of music notation software (Finale, Sibelius, Dorico, Musescore, etc.) to create new symbols, unless it is absolutely necessary. It is imperative that when composers decide to design new symbols to notate their ideas, they are first confident no notation is in place for the sound effect they desire, and secondly, are acquainted with their software designing limitations. Skipping any of those two steps increases the problems addressed in this paper. Interviews with composers would offer insightful information pertaining to the advantages and disadvantages of using any notation software. Nonetheless, it is most likely that as composers embark on this project, they must comply to the designing capabilities of the software they are working with. In that case, only a composer with contemporary notation experience will be able to 'troubleshoot' any challenges that may arise.

Composers and composer-flutists who are well-established professionals utilize extended techniques to showcase the instrument's voice and capabilities. They expand on unique ideas in which they ask the performer to portray subjects such as life and death, monsters and mythological creatures, urban and industrial life concepts, sciences, or socio-political movements. But most importantly they take matters of notation seriously and have substantial experience creating a comprehensive and clear notational system for extended techniques for the flute.

According to champion flutist of new music Helen Bledsoe, some exemplary contemporary composers who have displayed excellent notation methods throughout the years are Gergely Ittzés, Robert Dick, Wil Offermans, Ian Clarke, Anne La Berge, and Karlheinz Stockhausen. ${ }^{55}$ Worth adding on this exceptional list are also composer-flutists Jennifer Higdon, Shulamit Ran, Maggi

55 “Helen Bledsoe, Flutist" www.helenbledsoe.com/?p=1033 (accessed on March 9, 2019) 
Payne, Harvey Sollberger, Katherine Hoover and Kaija Saariaho. With the exception of Karlheinz Stockhausen and Kaija Saariaho, all composers listed above are flutists first. Their knowledge of playing the instrument is advantageous and has led to exemplary contemporary notation strategies. For this reason, excerpts of their scores will be used for the purposes and analysis of this paper.

Luckily, in the time span of the past forty years, the awareness for better notational musical systems has increased. This is especially true for the flute and its auxiliary instruments as new extended playing techniques have become an integral part of the instrument's basic technique and practice. ${ }^{56}$ Nevertheless, it is a fact that the notation of many extended flute techniques is still nonstandardized, which has only heightened the need for standardized notation. ${ }^{57}$ The aim of this paper is to suggest the use of symbols which lead to immediate and clear comprehension, and both composers and performers can benefit greatly from their use.

\section{Extended Techniques for the Flute: Standardized and Non-standardized Techniques}

The purpose of this section is to "define the full range of the flute's potential as a sound generator. ${ }^{" 58}$ In an attempt to inform and educate students, performers, and composers as they decide to delve into the world of contemporary music for the flute, it lists and highlights the majority of extended playing techniques in use by flutists and composers today, identifying them with their various symbols and names. The comprehensive guide that follows will aid towards a greater knowledge of symbols and practices currently.

\footnotetext{
${ }^{56}$ Susan J. Maclagan, A Dictionary for the Modern Flutist (Lanham, Md.: Scarecrow Press, 2009), 56.

${ }^{57}$ Rita Ann Linard, "An Analysis of Three Solo Flute Works that Bridge the Gap between Traditional and Twentieth-Century Techniques," (doctoral treatise, The University of Texas at Austin, 1997), 57.

${ }^{58}$ Thomas Howell, The Avant-Garde Flute: A Handbook for Composers and Flutists (Berkeley: University of California Press, 1974), v.
} 


\section{TONE COLORATION \& SPECIAL EFFECT TECHNIQUES}

\section{$\underline{\text { Harmonics }}$}

Harmonics are considered an "old," therefore, standard technique for the flute. They are based on one of the most fundamental principles of the flute, overblowing. ${ }^{59}$ The concept of harmonics is based on the overtone series; therefore, a harmonic is an overblown fundamental tone. If we take the lowest $\mathrm{C}$ possible on the flute as the middle $\mathrm{C}\left(\mathrm{C}^{4}\right)$, then by fingering any fundamental tone from $\mathrm{B}^{3}$ (lowest $\mathrm{B}$ on the flute) to $\mathrm{D} \#^{4}$, a flutist should be able to produce many consecutive overtone partials of the harmonic series, by increasing the speed of the air and maintaining support. They have been used for many years among composers for echo effects or extremely soft fade-outs on the high notes and they are the simplest way to alter the flute's tone quality. ${ }^{60}$ In comparison to other instruments, the flute has just enough overtones. This means that the fuller one's tone is the more overtones it contains. By fingering a fundamental tone and overblowing in the flute to get the overtones one can produce the following mathematical series:

Figure 2.4: Mathematical harmonic series (note representation), www.flutetunes.com

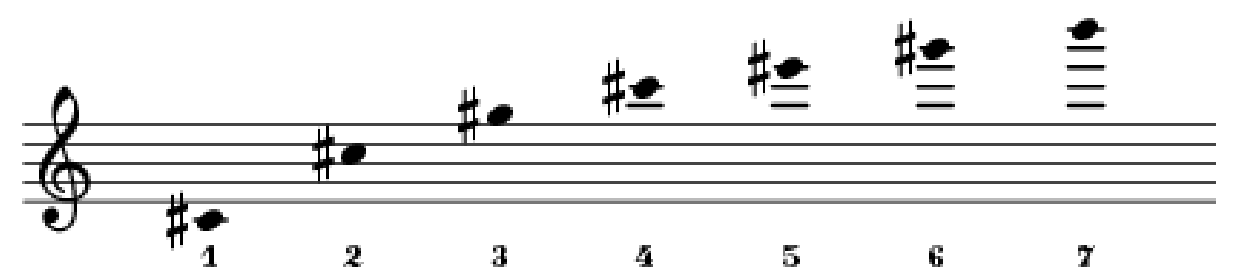

\footnotetext{
${ }^{59}$ Carin Levine and Christina Mitropoulos-Bott, The Techniques of Flute Playing: Die Spieltechnik der Flöte (Kassel: Bärenreiter, 2002), 14.

${ }^{60}$ Dick, Robert. The Other Flute: A Performance Manual of Contemporary Techniques (St. Louis, MO: Multiple Breath, 1989), 12.
} 
Figure 2.5: Alternative Name and Notation for the technique of Harmonics

Harmonics Overtones

\section{Whistle Tones}

Whistle tones or whisper tones are also considered a standard technique. They are individual partials of notes, and they are high, pure sine tones. ${ }^{61}$ They sound like whistling, which is how they got this name. They are slightly fluctuating tones in the third register based on the harmonic series and one can produce them using the fingerings of the first and third register. ${ }^{62}$ They occur when the air is moving slowly with very low pressure, like a gentle exhale and sound best when fingerings of the third register are used (especially on alto, bass, and contrabass flute). ${ }^{63}$

\footnotetext{
${ }^{61}$ Dick, Robert. The Other Flute: A Performance Manual of Contemporary Techniques (St. Louis, MO: Multiple Breath, 1989), 140.

${ }^{62}$ Carin Levine and Christina Mitropoulos-Bott, The Techniques of Flute Playing: Die Spieltechnik der Flöte (Kassel: Bärenreiter, 2002), 15.

63 "Flutexpansions: Whistle Tones" https://www.flutexpansions.com/whistle-tones (accessed March 28, 2019)
} 
Whistle tones can by produced with every fingering and depending on the fingering used from five to fourteen whisper tones can be sounded. ${ }^{64}$ In addition, they may also be produced inside the flute, by completely covering the embouchure hole with the lips while inhaling or exhaling air. ${ }^{65}$ Whistle tones are notated with the full word "whistle tones" or by the initials of the words "W.T.", among other ways seen in the table below, and their notation is considered standard.

Figure 2.6: Alternative Name and Notation for the technique of Whistle Tones

Whistle Tones Whisper Tones

\footnotetext{
${ }^{64}$ Dick, Robert. The Other Flute: A Performance Manual of Contemporary Techniques (St. Louis, MO: Multiple Breath, 1989), 140.

65 "Flutexpansions: Whistle Tones" https://www.flutexpansions.com/whistle-tones (accessed March 28, 2019)
} 


\section{Glissando and Pitch bending}

Glissando is a seamless transition between two pitches. ${ }^{66}$ The connection between the two pitches can happen with either of the three following ways: (a) a chromatic glissando, for which a flutist plays all notes between the two pitches (this type of glissando can be performed on both an open-hole and closed-hole flute,) (b) a finger glissando, for which a flutist smoothly slides the fingers on the rims to cover or uncover the holes on an open-hole flute, and (3) a lip glissando or pitch bending, for which a flutist covers and uncovers the embouchure hole either with lip movement or rolling the head-joint inwards/outwards, or a combination of both. ${ }^{67}$ Robert Dick's The Other Flute includes a chart on how to successfully accomplish glissandi starting on a low B and going up to an A\# of the third register as well as the pitch range possible when bending the pitch upwards or downwards. Similar to harmonics and whistle tones, the notation of glissando and pitch bending is considered standard.

Figure 2.7: Alternative Name and Notation for the technique of Glissando and Pitch bending

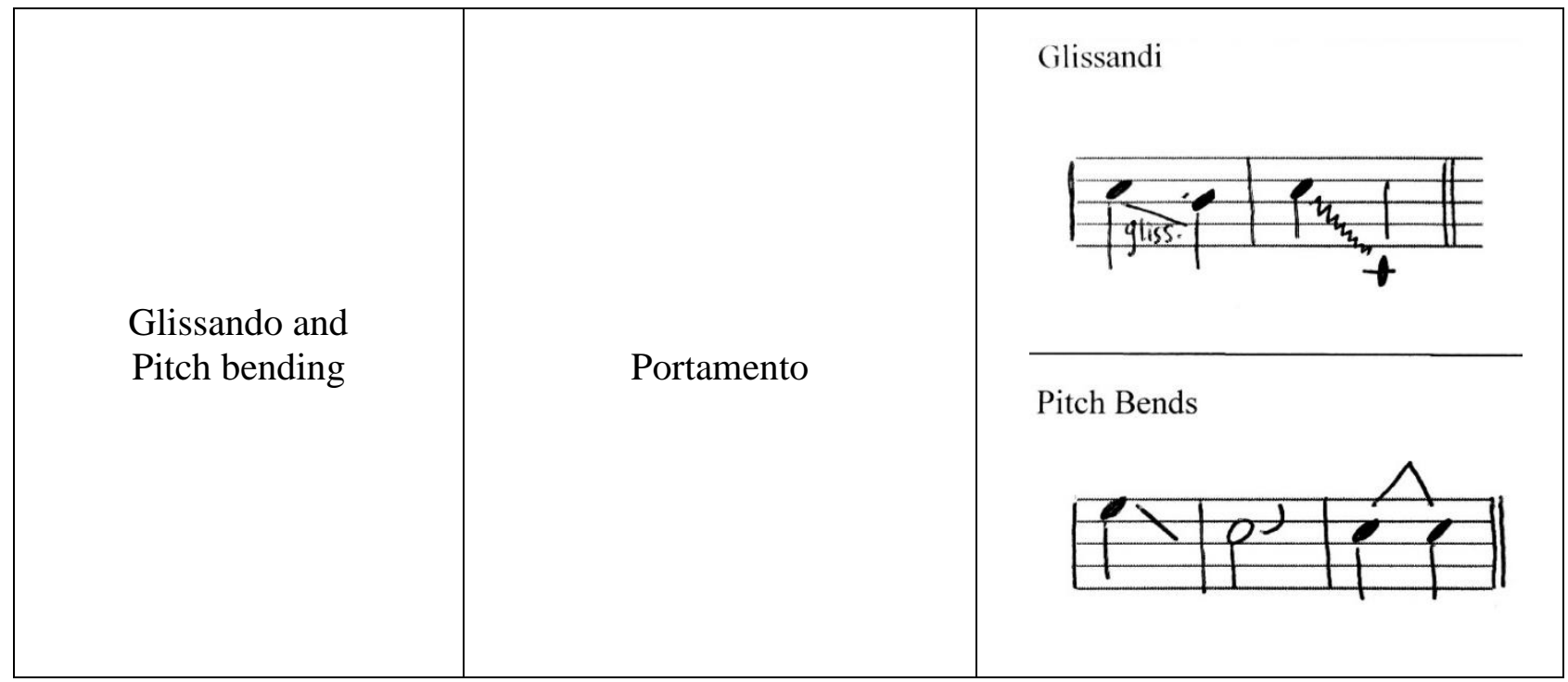

\footnotetext{
${ }^{66}$ Carin Levine and Christina Mitropoulos-Bott, The Techniques of Flute Playing: Die Spieltechnik der Flöte (Kassel: Bärenreiter, 2002), 46.

${ }^{67}$ Susan J. Maclagan, A Dictionary for the Modern Flutist (Lanham, Md.: Scarecrow Press, 2009$), 79$.
} 


\section{Multiphonic}

Multiphonics or multiple sonorities are "the most singular outgrowth from traditional flute playing in recent decades." ${ }^{\prime 68}$ They have been used in modern flute repertoire since 1958 and are considered a standard technique. ${ }^{69}$ This is a technique that defied the notion that the flute is a monophonic instrument. On the contrary, a flutist can produce two, three, four, and up to five pitches simultaneously. They are produced by overblowing a special fingering while maintaining the optimal lip opening size and a focused air stream at an angle in order for all sonorities to be heard. ${ }^{7071}$

Due to their complex nature, composers should carefully examine the fingerings they provide performers with for any given multiphonic. ${ }^{72}$ For example, there are instances of sources in which the multiphonic fingerings provided do not produce the pitches displayed on the staff. Therefore, it would be advisable for composers to consult flutists and for flutists to double-check with the following manuals: Bruno Bartolozzi's New Sounds for Woodwind (1967), Thomas Cowell's The Avant-garde Flute: A Handbook for Composers and Flutists (1974), Robert Dick's The Other Flute: A Performance Manual of Contemporary Techniques (1975), James Pellerite's

A modern Guide to Fingerings for the Flute (1964), Hiroshi Koizumi's Technique for Contemporary Flute Music for Players and Composers (1996), Pierre-Yves Artaud's Present Day Flutes: Treatise on Contemporary Techniques of Transverse Flutes for the Use of Composers and Performers (1980), and Techniques of Flute Playing: Die Spieltechnik der Flöte (2002) by Carin Levine and Christina Mitropoulos-Bott.

\footnotetext{
${ }^{68}$ Dick, Robert. The Other Flute: A Performance Manual of Contemporary Techniques (St. Louis, MO: Multiple Breath, 1989), 83.

${ }^{69}$ Carin Levine and Christina Mitropoulos-Bott, The Techniques of Flute Playing: Die Spieltechnik der Flöte (Kassel: Bärenreiter, 2002), 22.

70 Ibid., 83

71 "Flutexpansions: Multiphonics" https://www.flutexpansions.com/multiphonics (accessed March 28, 2019)

${ }^{72}$ David Cope, Techniques of the Contemporary Composer (Belmont, CA: Schirmer Books, 1997), 138.
} 
Figure 2.8: Alternative Name and Notation for the technique of Multiphonics

Multiphonic

\section{Microtonality: Quartertones/Microtones}

Quartertones/microtones are intervals smaller than a semitone, which is the smallest interval in Western music. ${ }^{73}$ To produce an interval or pitch a quartertone/microtone away from another tone a flutist can either use the techniques of pitch pending, finger glissando, or special fingerings. All three methods mentioned above are possible on both an open-hole and closed-hole flute with the exception of finger glissando, which is possible only on an open-hole flute. Even though composers will often suggest the fingerings, especially when that involves a microtonal scale, it is not impossible for the performer to have to seek them out or experiment with ways to alter the pitch. Composer Karlheinz Stockhausen and composer-flutist Ian Clarke are exemplary composers when it comes to providing those special fingerings. In fact, Stockhausen provides

\footnotetext{
${ }^{73}$ Susan J. Maclagan, A Dictionary for the Modern Flutist (Lanham, Md.: Scarecrow Press, 2009), 109.
} 
fingerings meant for closed-hole flute and insists the flutist uses only those, since they have been tested by flutist Kathinka Pasveer and they produce the timbral color desired (Figure 2.6). ${ }^{74}$

Figure 2.9: Stockhausen, Flautina, micronotal scale, rehearsal \#8

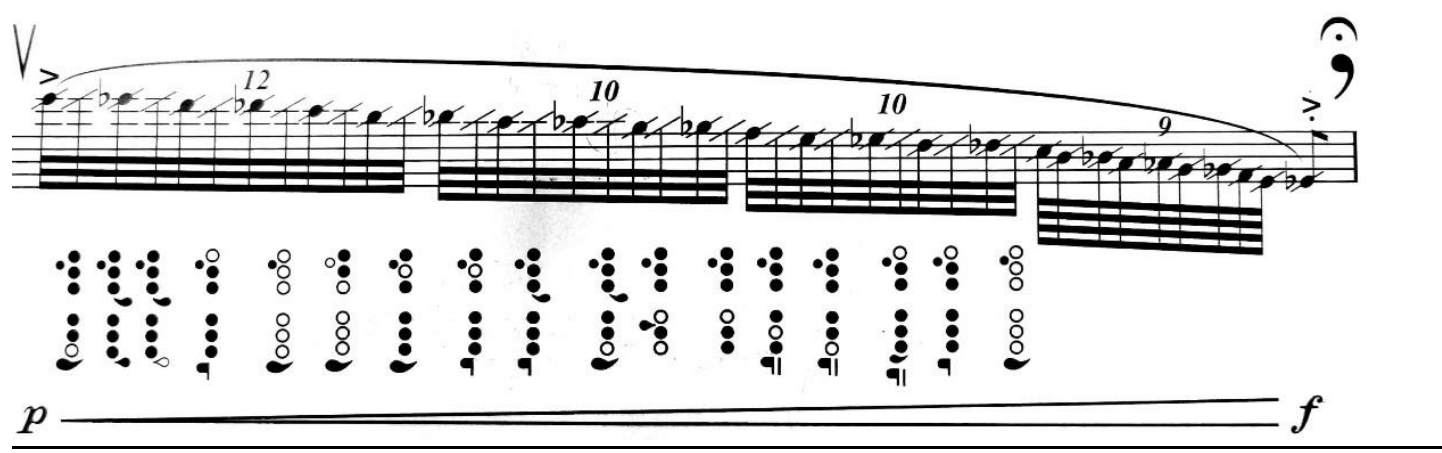

Quartertones/microtones are considered a standard technique when it comes to their notation and in general the following accidentals are often used to notate them:

\begin{tabular}{|c|c|}
\hline II & $1 / 4$ higher than a regular sharp \\
\hline$\frac{1}{4}$ & $1 / 4$ higher than a regular sharp \\
\hline$\pi$ & regular sharp \\
\hline $\mathbb{H}$ & $1 / 4$ lower than a regular sharp \\
\hline$\phi$ & $1 / 4$ lower than a regular sharp \\
\hline b & $1 / 4$ higher than a regular flat \\
\hline d & $1 / 4$ higher than a regular flat \\
\hline$p$ & $1 / 4$ lower than a regular flat \\
\hline bb & double flat \\
\hline$\hat{\natural}$ & $1 / 4$ higher than a regular natural \\
\hline$q$ & $1 / 4$ lower than a regular natural \\
\hline
\end{tabular}

\footnotetext{
${ }^{74}$ Kathinka Pasveer shared this information in a personal email thread with Eftihia Arkoudis pertaining to the performance practice of Flautina for Solo Flute with Piccolo and Alto flute (1989).
} 
Figure 2.10: Alternative Name and Notation for the technique of Quartertones/Microtones

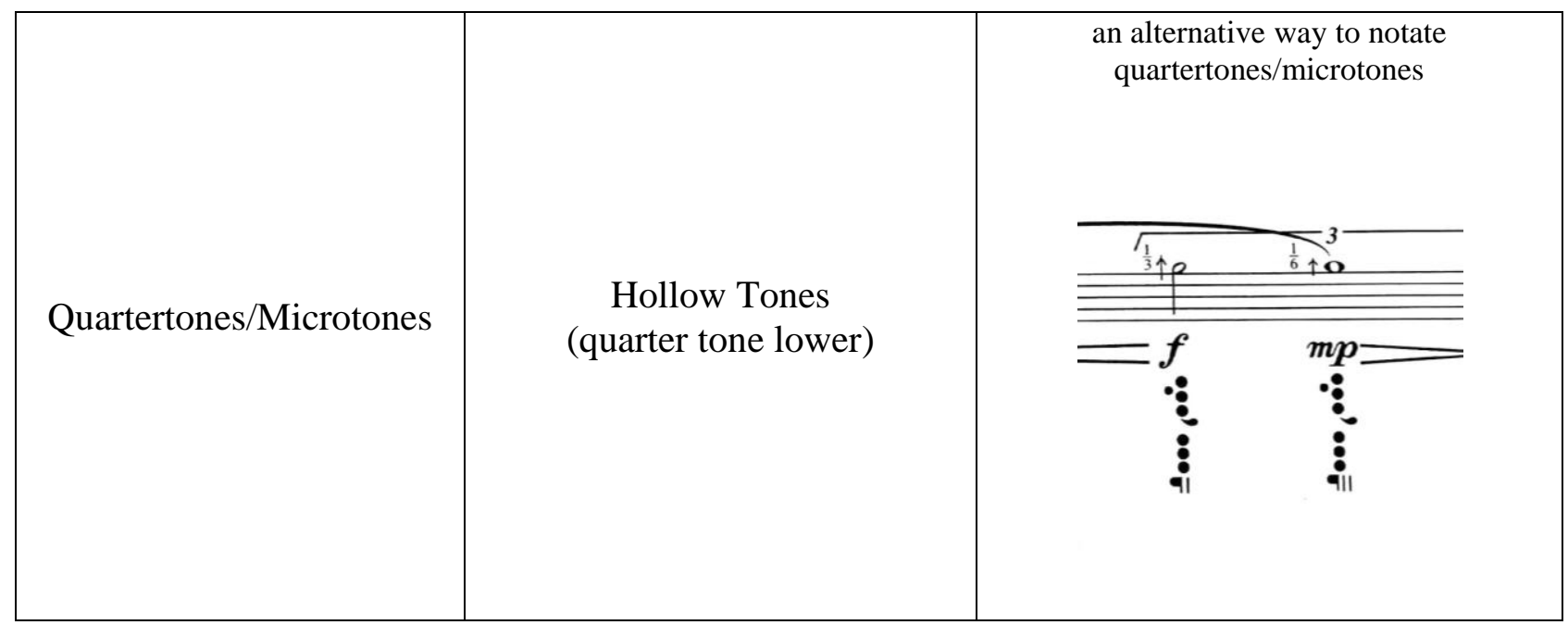

\section{$\underline{\text { Bisbigliando }}$}

Bisbigliando is also known as unison tremolo, enharmonic trill, timbre trill or klangfarbentrill. It is a tremolo between different fingerings of the same pitch. ${ }^{75}$ The purpose of a bisbigliando is not to change the pitch of the note, but the color of the note; the result is a fast, shimmery change of tone color that resembles playing a trill. ${ }^{76}$ If the fingerings are not provided by the composer then the flutist is to experiment until he or she finds the trilling key that yields the desired sounding result. The technique is often indicated in the score with the word bisb. along with a wavy line and its notation is considered standard.

75 "Flutexpansions: Bisbigliando" https://www.flutexpansions.com/bisbigliando (accessed March 28, 2019)

${ }^{76}$ Christian Dimpker, Extended Notation: The Depiction of the Unconventional (Vienna: Lit, 2013), 61. 
Figure 2.11: Alternative Name and Notation for the technique of Bisbigliando

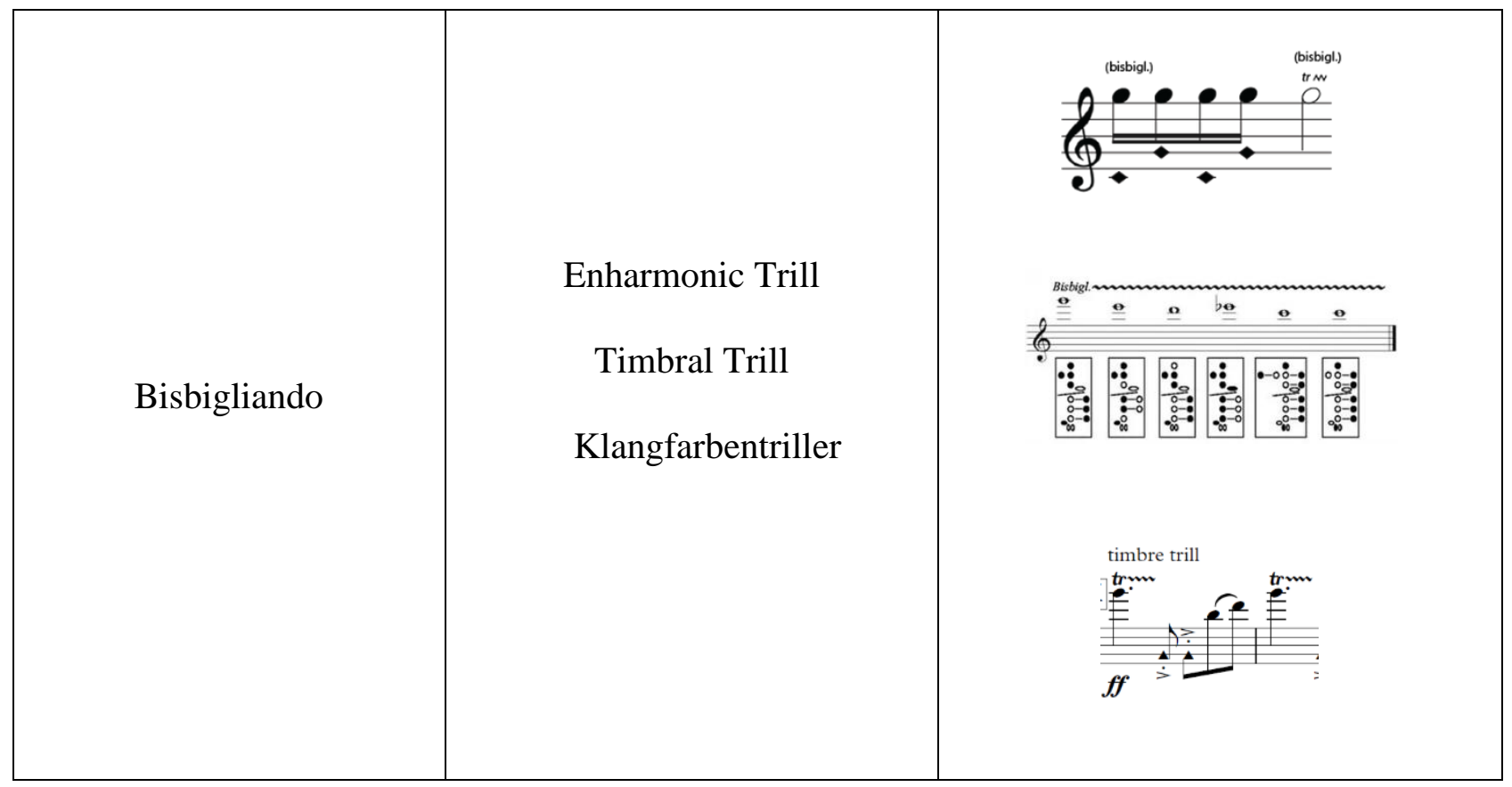

\section{Buzz Tone}

Buzz tone is a technique meant to imitate the sound of a trumpet, which is why it is also known as trumpet-embouchure. The sound is produced through the combination of lip tension, air pressure, and the space in the oral cavity, while (a) blowing into the embouchure holes or (b) removing the headjoint and blowing into the upper part of the flute body, as if it is a recorder. ${ }^{77}$ It is usually notated with the words "trumpet attack," "buzz," or BZ and its notation is considered standard.

${ }^{77}$ Carin Levine and Christina Mitropoulos-Bott, The Techniques of Flute Playing: Die Spieltechnik der Flöte (Kassel: Bärenreiter, 2002), 18. 
Figure 2.12: Alternative Name and Notation for the technique of Buzz Tone

\begin{tabular}{|c|c|c|}
\hline Buzz Tone & Trumpet Embouchure & trumpet \\
aftack \\
alla tromba
\end{tabular}

\section{$\underline{\text { Bamboo Tones }}$}

According to composer-flutist Wil Offermans, who has published a book including studies devoted to practicing this extended technique, bamboo tones have a warm, hollow, windy sound. ${ }^{78}$ Composers will usually provide the flutist with the fingerings, but if that is not the case then Robert Dick's Tone Development through Extended Techniques and Wil Offerman's For the Contemporary Flutist: Twelve Studies for the Flute with Explanations in the Supplement are two manuals that include that information. The notation for bamboo tones is considered standard.

Figure 2.13: Alternative Name and Notation for the technique of Bamboo Tones

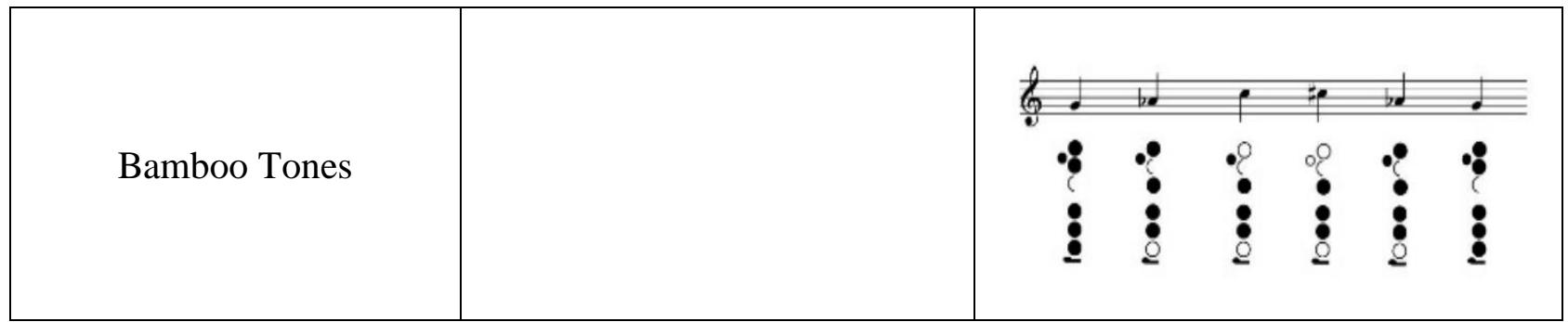

\footnotetext{
${ }^{78}$ Wil Offermans, For the Contemporary Flutist: Twelve Studies for the Flute with Explanations in the Supplement (Frankfurt am Main, Germany: Zimmermann, 1992), 45.
} 


\section{ARTICULATION TECHNIQUES}

\section{Flutter tonguing}

Flutter tonguing, in other languages known as flatterzunge (German), frullato (Italian), flatter, is considered a "classical new music technique" since it has been extensively used by composers since before the turn of the twentieth century. ${ }^{79}$

Flutter-tonguing can be described as a purring sound produced either by rolling the tip of the tongue $[\mathrm{r}]$ on the alveolar ridge or using the uvula in the back of the mouth, else known as glottal flutter tonguing (similar idea to 'gargling' water), while playing a note. Unless a composer specifies and notates a preference towards any of those two ways, then a flutist may choose the method which is the most effective according to the physiology of his or her oral cavity and context of the work. Usually, lower register and soft dynamics call for glottal flutter-tonguing, while higher register and louder dynamics call for rolling the tip of the tongue. The technique is possible on all registers of the flute.

Although the technique has multiple ways of being notated, all flutists are accustomed with the technique and can recognize it immediately in a score, therefore its notation is considered standard. According to Christian Dimpker, the two different kind of flutter tonguing may also be seen notated based on the International Phonetic Alphabet (IPA): the sign [r] - indicates the rolling of the tongue on the alveolar ridge, while the sign $[R]$ indicates the rolling of the back of the tongue at the uvula. ${ }^{80}$

\footnotetext{
${ }^{79}$ Carin Levine and Christina Mitropoulos-Bott, The Techniques of Flute Playing: Die Spieltechnik der Flöte (Kassel: Bärenreiter, 2002), 12.

${ }^{80}$ Christian Dimpker, Extended Notation: The Depiction of the Unconventional (Vienna: Lit, 2013), 64-65.
} 
Figure 2.14: Alternative Name and Notation for the technique of Flutter Tonguing

\begin{tabular}{|c|c|c|}
\hline Frullato \\
(Italian) \\
Flatterzunge \\
(German) \\
Flutter
\end{tabular}

\section{AIR SOUND TECHNIQUES}

\section{$\underline{\text { Aeolian Sound }}$}

Aeolian sound or residual tone is a colored air sound with no normal flute tone, resembling the sound of the wind. It is a breathy sound produced when the flutist blows across the embouchure hole with a relaxed and unfocused embouchure. The air sound can range from extremely soft to very loud or explosive by varying (a) the shape of the oral cavity with the use of vowels, (b) distance between the teeth, and (c) the speed and angle of the air stream. ${ }^{81}$ Due to the technique's various notational methods over the years, its notation is not considered standard. For this reason, its notation signs will be further discussed in chapter three.

81 "Flutexpansions: Aeolian Sound" https://www.flutexpansions.com/aeolian-colored-air (accessed March 28, 2019) 
Figure 2.15: Alternative Name and Notation for Air Sounds

Air Sounds

\section{Circular Breathing}

Circular breathing allows one to continue breathing in air without disrupting the melody for a long time. Someone who has mastered this extremely challenging technique will be able to perform longer phrases, with essentially one breath. What is mainly involved is the mouth, the tongue, and the cheeks. For a more thorough and educational approach to circular breathing, an invaluable source is Robert Dick's Circular Breathing for the Flutist (1987). 
Figure 2.16: Alternative Name and Notation for Circular Breathing

\begin{tabular}{|l|l|l|}
\hline Circular Breathing & &
\end{tabular}

\section{PERCUSSIVE EFFECTS}

\section{$\underline{\text { Key Clicks }}$}

Key clicks or key slaps are a percussive technique that involves strongly clicking the keys of the instrument to produce a pitch resonance. ${ }^{82}$ John Heiss refers to them as a "veteran" special effect for the flute, since they have been widely used since the early twentieth century.

Key clicks can be played with both sound and no sound and the pitch produced depends on (a) the fingering and (b) how much of the embouchure hole is covered. When the embouchure hole is covered with the lips then the actual pitch sounds a major seventh lower than the notated pitch (key slaps in this manner have been employed by George Crumb in his work Night of the Four Moons). ${ }^{83}$ In addition, flutists are often suggested to finger the desired note, then raise and slap the G-key with the fourth finger left hand for a louder and projecting effect. ${ }^{84}$ Finally, flutists can create a sound out of both slapping and lifting the keys. Due to their seniority their notation is considered standard. Nevertheless, due to their percussive nature, their notational signs can often represent other extended techniques as well.

\footnotetext{
82 "Flutexpansions: Key Clicks" https://www.flutexpansions.com/key-clicks (accessed March 28, 2019)

${ }^{83}$ Gardner Read, Contemporary Instrumental Techniques (New York: Schirmer Books, 1976), 6-7.

${ }^{84}$ John Heiss, "The Flute: New Sounds." Perspectives of New Music 10, no. 2 (1972): 153-58.
} 
Figure 2.17: Alternative Name and Notation for the technique of Key Clicks

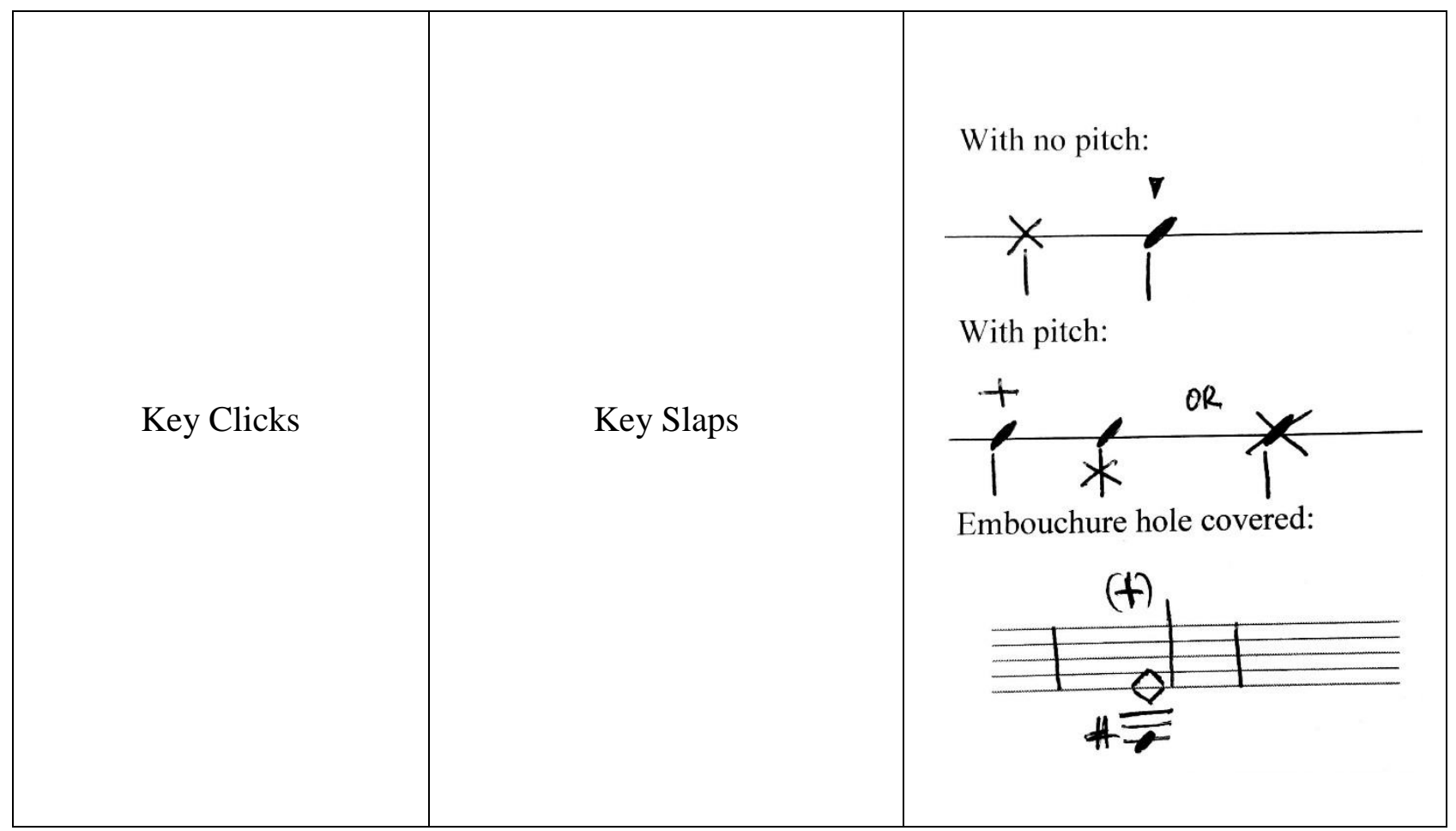

\section{Tongue Ram}

Tongue ram, or else known as tongue stop, tongue slap, or tongue thrust, is a percussive effect produced by completely covering the embouchure hole with the lips and rapidly extending the tip of tongue into the embouchure hole, in a "chameleon-like fashion." ${ }^{85}$ This technique is the most successful when the movement of the tongue is accompanied by a forceful exhalation of air, like a thrust. The sounding pitch will be a major seventh below the fingered note for a concert $\mathrm{C}$ flute, a major or minor seventh below the written pitch on an alto- and bass-flute, and a minor ninth below for the piccolo. ${ }^{86}$

Many flutists find it helpful to think of the word "Hot" or "ht" in order to achieve the "pop' sound that derives from the technique. For this reason, some composers may use the letters H.T.

\footnotetext{
${ }^{85}$ Susan J. Maclagan, A Dictionary for the Modern Flutist (Lanham, Md.: Scarecrow Press, 2009), 187.

86 "Flutexpansions: Tongue Ram" https://www.flutexpansions.com/tongue-ram (accessed March 28, 2019)
} 
to notate it, among many other notational signs that have been developed throughout the years, making its notation non-standard.

Figure 2.18: Alternative Name and Notation for the technique of Tongue Ram

Tongue Ram Tongue Stop

\section{Pizzicato}

Pizzicato, or else known as tongue slap, is a percussive effect reminiscent of the pizzicato technique for the strings. There are two kinds of pizzicato: tongue pizzicato and lip pizzicato. With tongue pizzicato, the tongue produces a hard articulation (letter $\mathrm{T}$ ) by being placed between the lips or against the hard palate behind the teeth. The sound produced has a dry quality. With lip pizzicato, the flutist must press the lips hard against each other and allow the air to separate them apart, to produce a [pa] percussive sound. This sound should have more of a wet quality. ${ }^{87}$

For both, there is no air stream from the lungs involved; therefore, this technique produces a pitch resonance in the first octave only, low B- middle D\#. Composers very rarely will define a

\footnotetext{
${ }^{87}$ Christian Dimpker, Extended Notation: The Depiction of the Unconventional (Vienna: Lit, 2013), 66-67.
} 
preference towards either of the two techniques in their scores. Therefore, the choice depends on the performer's mouth physiology and playing abilities, as well as the nature of the work. Even though the word pizzicato is often used to notate this technique, it has acquired multiple signs over the year, making it yet another technique with no standard notation.

Figure 2.19: Alternative Name and Notation for the technique of Tongue Pizzicato

\begin{tabular}{|c|c|c|c|}
\hline Tiz Pizzicato \\
Tongue Pizzicato \\
Tongue Slap
\end{tabular}

\section{$\underline{\text { Jet Whistle }}$}

Jet whistle, or else known as jet and air jet, is a loud attack of air reminiscent of a jet plane ${ }^{88}$ The flutist must seal the embouchure hole of the flute with the lips while forcefully exhaling a thrust of air into the tube. The pitch, tone quality, volume, and duration of the jet whistle are affected by the choice of fingering, breath pressure, vowel shape of the mouth, and angle of the embouchure hole relative to the lips. ${ }^{89}$ In general, the lower the pitch that is fingered, the richer the frequencies that are produced. ${ }^{90}$ Its notation is usually the words themselves combined with a downwards or upwards line.

\footnotetext{
88 "Flute Colors: Extended Techniques for Flute" https://www.flutecolors.com/techniques/jetwhistle/ (accessed March 26, 2019)

${ }^{89}$ Susan J. Maclagan, A Dictionary for the Modern Flutist (Lanham, Md.: Scarecrow Press, 2009), 96.

${ }^{90}$ Carin Levine and Christina Mitropoulos-Bott, The Techniques of Flute Playing: Die Spieltechnik der Flöte (Kassel: Bärenreiter, 2002), 17.
} 
Figure 2.20: Alternative Name and Notation for the technique of Jet Whistle

\begin{tabular}{|l|l|l|c|}
\hline Jet Whistle & Jir jet & \\
\hline
\end{tabular}

\section{VOCAL TECHNIQUES}

\section{Singing and playing}

Carin Levine and Christina Mitropoulos-Bott describe singing and playing simultaneously as an effect that is produced when "the vocal chords rub against one another (as in speaking) while simultaneously exhaling; air flows out through the larynx into the flute." 91 The effect is one of multiple sonorities as the sound produced can vary greatly depending on the flute pitch and vocal range of the flutist. Composers will often strategically choose which intervals the flutist should finger and sing at the same time, especially when they are aiming to emulate a specific sound effect. The technique can be realized in many ways: (a) sing and play the same pitch (unison or in octaves), which is called parallel singing, (b) sing a separate melody and play another (usually in intervals of thirds, fourths, or fifths), known as polyphonic singing, and (c) holding a steady flute pitch as a drone while moving through a sequence of pitches in the voice.

\footnotetext{
${ }^{91}$ Carin Levine and Christina Mitropoulos-Bott, The Techniques of Flute Playing: Die Spieltechnik der Flöte (Kassel: Bärenreiter, 2002), 19-20.
} 
In general, in singing and playing, it is preferred the voice to have the leading role, while the flute reinforces the voice in a supporting role. ${ }^{92}$ In addition, flutists should be mindful of intonation between the voice and flute pitch, if they wish to avoid producing a "noisy" timbral sound. Of course, this would be an exception if the composer requests that kind of timbre. The use of vowels reinforces the success of the technique. ${ }^{93}$ Robert Dick has crafted exceptional exercises for this purpose and coined the term for this practice throat tuning. ${ }^{94}$

The most common form of notation is to notate this technique in two systems, with the system on top representing the flute. Nevertheless, it is also common for composers to notate both in one system. Due to the multiplicity of notational signs, the notation of technique of singing and playing will be discussed further in chapter three.

Figure 2.21: Alternative Name and Notation for Singing and Playing

Singing and playing

92 "FluteXpansions: "Singing and playing” https://www.flutexpansions.com/singing-playing (accessed March 28, 2019)

93 The vowel signs according to the International Phonetic Alphabet are:

[i] $=$ ee, as in seek

$[\mathrm{e}]=\mathrm{a}$, as in maid

$[\mathrm{a}]=\mathrm{ah}$, as in art

$[\mathrm{o}]=\mathrm{o}$, as in coal

$[\mathrm{u}]=\mathrm{oo}$, as in ooze

94 These exercises are included in Robert Dick's book Tone Development through Extended Techniques (1986) 


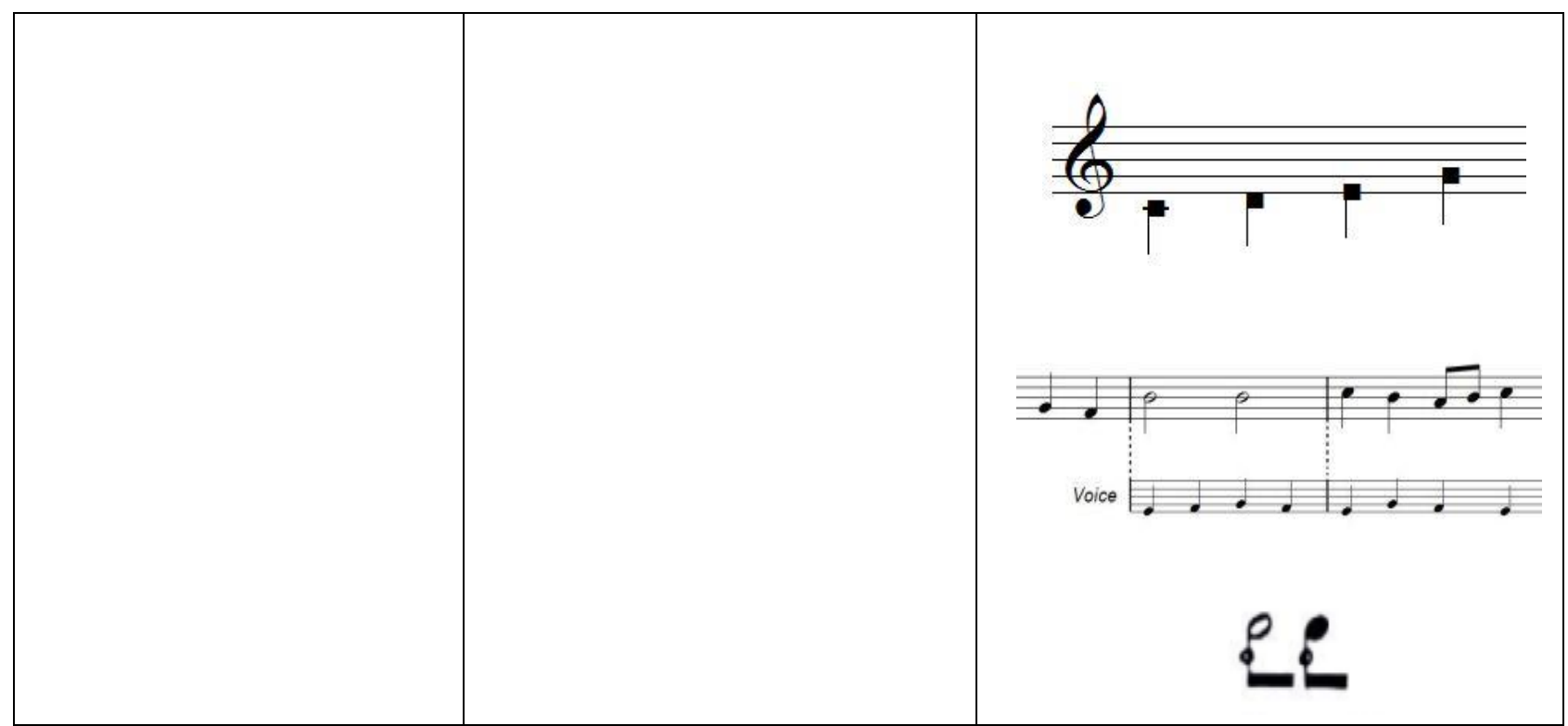

\section{Speaking and playing}

Speaking and playing simultaneously is an effect many composers choose when they want to set up a dramatic atmosphere. It is a popular technique in which the airy, human-like sound of the flute is merged with words or text and the fingered pitch colors the resulting sound. Joyce Mekeel, Toru Takemitsu and Kaija Saariaho are only some of the many composers to have applied this technique in their works The Shape of Silence, Voice, and Laconisme de l'Aile respectively. It can be done in the following three ways: (a) by placing the instrument on the lips while at the same time reciting the text, (b) covering the entire embouchure hole with the lips while speaking through the tube of the instrument, and (c) reciting only the text while slowly bringing the flute to playing position to merge the both, as two different events that co-exist in the same work.

The following technique may not be speaking and playing, nevertheless it is a derivative of it as it requires that the flutist rhythmically pronounces phonemes/syllables ("chi," "ki," "cha," "sha," "ka," "ta") while playing. The technique of vocalizing phonemes/syllables and playing is the first stage of beatboxing, unless it is used as an isolated event on selected notes. In that case, it 
is more of a percussive effect or sound. Composers who prolifically use this technique in their works are flutists Ian Clarke and Derek Charke, while Greg Patillo takes it a step further and pushes the flutist to beatbox while playing the flute, which requires the flutist mimics drum beats using their mouth, lips, tongue, and voice.

Similar to singing and playing, the most common form of notation for both those techniques is to notate this technique in two systems, with the system on top representing the flute. Nevertheless, it is also common for composers to notate both in one system. Due to the multiplicity of notational signs, the notation of technique of speaking and playing will be discussed further in chapter three.

Figure 2.22: Alternative Names and Notation for Speaking and Playing

\begin{tabular}{|c|c|}
\hline \multirow[t]{2}{*}{ Speaking and playing } & $\begin{array}{l}\text { Speak into instrument } \\
\text { Speak with no instrument } \\
*=\text { Sprechstimme } \\
*=\text { tonlos (whispered) }\end{array}$ \\
\hline & $f_{\text {loud, intense, empbatic whisper }}$ \\
\hline
\end{tabular}




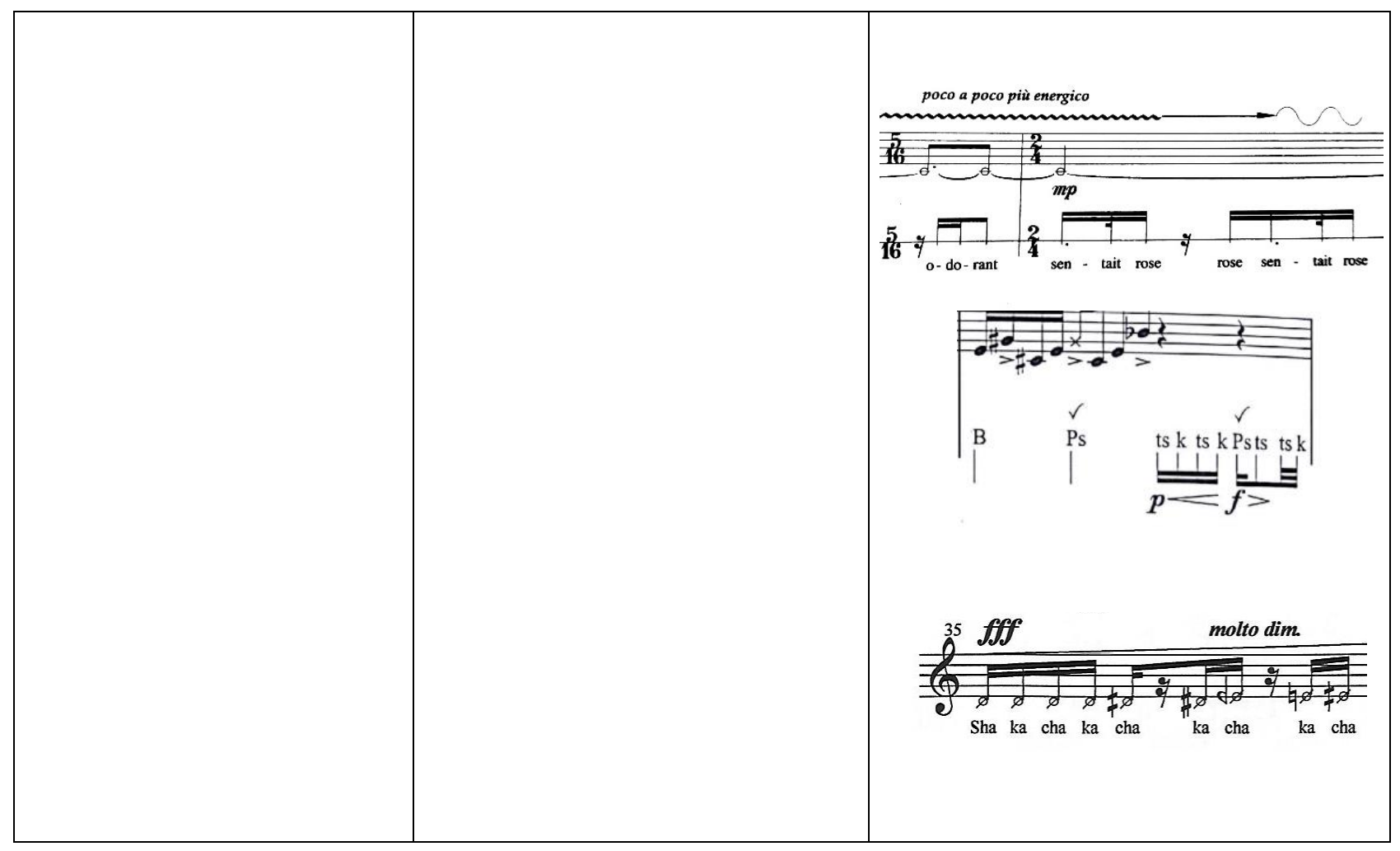




\section{CHAPTER 3}

\section{CREATING A UNIFIED LANGUAGE}

In his 1969 book Music Notation: A Manual of Modern Practice, Gardner Read wrote: “...before the philosophy of new music can make sense, its format on the printed page must be clearly understood."95 With these words in mind contemporary notation for flute extended techniques shall eventually become coherent, consistent, and universally understood among composers and performers of all levels and backgrounds.

In this chapter the reader shall find recommendations as to how to notate flute extended techniques whose notation is still today non-standardized, though in use for many years. These techniques include percussive effects such as key clicks, pizzicato, and tongue ram, the aeolian air sound effect, and the vocal techniques of singing and playing and speaking and playing. The choice to study the notational signs of these six specific techniques was made solely on grounds that there are several ways to notate them and often the notation of one, be the notation of another. Reasonably, when one sign is used to notate six entirely different techniques in nature, performers can find themselves in the bewildering position of contemplating what to do next. This persistent notational challenge becomes more intensified as composers approach composing for the flute in an individualistic way rather through a holistic approach inclusive of the flute's modern music history, new music notation literature, and the works of celebrated composers.

All the findings in this chapter are based on studying major literature sources pertaining to contemporary instrumental notation as well as comprehensive guides to contemporary flute notation, and the study of over thirty works for solo flute and flute ensemble. Bearing in mind that contemporary notation should completely remove itself from the perplexity that has defined it for

\footnotetext{
${ }^{95}$ Gardner Read, Music Notation: A Manual of Modern Practice (2d ed. Boston: Allyn and Bacon, 1969), 453.
} 
decades, this study will take the following factors in mind: flexibility, structure, and universality. In other words, the main goal is to choose one unique symbol for each of the techniques mentioned above after examining its symbolic simplicity and clarity. Any symbol whose visual representation is perceived as a logical extension from traditional notation and immediately communicates its unique function will be chosen as the final symbol for that technique. Any symbols that resemble one another, overlap, or are too abstract, will be rejected, and symbols that efficiently combine "old" and "new" - "action" and "symbol" will be retained. ${ }^{96}$

Finally, in the process of eliminating symbols, my personal experience as a flutist had been taken into account. As a flutist who five years ago had very little to no experience performing works that incorporate extended techniques, matters of notation became frustrating at times. For this reason, one of the variables of this study is the ability to logically and instantaneously recognize modern notation as a novice flutist with such repertoire. Thus, this method is inclusive of young professionals and students who wish to delve into performing this style of music but are intimidated by its appearances on paper.

\section{Key Clicks}

John Heiss refers to key clicks as a "veteran" percussive effect for the flute. They were introduced to the public by Edgard Varese in 1936 and ever since have been used widely. Due to the technique's seniority, its notation is considered standard, however, because of its percussive nature, its most common notation sign today (sign (1): the (x)-note-head shape) can be also seen as aeolian sound, pizzicato or tongue ram.

\footnotetext{
${ }^{96}$ Erhard Karkoschka, Notation in New Music: A Critical Guide to Interpretation and Realisation (New York: Praeger, 1972), 5.
} 
Figure 3.1: Notation possibilities for the technique of Key Clicks

(1)

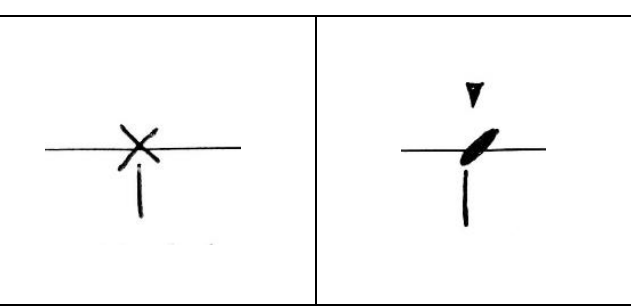

(3)

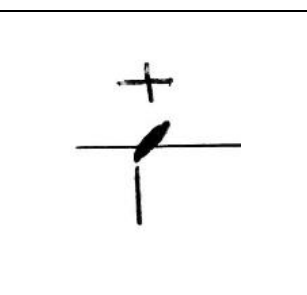

(4)

(5)

(6)

\section{Embouchure hole closed}

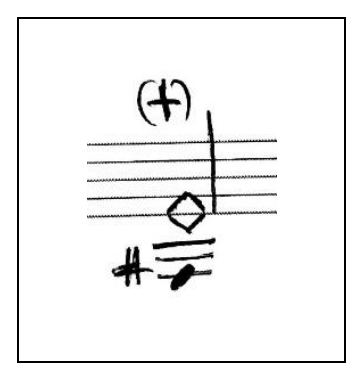

Sign (1) indicates a key click with no pitch and can be seen in Burt Levy's Orbs with Flute (1966), Brian Ferneyhough's Cassandra's Dream Song (1976), Donald Erb's Music for Mother Bear (1977), Robert Dick's Lookout (1989), and Christos Hatzis Departures Concerto for Flute and String Orchestra (2011). Sign (2) indicates a key click with no pitch and among the works examined for this paper it can be seen only in Kazuo Fukushima's Mei for solo flute (1962). Sign (3) indicates a key click with pitch and can be seen in Luciano Berio's Sequenza I, George Crumb's Vox Balaenae (1971), Brian Ferneyhough's Cassandra's Dream Song (1976), John Heiss' Etudes op.20: Shadows (1979), Shulamit Ran's East Wind (1987), and Maggi Payne's Reflections (2003). Sign (4) is another sign that indicates a key click with pitch and can be seen in Toru Takemitsu's Voice for solo flute (1971), and Sign (5) also indicates a key click with pitch and can be seen in the works of Kaija Saariaho who uses the notational signs suggested by Pierre Yves Artaud in his 
treatise Present Day Flutes: Treatise on Contemporary Techniques of Transverse Flutes for the Use of Composers and Performers (1980).

\section{Discussion:}

Considering that sign (2) occurs rarely in the modern flute repertoire, in addition to resembling notation for tongue articulation, it has been forgotten throughout the years. Composers have been using sign (1) as the best and most common sign to notate key clicks with no pitch as it logically connects to the standard way of notating rhythms in traditional music for percussion.

When it comes to notating key clicks with pitch, the remaining three signs $(3,4$, and 5) are used frequently and are most of the time recognized as such among flutists. Sign (3) was the way Varese notated key clicks in 1936 when he introduced them in his work Density 21.5 (1936) thus making it the first notational sign to instantly recognize this new instrumental technique. Many composes used it exclusively until sign (4) and sign (5) were presented as alternative ways to notate key clicks with pitch.

\section{Recommendation:}

Accepting that sign (3) has a historical substance and is immediately recognized among flutists as a key click it will not be eliminated from this process. However, it does not fit the criteria of the study due to its overlapping with a preceding symbol in music notation, the Baroque trill. The fact that the same sign can be seen for two different techniques makes it not preferable to use in new music for the flute written today. Moreover, and with no disrespect towards PierreYves Artaud notation suggestion in sign (5), an X over a regular note-head for many may suggest that there should be no pitch. This is the opposite from what the symbol is meant to depict, therefore it does not fit the criteria of immediately communicating its function. On the other hand, 
sign (4), which is used by Toru Takemitsu in his works, is visually straightforward and precise making it the ideal symbol for key clicks with pitch.

Finally, taking sign (4) as the ideal sign moving forwards to use for key clicks with pitch, for key clicks that require the flutist covers the embouchure hole with the lips - meaning that the resulting pitch sounds a major seventh lower than the notated pitch - the sign suggested for these kinds of key clicks is the one found in Thomas Howell's The Avant-Garde Flute (Figure 3.1) and which Burt Levy uses in Orbs with Flute (1966).

Figure 3.2: Howell, The Avant-Garde Flute, pg.22

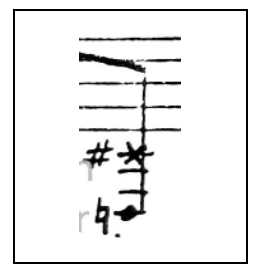

\section{Pizzicato}

The notation of percussive effects on the flute is probably one of the most confusing matters in contemporary flute notation as the number of conflicting symbolic notations is substantial. ${ }^{97}$ The notation of the pizzicato and tongue ram is no exception. Due to the flute pizzicato (tongue slap), deriving as a special effect meant to imitate the resulting sound of the string pizzicati, it will be a significant variable in choosing its future standard notation.

\footnotetext{
${ }^{97}$ Kathryn Emma Moorhead, "A Performer's Perspective on the Evolution and Realisation of Extended Flute Techniques: A Portfolio of Recorded Performances and Exegesis," (Ph.D. diss., University of Adelaide, Elder Conservatorium of Music, 2012): 50.
} 
Figure 3.3: Notation possibilities for the technique of Pizzicato

(1)

(2)

(3)

(4)

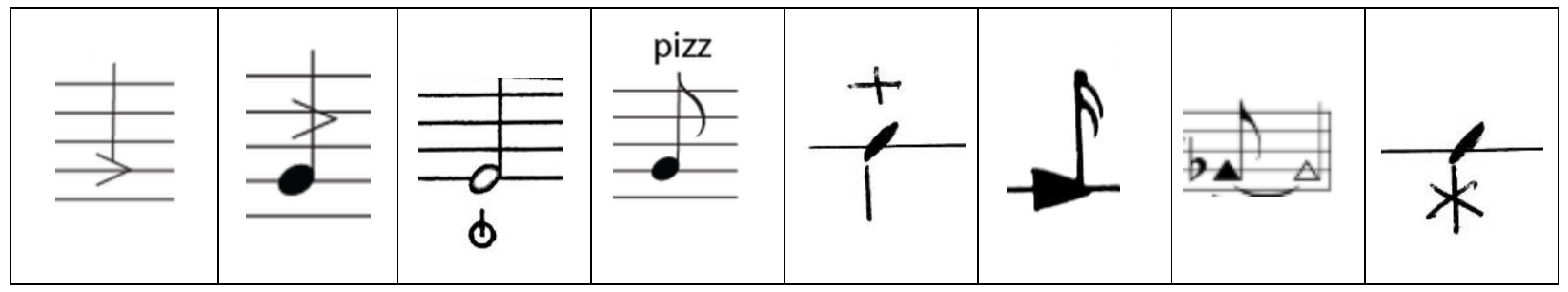

All the signs depicted above have been used by composers throughout the years to notate the pizzicato percussive effect. In the works studied for this paper sign (1) can be seen in Brian Ferneyhough's Cassandra's Dream Song (1976), sign (2) in all Takemitsu's works, sign (3) in Shulamit Ran's East Wind (1987) and sign (5) can be seen in Gergely Ittzes Pizzicato-Polka for four flutes. Furthermore, sign (7) can be seen in the works of Heike Beckmann Levada (1999) and Anže Rozman's Dance of the Nuraghi Warriors for Flute Trio (2017), and sign (8) can be seen in Hatzis' Departures for Flute and String Orchestra (2011). In his treatise, Artaud also recognizes sign (6) as an alternative for sign (1).

\section{Discussion:}

As mentioned in chapter two, flute pizzicato may be achieved either by the means of the tongue (tongue pizzicato) or with the lips (lip pizzicato.) For this reason, Christian Dimpker in his book Extended Notation: The Depiction of the Unconventional (2013) suggests that when composers wish to identify a preference over one of the two techniques they shall use the symbols of the International Phonetic Alphabet (IPA). ${ }^{98}$ For example, he points out that lip pizzicato should

\footnotetext{
${ }^{98}$ Christian Dimpker, Extended Notation: The Depiction of the Unconventional (Vienna: Lit, 2013), 66-67.
} 
be notated with the sign $[\odot]$ and tongue pizzicato with the sign [!] ${ }^{99}$ Taking in mind that one of the criteria in choosing the right symbol is the ability of musicians of all ages, levels, and cultures to immediately recognize it, this recommendation will not be considered for this study. Although it is a reasonable and correct suggestion, not everyone is familiar with the symbols of the IPA, which would require they search for further instructions in outside sources.

At this point, it is worth mentioning that sign (5), (7), and (8) shall also be eliminated from the discussion based on the criteria of this study. All three signs are also used for other techniques making them unsuitable to notate this technique. For example, sign (5) and (8) are used to notate key clicks with pitch, while sign (7) is used to notate aeolian sound and is also recognized as such by Artaud.

\section{Recommendation:}

Since this technique is a borrowed technique from plucked instruments, the use of the word pizzicato over regular notes shall suffice. Moving forward composers should use sign (4) to notate the technique of pizzicato, with the words tongue pizz. or lip pizz., accordingly, and indicate if the effect carries over to the following notes with a dotted line above them. If a composer wishes to use a symbol for purposes of space on the score or consistency, then sign (1) with the occasional accompaniment of the words tongue pizz. or lip pizz. shall be used in place of sign (4).

\footnotetext{
${ }^{99}$ According to the IPA, the symbol [๑] stands for bilabial consonants, while [!] stands for alveolar consonants.
} 


\section{Tongue Ram}

Tongue ram (tongue stop, tongue slap, or tongue thrust) is yet another percussive effect with no standard notation and similar to the pizzicato technique it has acquired myriad of symbols throughout the years. This is very surprising as it is not used by composers as often as the other percussive effects. As flutists find it helpful to think of the word "Hot" or "ht" in order to achieve the thrusting sound, the initials H.T. will also be kept in mind alongside T.R.

Figure 3.4: Notation possibilities for the technique of Tongue Ram

(1)

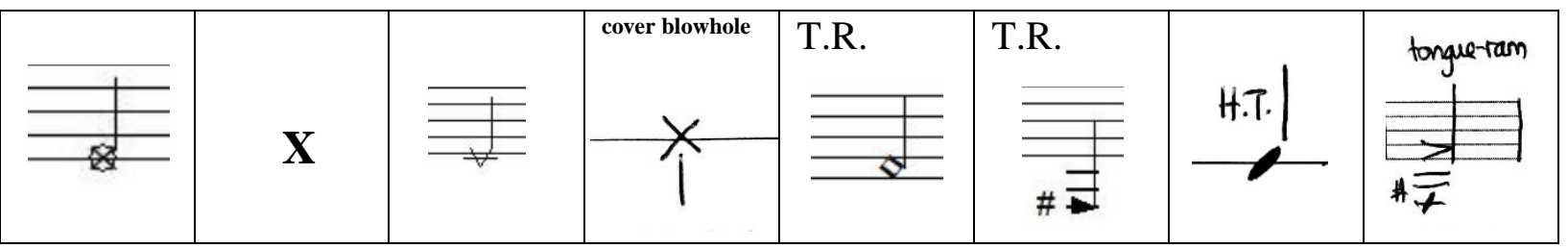

In the works studied for this paper sign (2) can be encountered in Maggi Payne's Reflections (2003), sign (4) in John Heiss' Etudes op.20: Shadows (1979) accompanied by the words “cover blowhole" and Robert Dick's Eyewitness (1991), and sign (7) in Elainie Lillios Among Fireflies (2010).

\section{Discussion:}

Based on the criteria of this study signs (2), (4), (8) will be rejected due to their conflicting nature with techniques such as key clicks and pizzicati. In addition, sign (5) will be removed from this discussion because diamond-shaped note-heads are used for harmonics and whistle tones and can also come across as a half note if the size of the score is not large enough. Furthermore, sign 
(3) shall not be further considered due to its visual representation being abstract and not a logical extension of traditional notation.

\section{Recommendation:}

Considering the discussion above, signs (1), (6), and (7) are all plausible choices. With this specific technique, the initials H.T. or T.R. over a regular note, or even the word tongue-ram, communicates the technique immediately and clearly. Therefore, no matter which option a composer uses, he or she should not neglect to add either of the two choices of initials. If a composer does not care to notate the resulting sound pitch and bearing in mind that the nature of this technique is to stop a thrust of air with the tongue, out of all the signs depicted above, sign (1) is the most visually successful.

\section{T.R or H.T.}

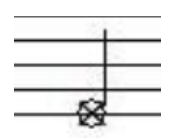

\section{Aeolian Sound}

Aeolian sound or residual tone are both terms to describe air tones colored by the shape of the oral cavity and according to Helen Bledsoe composers should make a point to notate whether or not they would like for the air tone to have pitch (blowing air across the embouchure hole) or not to have pitch (blowing air inside the flute by covering the embouchure hole). ${ }^{100}$ The various symbols designed to notate the technique throughout the years have only blurred the lines between air sounds with no pitch and air sounds with pitch. This might be a reason why in recent times

\footnotetext{
100 "Helen Bledsoe: Tips for Composing and Notation Aeolian” http://bledsoe22.blogspot.com/2010/02/tips-for-
} composing-and-notating-aeolian.html (accessed March 28, 2019) 
composers have begun to limit the use of only symbols and have reinforced notation with 'action' words.

Figure 3.5: Notation possibilities for the technique of Aeolian Sounds

(1)

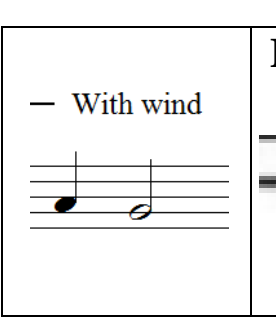

(9)

(2)

(3)

(4)

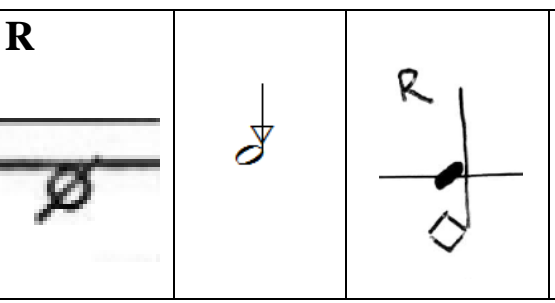

(11)

(10)

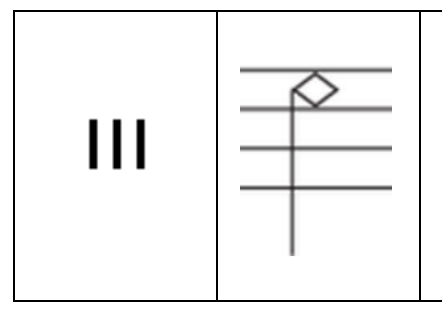

(5)

(6)

(7)

(8)

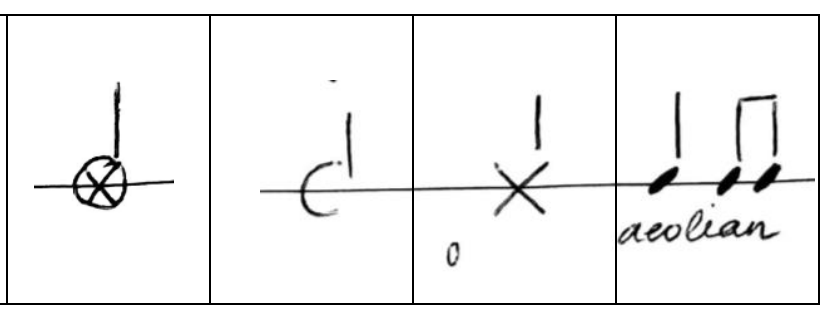

(12)

(13)

(14)

\section{Discussion:}

Sign (1) and (8) can be seen in numerous works written for the flute including John Heiss' Etude op. 20: Shadows (1979), Shulamit Ran's East Wind (1988), Michael Culquhoun's Charanga (1993), and Christos Hatzis' Departures Concerto for Flute and Strings (2011). Sign (2) is Ian Clarke's staple way of notating what he calls a residual tone, thus the use of the letter $\mathbf{R}$ in all of his works, including Zoom Tube (1999) and Great Train Race (2000). Another composer who chooses the same notation is Karlheinz Stockausen, who has used it in his work Flautina for Solo Flute with Piccolo and Alto Flute (1989). Sign (4) is Robert Dick's symbol for the technique, which shares the letter R with Ian Clarke's notation, to indicate that it is a residual breathy tone. 
Sign (5) has been used by Donald Erb in Music for Mother Bear Song for a Mother Bear (1977), while sign (6) is Takemitsu's way of notating aeolian sounds in Voice for solo flute (1971). Sign (7) has been used by Anže Rozman in the Dance of the Nuraghi Warriors (2017), who has also used sign (10) with the accompaniment of words in his Little Suite of Mythological Beings (2010). The latter one, can also be seen in Heinz Holliger's Sonate (in) solit (air) e for flute solo (1995). Sign (9) is in works by Wil Offermans and sign (3) and (11) can be seen in Artaud's treatise. Finally, sign (13) is Kaija Saariaho's way of notating aeolian sound and has also been used by Robert Aitken in Plainsong (1977). A sign that has not been included in this table but is also for breathy sounds is the one used by Maggi Payne in her work Reflections (2003). It is a square-spaced empty note-head indicating that the player should produce an air pitched glissando. She also uses sign (10) for humming.

Thus far, commonly used symbols for air tones have been the hollow diamond-shaped signs or triangle shaped-note heads [signs (3), (10), (11)]. However, because of the diamondshaped note heads belonging to harmonics and whistle tones they shall be rejected from this discussion. Furthermore, because any hollow notes can be confused with half notes, even when the note stems clearly define rhythm, signs (6) and (13) shall also be excluded. In an article Helen Bledsoe wrote in 2010 she urged composers to cease using any symbols with empty note-heads. She explained that they look like half notes and can easily confuse the performer when it comes to rhythmic matters. This is a very logical request, which further explains why a total of five signs have been eliminated in this process. In addition, sign (4) which has been coined by Robert Dick shall be left out due to its similarity with the composer's notation for whistle tones, which is frequently used, and sign (9) due to its illogical design. Finally, sign (5) and (7) shall not be considered further on grounds that they represent a tongue ram and key click respectively. 


\section{$\underline{\text { Recommendation: }}$}

Following the discussion above, the most ideal and acceptable signs moving forward are signs (1), (2), and (8). Even though sign (2) is an empty note-head, the slash that splits it in half in combination with the letter $\mathrm{R}$, which stands for residual tone, is a precise notation that does not leave room for confusion. Nevertheless, the strongest way to notate aeolian sound with unambiguity is to use the words "with wind" or "aeolian," or "residual tone," while indicating if the effect carries over to the following notes with a dotted line above them.

\section{Singing and Playing}

Singing and playing simultaneously is a technique of multiple sonorities making it necessary for composers to precisely notate it in order for the resulting sound to be successful. Composers are strongly advised to strategically choose and notate the intervals a flutist will finger and sing at the same time. Not all combinations yield the desired effect as some may have a "noisy" timbral quality or inadequate projection power. Moreover, the vocal range of the flutist is another influencing variable further supporting the need for notational accuracy on behalf of the composers. For this reason, the most common form of notation is - and should be - to notate singing and playing simultaneously in two systems, with the system on top preferably representing the flute. ${ }^{101}$ Nevertheless, it is also common for composers to notate both in one system, for which Robert Dick's notation system is the best one to use (Figure 3.6). In this case, composers are welcome to also use action words such as 'with voice' or 'sing' or 'sing \& play,' etc., like composers Donald Erb, Michael Culquhoun, Ian Clarke and many others have done in the past.

${ }^{101}$ Christian Dimpker, Extended Notation: The Depiction of the Unconventional (Vienna: Lit, 2013), 80-81. 
Figure 3.6: Dick, Tone Development Through Extended Techniques, pg. 8

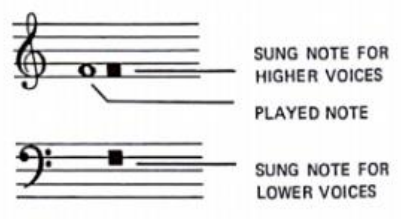

One of the most significant mistakes that take place when notating singing and playing is that composers do not account for the difference in sonorities when a female or male flutist sings in their natural range. For example, on flutes it is possible to finger a low tone while singing higher as well as vice versa. If a composer wishes to have the effect of two different registers clashing they should notate it or specify it in their program notes, otherwise flutists will sing in the range they feel most comfortable. This is another reason why the two-system notation is an exemplary way to notate this technique, as it also has the perk of allowing the composer to add desired accompanying vowels, if they wish to be so detailed. It is highly recommended that the International Phonation Alphabet is used when adding vowels to this technique due to linguistic differences among players.

The benefits of a two system, like the one seen by Rhonda Larson in Be Still My Soul (2011) (Figure 3.7), is that it allows the flutist to practice the flute line separately from the vocal line before merging the two together. This will ensure that no buzzing occurs and that the vocal part is masterfully louder than the flute part. Other composers who have incorporated this notational procedure in their scores are both George Crumb and John Heiss. 


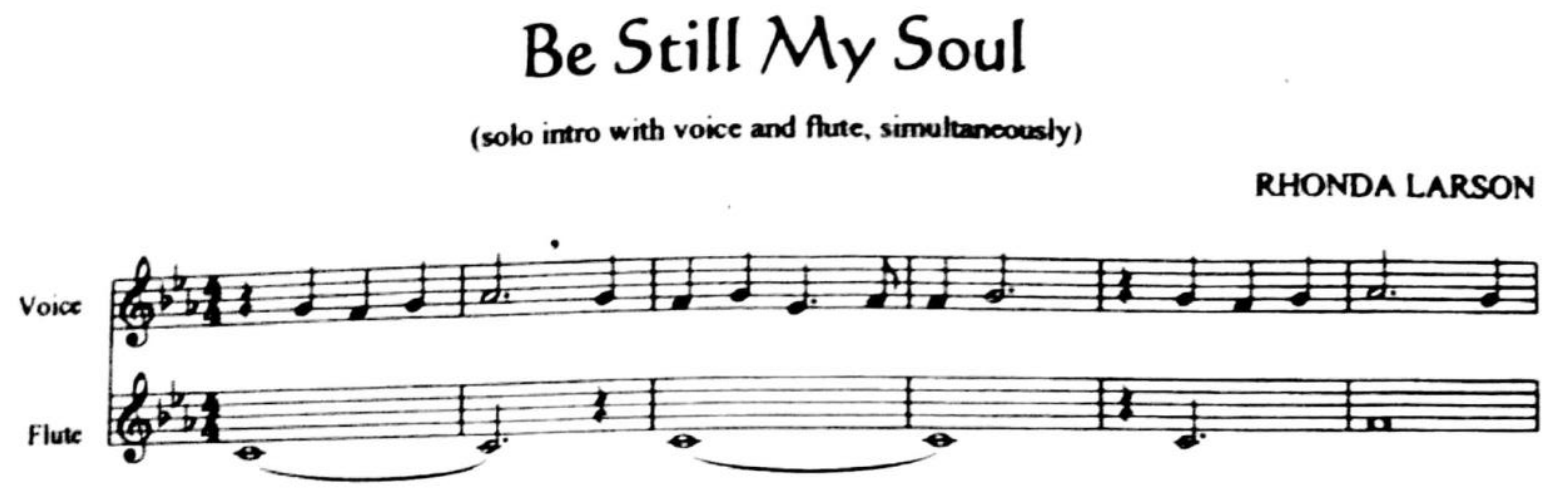

\section{Speaking and Playing and Vocalization of phonemes/syllables}

Speaking and playing simultaneously is the effect during which the airy, human-like sound of the flute is merged with words or text and the fingered pitch colors the resulting sound. Similar to singing and playing this technique is also subject to multiple sonorities given the means in which it is produced, which is why it is preferable that the composer strategically notates the fingered pitches (low register pitches work best for this technique) to accompany the reciting text, which should ideally take advantage of open vowels for more resonance. The same logical thought process applies when the technique requires the vocalization of phonemes or beatboxing.

As with singing and playing, the best way to notate this technique is with two systems, with the system on top preferably representing the flute. Kaija Saariaho's NoaNoa (1992) and Greg Patillo's Three Beats (2011) are exemplary of this notation as they both provide the performer with an accurate rhythmical line for both lines and the text or phonemes/syllables. Only negative observation would be that Saariaho's choice of an empty note-head does not adhere to the criteria of this study, therefore regular notes or empty note-heads with a slash across them are preferred. 
Figure 3.8: Saariaho, NoaNoa, mm.26-27

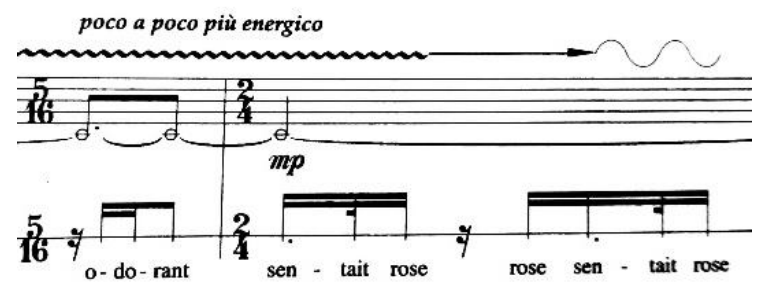

Figure 3.9: Patillo, Three Beats, m.6

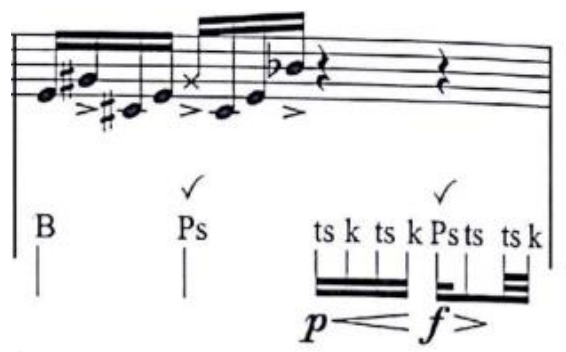

Nonetheless, it is also common to have both in one line, especially when the vocalization of phonemes/syllables and the flute line have the same rhythm. Examples like that can be seen by composers Ian Clarke and Derek Charke. The only difference between the two composers is that the one uses empty note-heads with a slash across them, while the other uses a triangle note-head. Clarke's way is preferred over the triangle shape for consistency, however both are acceptable due to the composers' overall notational clarity.

Figure 3.10: Clarke, Zoom Tube, mm.35-36

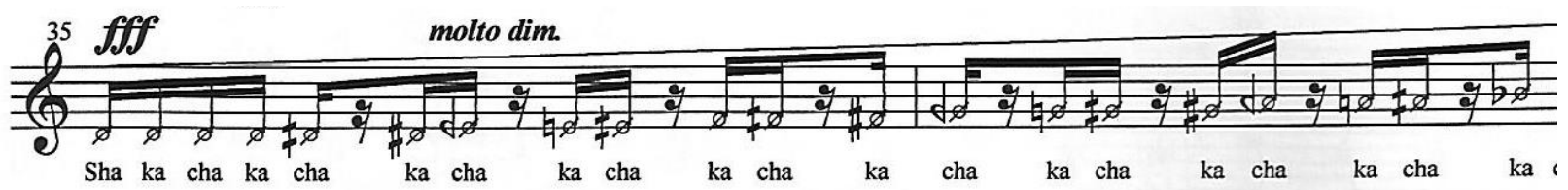

Figure 3.11: Charke, Raga Sept, mm.1-5

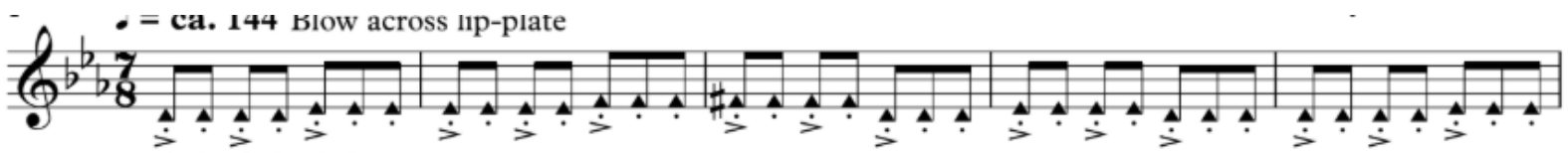

ch k ch k ch k t 


\section{CONCLUSION}

\section{OBSERVATIONS ON THE FUTURE OF NOTATION FOR FLUTE}

As we look towards the future of contemporary notation idiomatic to the flute, both composers and performers should bear in mind that simplicity is key. New music for the flute is not only for the brave anymore. Its accessibility and popularity have added one more musical style with which flutists should have a deep understanding and competence. The ability to perform new music for the flute and successfully produce extended techniques is a vital aspect of a professional flutist's life who wishes to build a career in the industry as a performer and teacher. Moreover, extended techniques are not intended only for the concert venue anymore as their incorporation in a musician's practice session is extremely beneficial. Daily practice of new music techniques for the flute brings awareness to properly and intrinsically using the human body to improve fundamental aspects of playing making it thus an exceptional educational tool.

The true concept driving the use of extended techniques for the flute has been to discover innovative ways to bring sounds from the world around us into the concert hall. Initially, it started with Luigi Russolo's futuristic idea to transform everyday sounds into music, whether that is the engine of a car, industrial machines, animals, objects in the house, screaming or crying. But most importantly, it was intended to emulate musical elements of other cultures in an attempt to unite the world through music: a universal language. It is a language that we all understand, and as such it should have the power to communicate its function immediately and clearly.

Admittedly, contemporary notation for the flute during this ongoing experimental era became oversaturated with a plethora of symbols that made deciphering scores a monumental task. Nevertheless, the need for reflection and re-imagination of the flute's contemporary notation has been present for a while. The literary contributions of musicologists, music theorists, composers, 
and composer-flutists can attest to that, even if their efforts, have limited inconsistency, confusion, and complexity only a little.

Composers will have to personally invest time in thoroughly researching what has been and build upon that when writing for the flute, instead of allowing callowness to define their art work. The truth is that matters of notation are improving and composers are becoming more aware of the hurdles complicated notation can create. Nonetheless, they are encouraged to delve further into this topic by reading the books that have been written by specialists in the field of notation and flute notation more specifically - studying the work of celebrated composers in the flute community, questioning their findings and conversing with performers. Finally, they are asked to refrain from designing new symbols for techniques unless they are confident there is none in place already. If they must design a new symbol, then they are requested to know the limitations and abilities of their notational software prior to using it for such a purpose. The creation of symbols should not be subject to technology, but the other way around.

New music notation for the flute should be characterized therefore by authenticity, logic, simplicity, and immediate comprehension. Hopefully, the goal of this paper has been fulfilled for the selected extended techniques discussed and has shed light upon which symbols are efficient and which not. Eventually, composers and performers shall come to a common agreement when it comes to notating the considerable amount of modern techniques that have been generated, while maintaining an individual artistic voice. ${ }^{102}$

102 David Cope, New Music Notation (Dubuque, Iowa: Kendall/Hunt Pub, 1976), xi. 
APPENDIX 1

Comprehensive Flute Extended Techniques Chart

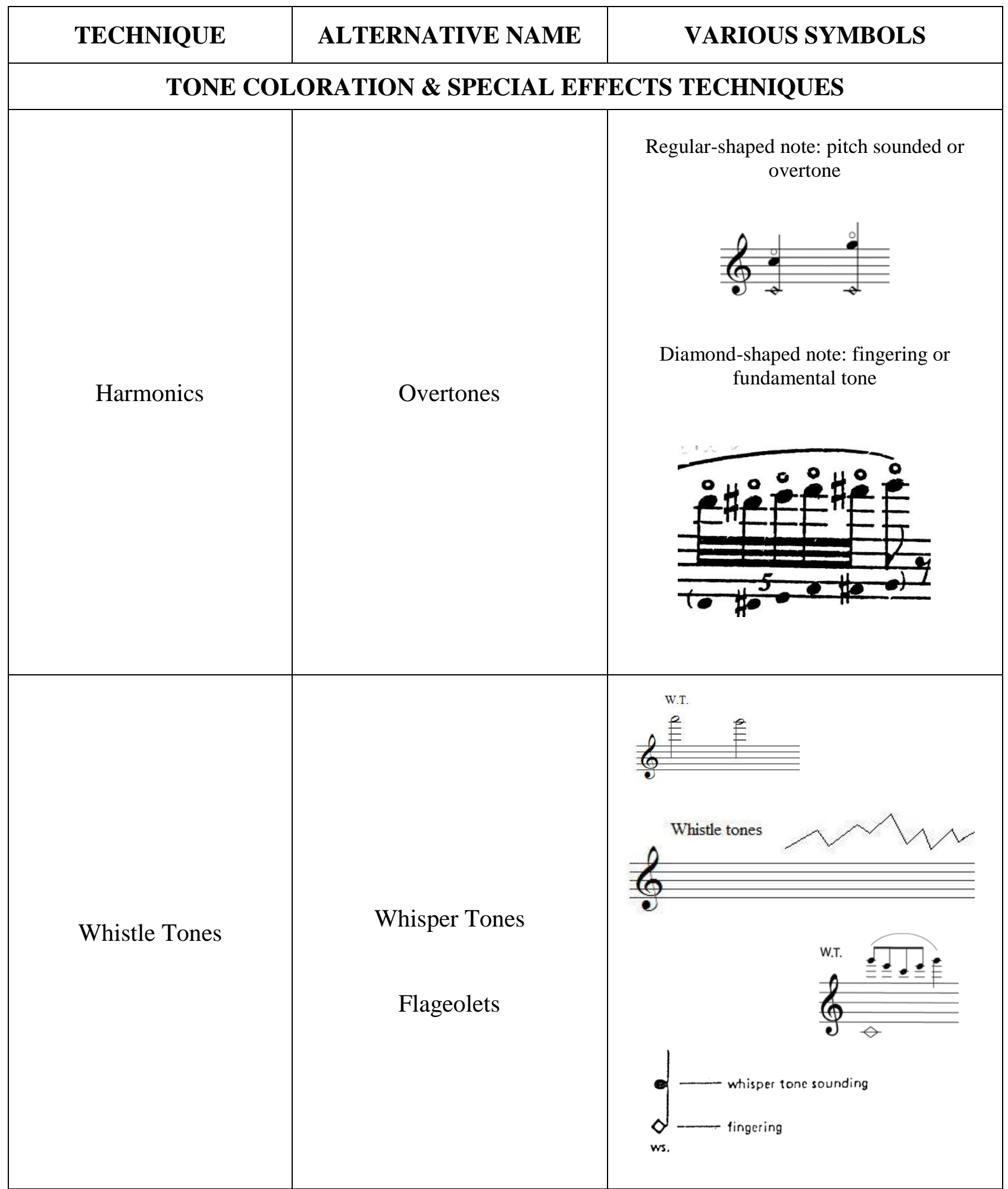




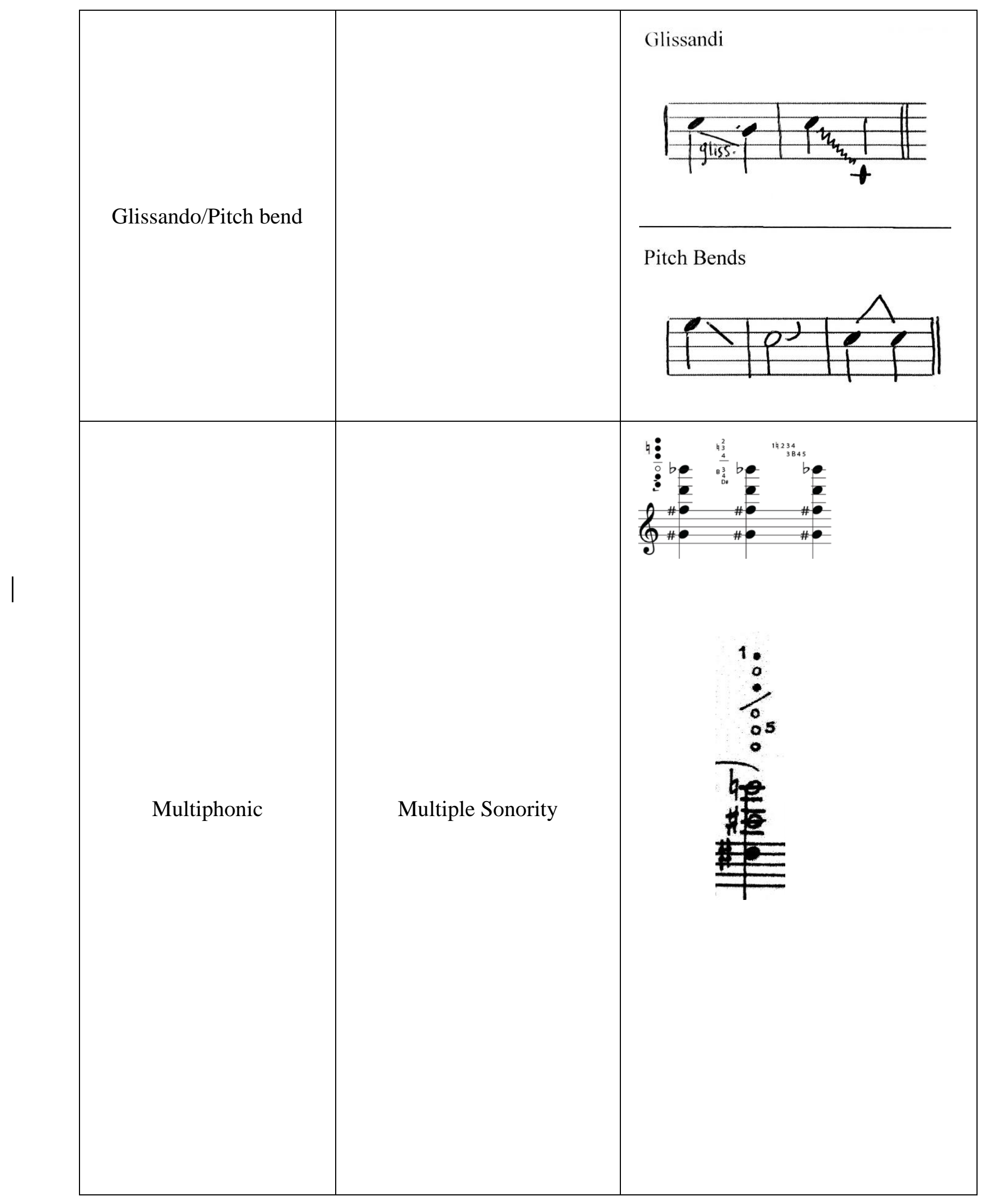




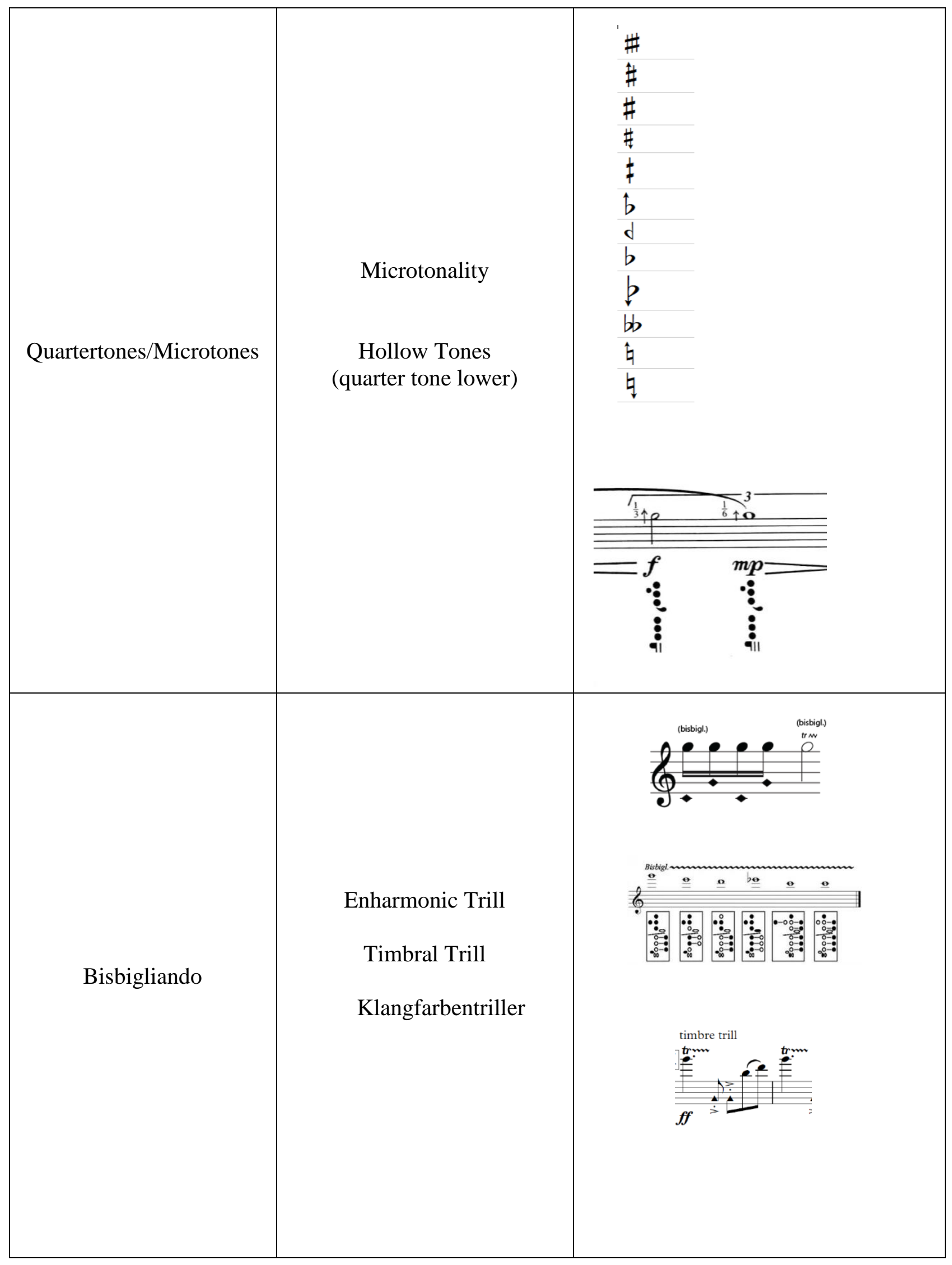




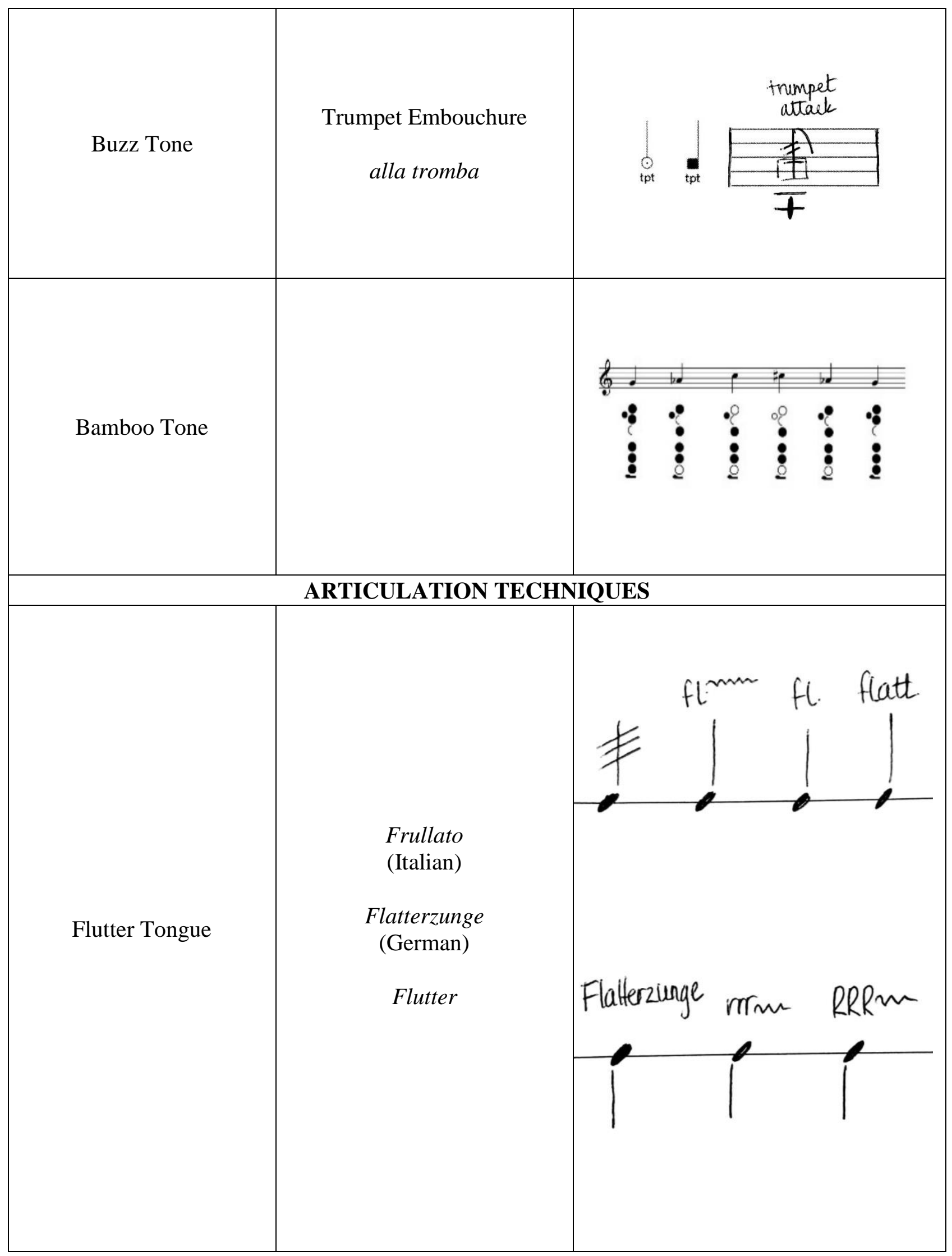




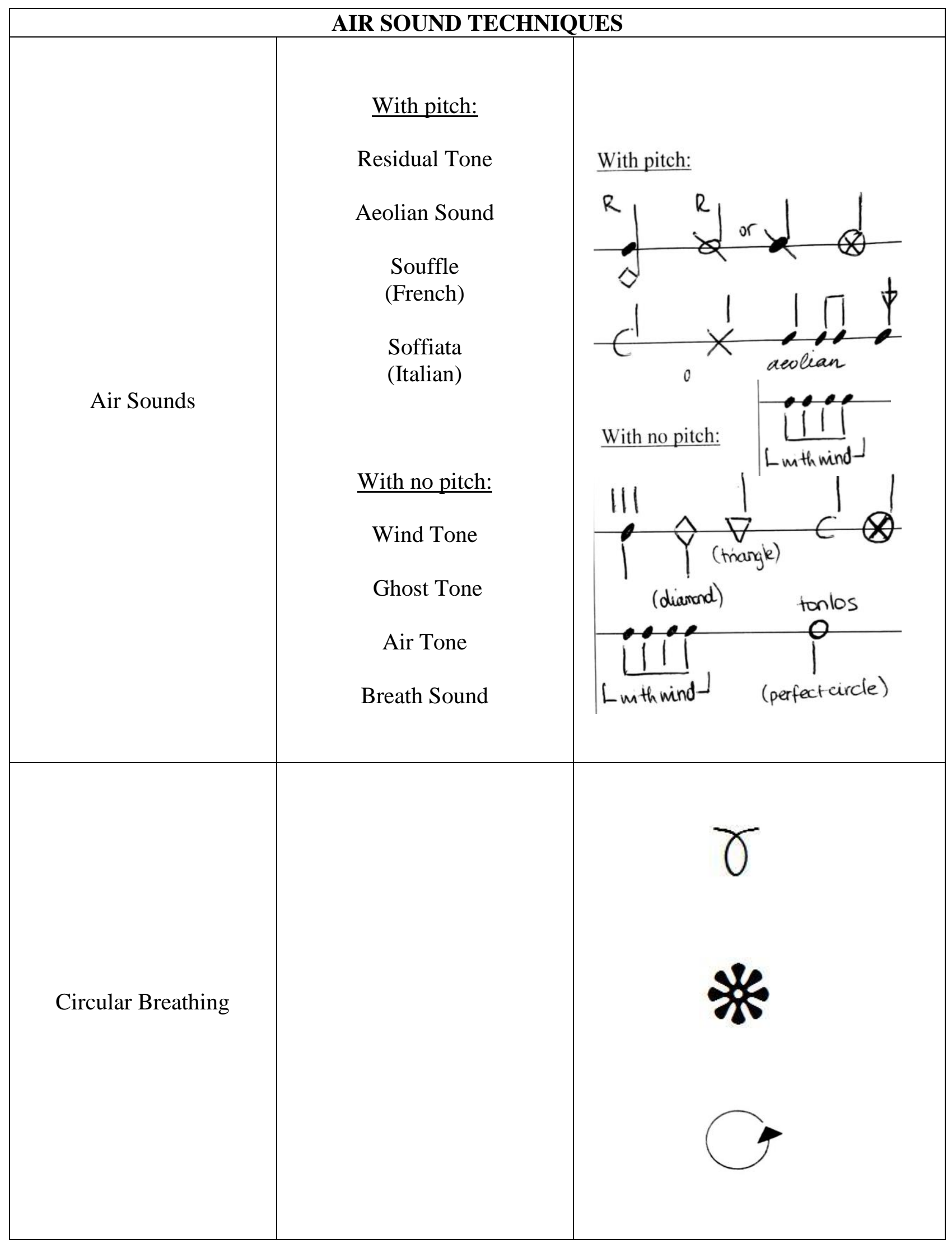




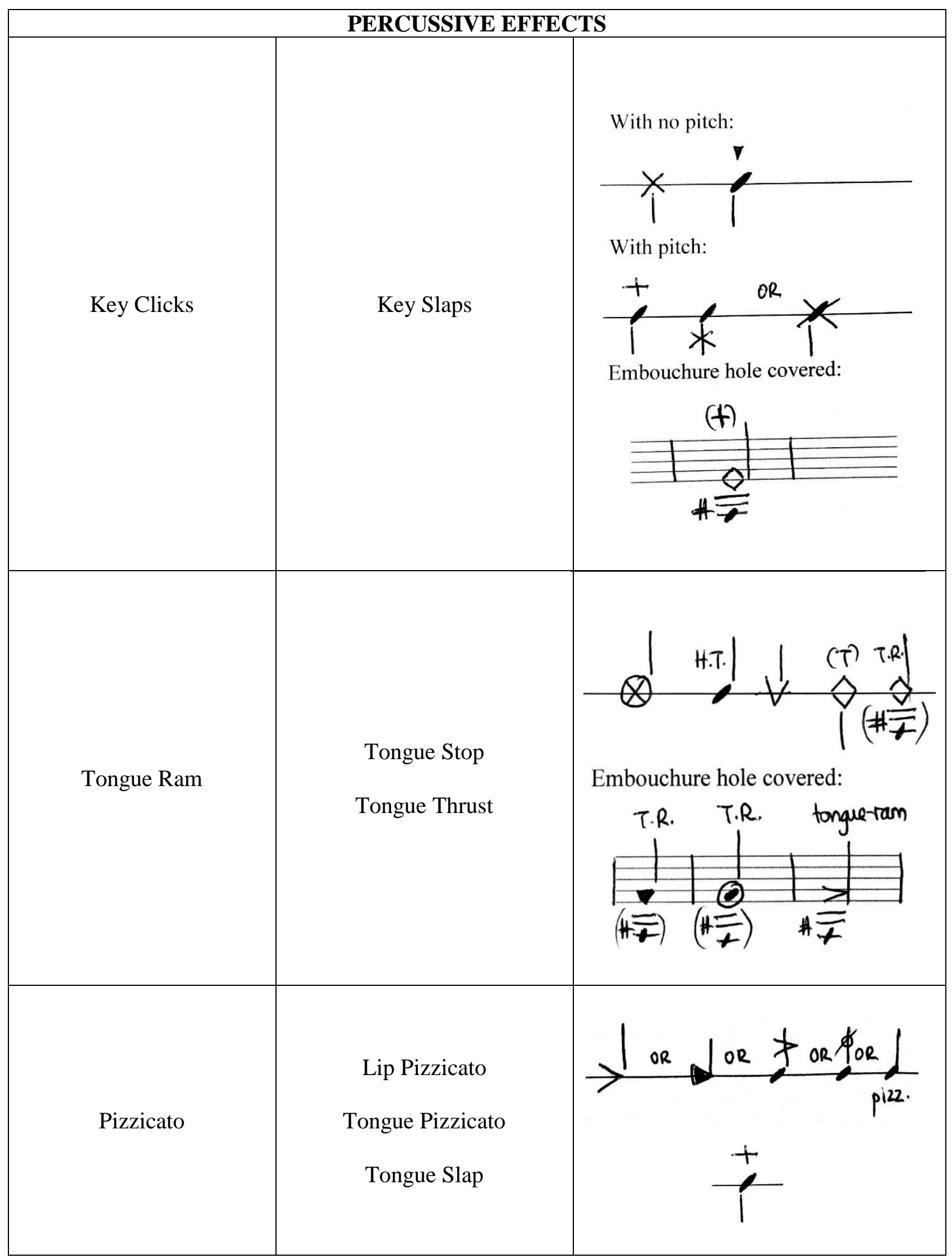




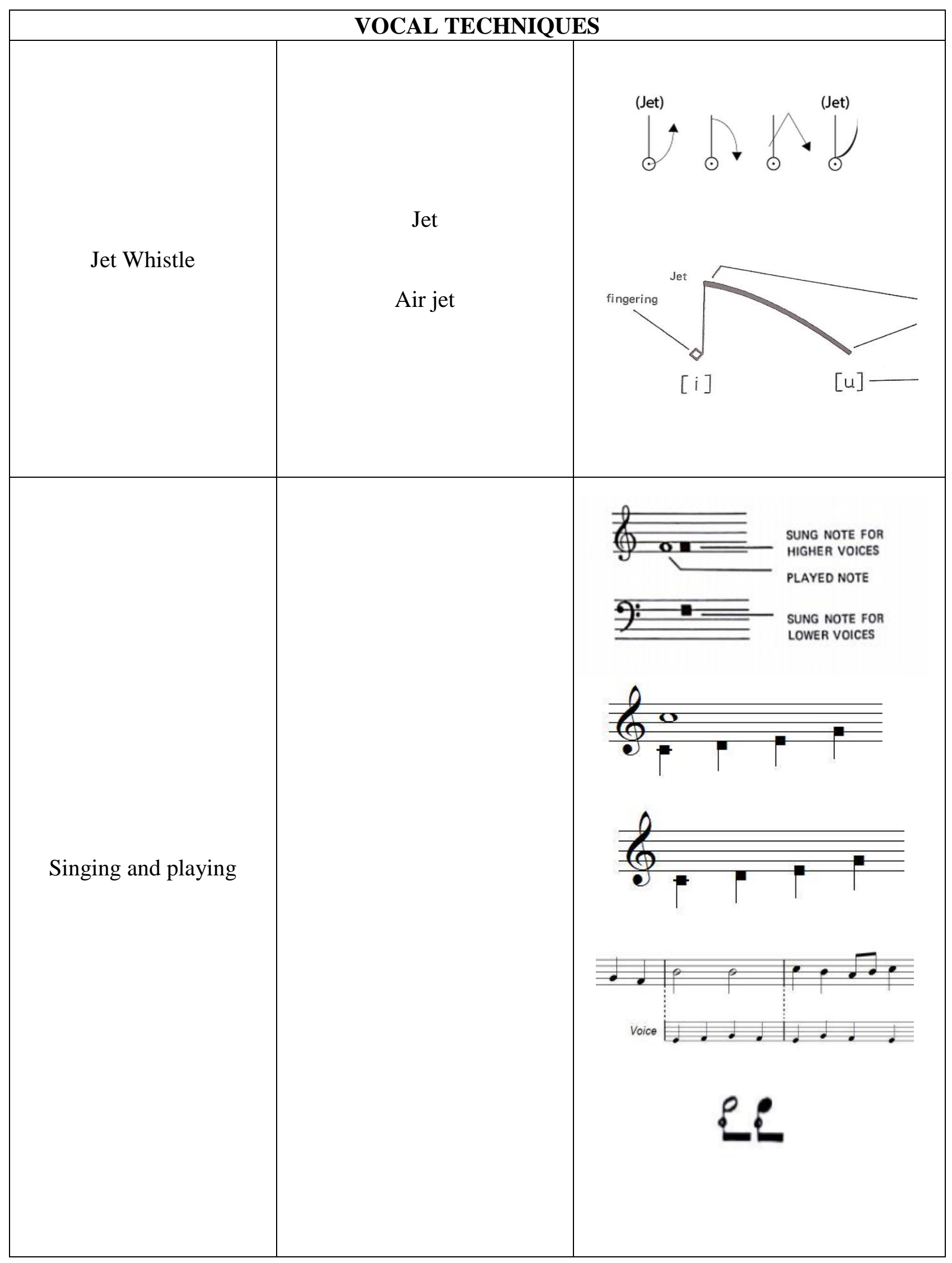




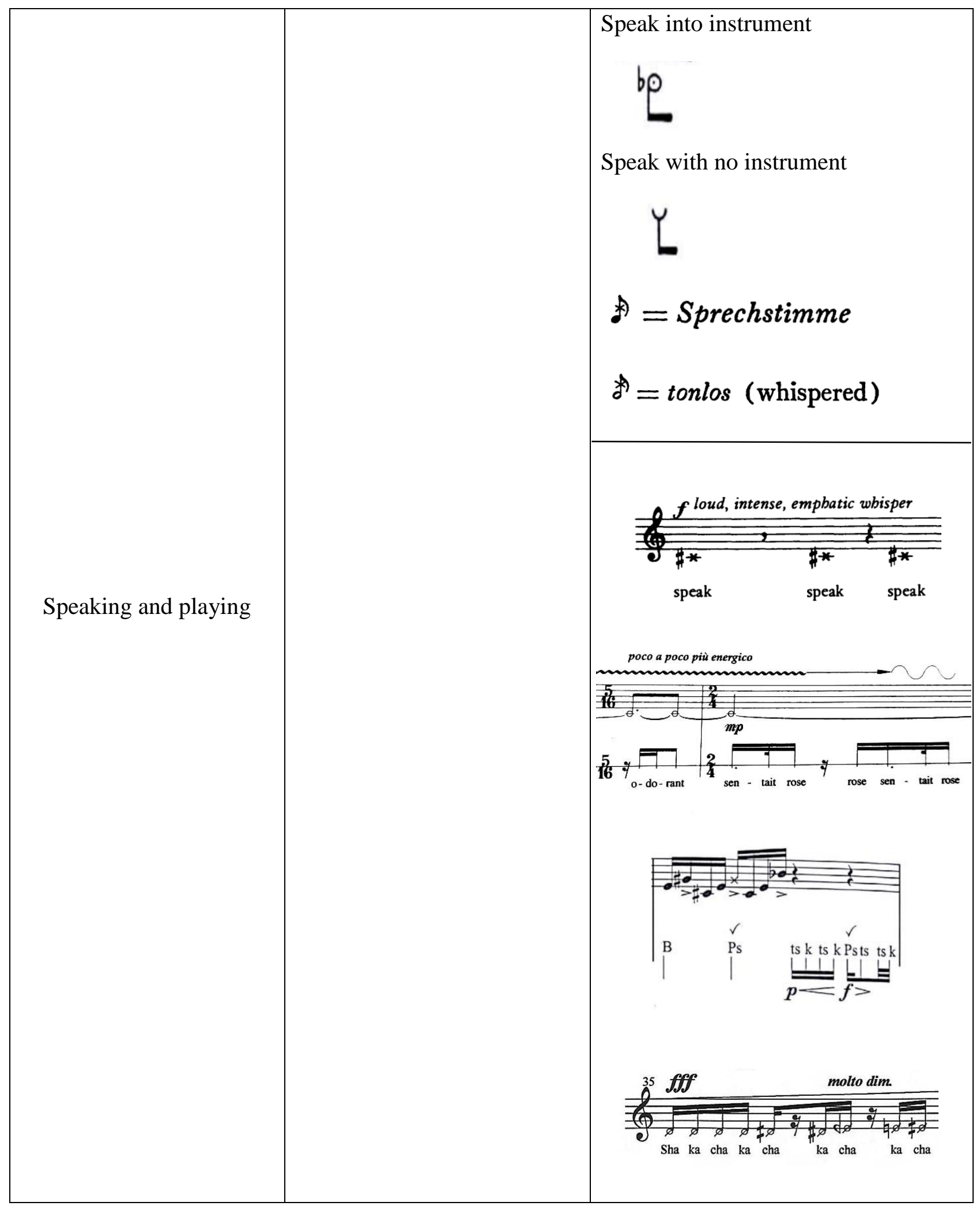




\section{List of Repertoire Examined}

\begin{tabular}{|c|c|c|}
\hline COMPOSER & WORK & DATE \\
\hline Anže Rozman & Dance of the Nuraghi Warriors for Flute Trio & 2017 \\
\hline Anže Rozman & Little Suite of Mythological Beings for Flute Quartet & 2014 \\
\hline Derek Charke & Raga Sept for Flute Quartet & 2014 \\
\hline Nicole Chamberlain & French Quarter for Flute Quartet & 2013 \\
\hline Christos Hatzis & Departures Concerto for Flute and String Orchestra & 2011 \\
\hline Rhonda Larson & Be Still My Soul & 2011 \\
\hline Greg Patillo & Three Beats for Beatbox Flute & 2011 \\
\hline Elainie Lillios & Among Fireflies for Flute and Live Electronics & 2010 \\
\hline Maggi Payne & Reflections for solo flute & 2003 \\
\hline Ian Clarke & Great Train Race & 2000 \\
\hline Ian Clarke & Zoom Tube & 1999 \\
\hline Heike Beckmann & Levada for four flutes & 1999 \\
\hline Michael Culquhoun & Charanga & 1993 \\
\hline Kaija Saariaho & NoaNoa & 1992 \\
\hline Jennifer Higdon & Rapid Fire for solo flute & 1992 \\
\hline Heinz Holliger & Sonate (in) solit (air) $e$ for flute solo & 1995 \\
\hline Robert Dick & Eyewitness for four flutes & 1991 \\
\hline $\begin{array}{c}\text { Karlheinz } \\
\text { Stockhausen }\end{array}$ & Flautina for Solo Flute with Piccolo and Alto flute & 1989 \\
\hline Robert Dick & Lookout & 1989 \\
\hline Shulamit Ran & East Wind & 1988 \\
\hline John Heiss & Etudes op.20 for Solo Flute, V.Birthday Greetings & 1986 \\
\hline Kaija Saariaho & Laconisme de l'aile & 1982 \\
\hline John Heiss & Etudes op. 20 for Solo Flute, II.Shadows & 1979 \\
\hline Robert Aitken & $\begin{array}{r}\text { Plainsong } \\
\end{array}$ & 1977 \\
\hline Donald Erb & Music for Mother Bear for regular or alto flute & 1977 \\
\hline Brian Ferneyhough & Cassandra's Dream Song & 1975 \\
\hline Toru Takemitsu & Voice for flute solo & 1971 \\
\hline George Crumb & Vox Balaenae & 1971 \\
\hline Joyce Mekeel & The Shape of Silence & 1969 \\
\hline George Crumb & The Night of the Four Moons & 1969 \\
\hline Burt Levy & Orbs with Flute & 1966 \\
\hline Kazuo Fukushima & Shun-San & 1969 \\
\hline Kazuo Fukushima & Mei for solo flute & 1962 \\
\hline Luciano Berio & Sequenza I & 1958 \\
\hline Edgard Varese & Density 21.5 for Solo Flute & 1936 \\
\hline Gergely Ittzés & Pizzicato Polka by J.Strauss for four flutes & (unknown) \\
\hline
\end{tabular}




\section{APPENDIX 2}

\section{IPA Chart}

103

\section{TABLE 1
INTERNATIONAL PHONETIC ALPHABET \\ Phonetic Symbols with Equivalent Sounds \\ of English, French, German, and Italian}

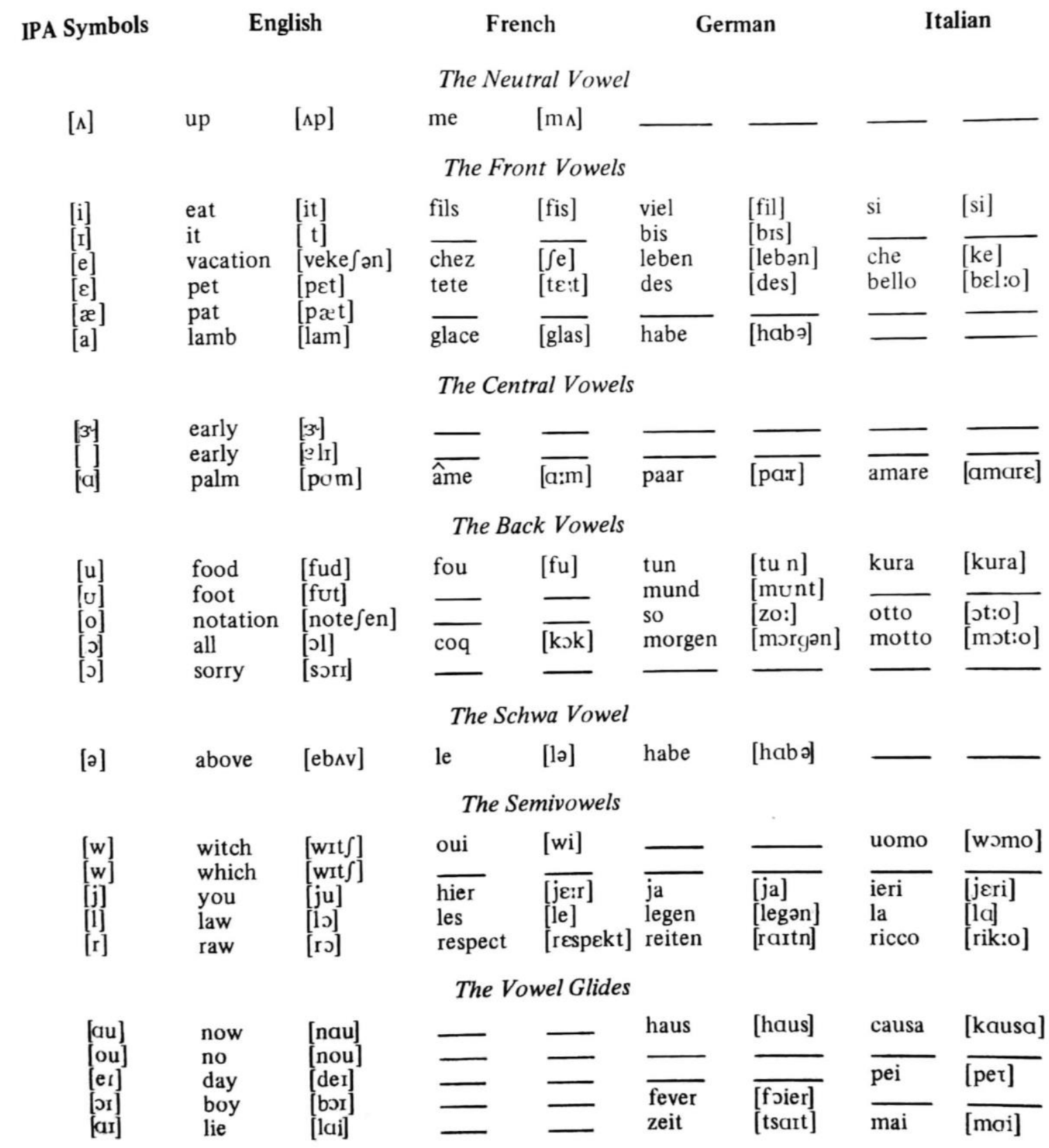

${ }^{103}$ Cope, David, New Music Notation (Dubuque, Iowa: Kendall/Hunt Pub, 1976), 103-104 


\begin{tabular}{|c|c|c|c|c|c|c|c|c|}
\hline IPA Symbols & \multicolumn{2}{|c|}{ English } & \multicolumn{2}{|c|}{ French } & \multicolumn{2}{|c|}{ German } & \multicolumn{2}{|c|}{ Italian } \\
\hline \multicolumn{9}{|c|}{ Laryngeal Migrations of Vowels } \\
\hline $\begin{array}{l}{[\mathrm{h}]} \\
{[\mathrm{hj}]} \\
{[?]}\end{array}$ & $\begin{array}{l}\text { hop } \\
\text { hue } \\
\text { oh! oh! }\end{array}$ & $\begin{array}{l}\text { [hap] } \\
\text { [hju] } \\
\text { [?o!?o!] }\end{array}$ & & & hat & [hat] & & \\
\hline \multicolumn{9}{|c|}{ Oral Migrations of Vowels } \\
\hline $\begin{array}{l}{[\mathrm{p}]} \\
{[\mathrm{b}]} \\
{[\mathrm{t}]} \\
{[\mathrm{d}]} \\
{[\mathrm{k}]} \\
{[\mathrm{g}]}\end{array}$ & $\begin{array}{l}\text { pat } \\
\text { bat } \\
\text { two } \\
\text { do } \\
\text { class } \\
\text { glass }\end{array}$ & 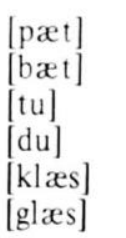 & $\begin{array}{l}\text { pas } \\
\text { bête } \\
\text { ta } \\
\text { du } \\
\text { que } \\
\text { guide }\end{array}$ & $\begin{array}{l}\text { [pas] } \\
{[\text { bet] }} \\
{[\text { ta] }} \\
\text { [du] } \\
\text { [ka] } \\
\text { [gid] }\end{array}$ & $\begin{array}{l}\text { pressen } \\
\text { bett } \\
\text { tal } \\
\text { des } \\
\text { könig } \\
\text { gabe }\end{array}$ & $\begin{array}{l}\text { [presən] } \\
\text { [bet] } \\
\text { [tal] } \\
\text { [des] } \\
\text { [k }{ }^{2} \text { niç] } \\
\text { [gabə] }\end{array}$ & $\begin{array}{l}\text { pei } \\
\text { barca } \\
\text { tempo } \\
\text { dente } \\
\text { che } \\
\text { golfo }\end{array}$ & $\begin{array}{l}\text { [per] } \\
\text { [barka] } \\
\text { [tempo] } \\
\text { [dente] } \\
\text { [ke] } \\
\text { [golfol }\end{array}$ \\
\hline
\end{tabular}

The Continuant Fricatives

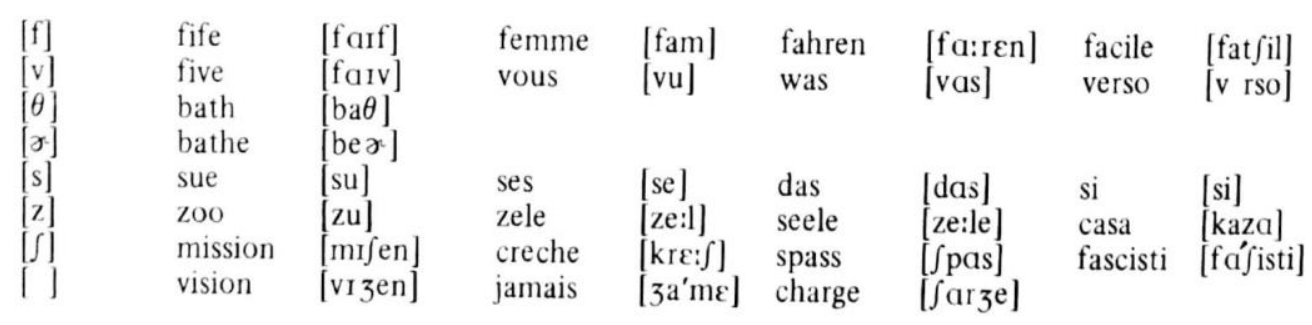

The Affricates

\begin{tabular}{|c|c|c|c|c|c|c|}
\hline$\left[\begin{array}{l}\left.\mathrm{t} \int\right] \\
{\left[\begin{array}{l}\mathrm{s} \\
{[\mathrm{d}}\end{array}\right]}\end{array}\right]$ & $\begin{array}{l}\text { church } \\
\text { rushed } \\
\text { judge }\end{array}$ & 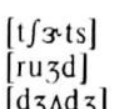 & klatch & [klat $\left.\int\right]$ & cera & [tfera] \\
\hline$\left[\begin{array}{l}\mathrm{d} \\
\mathbf{1} \\
\mathrm{d}\end{array}\right]$ & $\begin{array}{l}\text { judge } \\
\text { rouged }\end{array}$ & $\left.\begin{array}{l}{\left[\mathrm{d}_{3} \wedge \mathrm{d}\right.} \\
{[\mathrm{ruz}}\end{array}\right]$ & & & gente & {$\left[\mathrm{d}_{3} \varepsilon n t i\right]$} \\
\hline
\end{tabular}

The Nasal Migrations of the Vowels

\begin{tabular}{|c|c|c|c|c|c|c|c|c|}
\hline$\left[\begin{array}{l}{[m]} \\
{[n]} \\
{[1]}\end{array}\right.$ & $\begin{array}{l}\text { mow } \\
\text { no } \\
\text { sing }\end{array}$ & $\begin{array}{l}{[\mathrm{mo}]} \\
{[\mathrm{no}]} \\
{[\mathrm{sin}]}\end{array}$ & $\begin{array}{l}\text { mons } \\
\text { non }\end{array}$ & $\begin{array}{l}{[\mathrm{m} \tilde{]}]} \\
{[\mathrm{n} \tilde{5}]}\end{array}$ & $\begin{array}{l}\text { memel } \\
\text { nun } \\
\text { finger }\end{array}$ & $\begin{array}{l}\text { [me:mel] } \\
\text { [nu:n] } \\
\text { [f iner] }\end{array}$ & $\begin{array}{l}\text { prima } \\
\text { vano } \\
\text { vengo }\end{array}$ & $\begin{array}{l}\text { [prima] } \\
\text { [vano] } \\
\text { [veygo] }\end{array}$ \\
\hline
\end{tabular}

${ }^{104}$ Cope, David, New Music Notation (Dubuque, Iowa: Kendall/Hunt Pub, 1976), 103-104. 


\section{BIBLIOGRAPHY}

\section{BOOKS and BOOK CHAPTERS}

Apel, Willi. Harvard Dictionary of Music. Cambridge, Mass: Belknap Press of Harvard University Press, 1969.

Artaud, Pierre-Yves. Die Flöte. Frankfurt am Main: Zimmermann, 1991.

Artaud, Pierre-Yves. Flûtes au présent: Traité des techniques contemporaines sur les flûtes traversières à l'usage des compositeurs et des flutistes. Paris: G. Billaudot, 1995

Bartolozzi, Bruno. New Sounds for Woodwind. Oxford: Oxford University Press, 1967.

Borkowski, Jennifer A. Modernizing Practice Paradigms for New Music: Periodization Theory and Peak Performance Exemplified through Extended Techniques. The Art and Science of Music Teaching and Performance. Frankfurt am Main: PL Academic Research, 2016.

Boulez, Pierre, and Jean Jacques Nattiez. Orientations. Cambridge, Mass.: Harvard University Press, 1986.

Brindle, Reginald Smith. The New Music: The Avant-Garde Since 1945. 2nd ed. Oxford Oxfordshire: Oxford University Press, 1987.

Cope, David. Techniques of the Contemporary Composer. Belmont, CA: Schirmer Books, 1997.

—. New Music Notation. Dubuque, Iowa: Kendall/Hunt Pub, 1976.

. New Directions in Music. 5th ed. Dubuque, Iowa: W.C. Brown, 1989.

Dahlhaus, Carl. "Notenschrift heute." In Darmstädter Beiträge zur Neuen Musik IX, edited by Ernst Thomas, 9-34. Mainz: B.Schott's Söhne, 1965.

Debost, Michel, and Jeanne Debost-Roth. The Simple Flute: From A to Z. New York: Oxford University Press, 2010.

Dick, Robert. The Other Flute: A Performance Manual of Contemporary Techniques. St. Louis, MO: Multiple Breath, 1989.

—. Tone Development through Extended Techniques. New York: Multiple Breath, 1986.

Dimpker, Christian. Extended Notation: The Depiction of the Unconventional. Vienna: Lit, 2013.

Dzapo, Kyle J. Notes for Flutists: A Guide to the Repertoire. Notes for Performers. New York: Oxford University Press, 2016.

Gould, Elaine. Behind Bars: The Definitive Guide to Music Notation. London: Faber Music, 2011.

Howell, Thomas. The Avant-garde Flute. Berkeley: University of California Press, 1974.

Jaschinski, Andreas. Notation. Kassel: Bärenreiter, 2001. 
Koizumi, Hiroshi. Technique for Contemporary Flute Music for Players and Composers. Tokyo: Schott Japan, 1996.

Karkoschka, Erhard. Notation in New Music: A Critical Guide to Interpretation and Realisation. New York: Praeger, 1972.

Levine, Carin and Mitropoulos-Bott, Christina. The Techniques of Flute Playing: Die Spieltechnik der Flöte. Kassel: Bärenreiter, 2002.

Maclagan, Susan J. A Dictionary for the Modern Flutist. Lanham, Md.: Scarecrow Press, 2009.

Offermans, Wil. For the Contemporary Flutist: Twelve Studies for the Flute with Explanations in the Supplement. Frankfurt am Main, Germany: Zimmermann, 1992.

Pellerite, James J. A Modern Guide to Fingerings for the Flute. Bloomington, Ind.: Frangipani Press, 1982.

Powell, Ardal. The Flute. The Yale Musical Instrument Series. New Haven: Yale University Press, 2002.

Read, Gardner. 20th-Century Microtonal Notation. Westport: Greenwood Press, 1990.

—. Contemporary Instrumental Techniques. New York: Schirmer Books, 1976.

—. Music Notation: A Manual of Modern Practice. 2d ed. Boston: Allyn and Bacon, 1969.

Read, Gardner, and Gunther Schuller. Compendium of Modern Instrumental Techniques. Westport: Greenwood, 1993.

Risatti, Howard. New Music Vocabulary: A Guide to Notational Signs for Contemporary Music. Urbana: University of Illinois Press, 1975.

Russolo, Luigi. The Art of Noises. New York: Pendragon Press, 1986.

Schwartz, Elliott, Barney Childs, and James Fox. Contemporary Composers on Contemporary Music. New York: Da Capo Press, 1998.

Stokes, S and R. Condon. Special Effects for Flute. Santa Monica: Trio Associates, 1976.

Stolba, K. Marie. The Development of Western Music: A History. Boston, Mass.: McGraw Hill, 1998.

Stone, Kurt. Music Notation in the Twentieth Century: A Practical Guidebook. New York: W.W. Norton, 1980.

Stuckenschmidt, Hans Heinz. Twentieth Century Music. New York: McGraw-Hill Book, 1969.

Toff, Nancy. The Flute Book: A Complete Guide for Students and Performers. New York, NY: Oxford University Press, 2012.

Ueli Dörig. Flute Sound Effects: Beatboxing, Circular Breathing, Fourth-octave Playing, and Much More! Boston: Berklee Press, 2006. 
Vinton, John, ed. Dictionary of Contemporary Music Notation. New York: E.P. Dutton, 1974.

\section{DISSERTATIONS and THESES}

Borkowski, Jennifer Anne. "From Simple to Complex: Extended Techniques in Flute Literature-Incentive to Integrate Cognitive and Kinesthetic Awareness in University Programs." Ph.D diss., Universität für Musik und Darstellende Kunst Graz, 2008.

Bondurant, Kathleen Alice. "Twentieth-century flute performance techniques in selected compositions (interviewing)." Ph.D. diss., New York University, 1984.

Botieff, Jane d. "Flute Extended Techniques: A Practice Guide and Analytical Study of Hatching Aliens by Ian Clarke.” M.M. thesis, California State University, 2015.

Cella, Lisa Maria. "A Resource Manual for the Solo Flute Repertoire of the Twentieth Century." D.M.A. diss., University of California, San Diego, 2001.

Ford, Ronda Benson. "A Door to Extended Techniques: Five Analyses and Composer Interviews from the National Flute Association's High School Soloist Competition." D.M.A. diss., University of Southern Mississippi, 2005.

Gariazzo, Mariana Stratta. "Argentine Music for Flute with the Employment of Extended Techniques: An Analysis of Selected Works by Eduardo Bértola and Marcelo Toledo." D.M.A diss., The University of Texas at Austin, 2005.

Hodjati, Katayoon. "A Performer's Guide to the Solo Flute Works of Kaija Saariaho: "Laconisme De l'Aile" and "NoaNoa"." D.M.A. diss., Arizona State University, 2013.

Isaac, Carol Gertrud. "The Solo Flute Music of Three Contemporary flutist/composers: Robert Aitken, Robert Dick, and Harvey Sollberger." Ph.D. diss,, University of California, San Diego, 1991.

Jang, Seon Hee. "Interpretation of Extended Techniques in Unaccompanied Flute Works by EastAsian Composers: Isang Yun, Toru Takemitsu, and Kazuo Fukushima." D.M.A. diss., University of Cincinnati, 2010.

Linard, Rita Ann. "An Analysis of Three Solo Flute Works that Bridge the Gap between Traditional and Twentieth-Century Techniques." D.M.A diss., The University of Texas at Austin, 1997.

McIver, Sarah Eckman. "The Music of flutist/composers: Performances of Selected Works for Flute Composed between 1852 and 2005." D.M.A diss., University of Maryland, College Park, 2010.

Meador, Rebecca Rae. "A History of Extended Flute Techniques and an Examination of their Potential as a Teaching Tool." D.M.A diss., University of Cincinnati, 2001. 
Moorhead, Kathryn Emma. "A Performer's Perspective on the Evolution and Realisation of Extended Flute Techniques: A Portfolio of Recorded Performances and Exegesis." Ph.D. diss., University of Adelaide, Elder Conservatorium of Music, 2012.

Raymond, Meredith. "Incorporating Extended Techniques into the Current Curriculum: A Guide for the Contemporary Flutist Based on the Influence and Teaching Methods of Robert Dick and Greg Pattillo." M.M. thesis, California State University, Long Beach, 2012.

Rogers, Kallie. "Wil Offermans: The Pedagogy of a Contemporary Flutist-Composer." D.M.A treatise, The Florida State University, 2015.

Sanchez Escuer, Alejandro. "Interpretation of Extended Techniques: Flute Solo Compositions by Mexican Composers. Analysis and Performance Recommendations." Ph.D. diss., New York University, 1995.

Willis, Morya Elaine. "Notation and Performance of Avant-garde Literature for the Solo Flute." Ph.D. diss., University of Florida, 1982.

\section{JOURNAL ARTICLES}

Austin, William W, and Hugo Cole. "Sounds and Signs: Aspects of Musical Notation." Notes 31, no. 2 (1974): 288.

Bartolozzi, Bruno, and Brooks Shepard. "Proposals for Changes in Musical Notation." Journal of Music Theory 5, no. 2 (1961): 297-301.

Black, Robert. "Contemporary Notation and Performance Practice: Three Difficulties." Perspectives of New Music 22, no. 1-2 (Fall-winter-spring-summer 1983): $117-46$.

Gerlof, Antje, and Wiebke Schuler. "Einführung in Die Techniken Der Neuen Musik Für Anfänger Und Fortgeschrittene Auf Der Querflöte.” Tibia: Magazin Für Holzbläser 29 (2004): 2530 .

Heiss, John. "The Flute: New Sounds." Perspectives of New Music 10, no. 2 (1972): 153-58.

Lependorf, Jeffrey. "Contemporary Notation for the Shakuhachi: A Primer for Composers." Perspectives of New Music 27, no. 2 (1989): 232-51.

Rebelo, Pedro. "Notating the Unpredictable." Contemporary Music Review 29, no.1 (2010): 1727.

Partch, Harry. "Experiments in Notation." In Contemporary Composers on Contemporary Music, edited by WHO?, 210-220. Rev. Ed. New York: Da Capo, 1998.

Stillman, Mimi. “Writing for the Flute.” Flute Talk Magazine 28, no.6 (Winter, 2009): 20. 
Stone, Kurt. "Problems and Methods of Notation." Perspectives of New Music 1, no. 2 (1963): 931.

Varèse, Edgard. "The Liberation of Sound." In Collected Work: Contemporary Composers on Contemporary music. Rev.Ed. Published by: New York, NY, U.S.A.: Da Capo, 1998. Pages: 196-208.

Vinci, Jan. "Using Extended Techniques in Fukushima's "Mei for solo flute." Flute Talk Magazine 18, no.3 (Fall 1998): 14.

Walker, Robert. "Visual Metaphors as Music Notation for Sung Vowel Spectra in Different Cultures." Journal of New Music Research 26 (4), 1997: 315-45.

Waterman, Ellen. "Cassandra's Dream Song: A Literary Feminist Perspective." Perspectives of New Music 32, no. 2 (Summer, 1994): 154.

\section{WEBSITES}

Bledsoe, Helen. Website and Blog for Flutists and Composers. http://helenbledsoe.com/ (Accessed January 14, 2019)

Dick, Robert. Revolutionary Composer and Flutist. https://robertdick.net/ (Accessed March 25, 2019)

FluteXpansions. Contemporary flute resources: A laboratory for performers and composers. https://www.flutexpansions.com/repertoire (Accessed January 14, 2019)

Hugill, Andrea. The Orchestra: A user's manual, Flutes: Extended Techniques. http://andrewhugill.com/manuals/flute/extended.html (Accessed January 14, 2019)

International Phonetic Alphabet. http://www.internationalphoneticalphabet.org/ipa-sounds/ipachart-with-sounds/ (Accessed March 31, 2019)

Krantz, Larry. Extended Techniques Resource Page. http://www.larrykrantz.com/et/et.htm (Accessed January 14, 2019)

New Sounds for Flute - On Flute Techniques from the Twentieth Century. https://www.scribd.com/doc/23258862/Flute-Extended-Techniques-1 (Accessed March 29, 2019)

Offernans, Wil. For the Contemporary Flutist, https://www.forthecontemporaryflutist.com/ (Accessed March 25, 2019)

Pijper, Rogier de. Extended Techniques for flute. https://www.flutecolors.com/ (Accessed January 14, 2019)

Tchaikovksy Research. Letter 4633. http://en.tchaikovsky-research.net/pages/Letter_4633 (Accessed March 22, 2019) 
—. Aleksandr Khimichenko. http://en.tchaikovsky-research.net/pages/Aleksandr_Khimichenko (Accessed March 22, 2019)

Western Michigan University. Modern Art Music. https://wmich.edu/musgened/mus150/1500\%20webbook\%20modern\%20artmusic/Modern\%20ArtMusic.htm (Accessed February 27, 2019) 